\title{
Impfungen bei Immundefekten/Immunsuppression - Expertenstatement und Empfehlungen
}

\author{
Ursula Wiedermann · Harald H. Sitte · Heinz Burgmann · Alexander Eser · Petra Falb · Heidemarie Holzmann • \\ Maria Kitchen · Marcus Köller · Herwig Kollaritsch • Michael Kundi · Hans Lassmann · Ingomar Mutz • \\ Winfried F. Pickl · Elisabeth Riedl · Maria Sibilia · Florian Thalhammer · Barbara Tucek · Werner Zenz · Karl Zwiauer
}

Eingegangen: 25. Mai 2016 / Angenommen: 4. Juni 2016 / Online publiziert: 25. Juli 2016

(C) Der/die Autor(en) 2016. Dieser Artikel ist eine Open-Access-Publikation.

Zusammenfassung Immunsuppression unterschiedlicher Genese ist mit einem erhöhten Infektionsrisiko verbunden; daher ist die Prävention von impfpräventablen Erkrankungen bei den betroffenen Personengruppen besonders wichtig. Allerdings ist das Angehen von Impfungen oftmals reduziert bzw. die Applikation von Lebendimpfungen während Immunsuppression kontraindiziert.

Im folgenden Expertenstatement wurden Empfehlungen zur Impfversorgung auf der Basis bestehender Evidenz und auf theoretischen/immunologischen

Univ. Prof. Dr. U. Wiedermann $(\bowtie) \cdot H$. Kollaritsch Institut für Spezifische Prophylaxe und

Tropenmedizin, Medizinische Universität Wien,

Kinderspitalgasse 15, 1090 Wien, Österreich

ursula.wiedermann@meduniwien.ac.at

\section{H. H. Sitte}

Institut für Pharmakologie, Medizinische Universität Wien, Wien, Österreich

\section{H. Burgmann · F. Thalhammer}

Klinische Abteilung für Infektionen und Tropenmedizin, Medizinische Universität Wien, Wien, Österreich

\section{A. Eser}

Klinische Abteilung für Gastroenterologie und Hepatologie, Medizinische Universität Wien, Wien, Österreich

P. Falb $\cdot$ B. Tucek

Medizinmarktaufsicht, Agentur für Gesundheit und Ernährungssicherheit, Wien, Österreich

\section{H. Holzmann}

Department für Virologie, Medizinische Universität Wien, Wien, Österreich

\section{Kitchen}

Universitätsklinik für Dermatologie und Venerologie,

Medizinische Universität Innsbruck, Innsbruck, Österreich

\section{Köller}

Sozialmedizinisches Zentrum Sophienspital, Wien,

Österreich
Überlegungen erarbeitet. Ein erster, allgemeiner Teil geht auf Wirksamkeit und Sicherheit von Impfungen bei Immunsuppression, Wirkmechanismen immunsuppressiver Medikamente und empfohlene Zeitabstände zwischen immunsuppressiven Behandlungen und Impfungen ein. Ein Kernstück dieses Teils ist die Graduierung der Immunsuppression in drei Stadien, i.e. keine relevante, leichte bis mittelgradige und schwere Immunsuppression und die Zuordnung von diversen Medikamenten (einschließlich Biologi-

M. Kundi

Institut für Umwelthygiene, Medizinische Universität Wien, Wien, Österreich

H. Lassmann

Abteilung für Neuroimmunologie, Medizinische Universität Wien, Wien, Österreich

I. Mutz

Liga für Präventivmedizin, Salzburg, Österreich

W. F. Pickl

Institut für Immunologie, Medizinische Universität Wien, Wien, Österreich

\section{E. Riedl}

Universitätsklinik für Dermatologie, Medizinische Universität Wien, Wien, Österreich

\section{Sibilia}

Institut für Krebsforschung, Medizinische Universität Wien, Wien, Österreich

\section{W. Zenz}

Klinische Abteilung für allgemeine Pädiatrie, Medizinische Universität Graz, Graz, Österreich

\section{K. Zwiauer}

Klinische Abteilung für Kinder- und Jugendheilkunde, Universitätsklinikum St. Pölten, St. Pölten, Österreich 
ka) zu einem dieser drei Immunsuppressionsgrade, gefolgt von einer Übersicht der im jeweiligen Stadium möglichen und nötigen Impfungen.

Im zweiten speziellen Teil werden detaillierte Impfempfehlungen bei häufigen immunsuppressiven Erkrankungen bzw. unter immunsuppressiven Therapien behandelt. Dabei wurden auf angeborene Immundefekte, chronische Nierenerkrankungen, Diabetes mellitus, solide Tumoren und hämatologische Malignome, hämatopoietische Stammzelltransplantation, Transplantation solider Organe, Asplenie, rheumatologische-, gastroenterologische-, dermatologische, neurologische Erkrankungen, Biologika in der Schwangerschaft und HIV-Infektion eingegangen. Diese in Österreich erstmals zusammengefassten Impfempfehlungen sollen in der Praxis zu einer erleichterten und verbesserten Impfversorgung dieser Patientengruppen und deren Kontaktpersonen beitragen.

Schlüsselwörter Schweregrad Immunsuppression · Biologika - Rheumatische Erkrankung · solide Tumoren · Hämatologische Tumoren · Multiple Sklerose • Lebendimpfung · Impfschema · Zeitinterval · Kontraindikation

\section{Guidelines for vaccination of immunocompromised individuals}

Summary Immunosuppression of various origins is associated with an increased risk of infection; therefore the prevention of infectious diseases by vaccination is especially important in immunocompromised patients. However, the response to vaccinations is often reduced in these risk groups and the application of live vaccines is contraindicated during immunosuppression.

In the following expert statement, recommendations for vaccination were created on the basis of current evidence and theoretical/immunological considerations. A first, general part elaborates on efficacy and safety of vaccinations during immunosuppression, modes of action of immunosuppressive medications and recommended time intervals between immunosuppressive treatments and vaccinations. A core piece of this part is a graduation of immunosuppression into three stages, i. e. no relevant immunosuppression, mild to moderate and severe immunosuppression and the assignment of various medications (including biologicals) to one of those stages; this is followed by an overview of possible and necessary vaccinations in each of those stages.

The second part gives detailed vaccination guidelines for common diseases and therapies associated with immunosuppression. Primary immune deficiencies, chronic kidney disease, diabetes mellitus, solid and hematological tumors, hematopoetic stem cell transplantation, transplantation of solid organs, aspenia, rheumatological-, gastroenterologic-, derma- tologic-, neurologic diseases, biologicals during pregnancy and HIV infection are dealt with.

These vaccination guidelines, compiled for the first time in Austria, aim to be of practical help for physicians to facilitate and improve vaccination coverage in immunocompromised patients and their household members and contact persons.

Keywords Graduation of immunosuppression · biologicals $\cdot$ cancer patients $\cdot$ rheumatic disease $\cdot$ multiple sclerosis - live vaccines - vaccination schedules - timing $\cdot$ contraindication

\section{Abkürzungen}

5-FU 5-Fluorouracil

ACIP Advisory Committee on Immunization Practices

ADCC Antikörper-abhängige zelluläre Zytotoxizi-

AGES $\quad$ tät $\quad$ Agentur für Gesundheit und Ernährungssicherheit

AK Antikörper

AMPA Alpha-Amino-3-Hydroxy-5-Methyl-4-Isoxazolpropion-Säure

ASA Aminosalizylsäure

ATP Adenosin-Triphosphat

BlyS B-Lymphozyten-Stimulator

CD Cluster of Differentiation (gibt, gefolgt von einer Zahl, ein bestimmtes Oberflächenantigen, vor allem auf Leukozyten, an, z. B. CD25)

CDC Centers for Disease Control and Prevention

CGD Chronic Granulomatous Disease

CIDP Chronische Inflammatorische Polyneuropathie

CKD Chronic Kidney Disease

CLL Chronisch-lymphatische Leukämie

CpG Cytosin-phosphat-Guanin (DNS-Basensequenz)

CS Connecting Segment

CTLA Zytotoxisches T-Lymphozyten-Antigen

CVI Common Variable Immunodeficiency

DLE Diskoider Lupus erythematodes

DNS Desoxyribonukleinsäure

EGF Epidermal Growth Factor

EGFR Epidermal Growth Factor Receptor

ELISA Enzyme-Linked Immunosorbent Assay

ErbB Erythroblastosis Oncogene B

ESRD End-Stage Renal Disease

EULAR European League Against Rheumatism

FK506 Tacrolimus

FKBP FK506 Binding Protein

FSME Frühsommer-Meningoenzephalitis

GABA Gamma-Amino-Buttersäure

GBS Guillain-Barré-Syndrom

G-CSF Granulozyten-stimulierender Faktor

GFR Glomeruläre Filtrationsrate

GM-CSF Granulozyten-Makrophagen-stimulieren- 
der Faktor

GvHD Graft-versus-Host-Disease

HBV Hepatitis-B-Virus

HER Human Epidermal Growth Factor Receptor

HiB Haemophilus influenzae B

HIGM Hyper-IgM-Syndrom

HIV Humanes Immundefizienz-Virus

HPV Humanes Papillomavirus

HWZ Halbwertszeit

HZ Herpes zoster

IBD Entzündliche Darmerkrankungen („Inflammatory Bowel Diseases“)

$\begin{array}{ll}\text { IDSA } & \text { Infectious Diseases Society of America } \\ \text { IFN } & \text { Interferon }\end{array}$

Ig Immunglobulin

IL Interleukin

IPV Inaktivierte Poliovakzine

ISP Immunsuppression

ITP Immunthrombopenie

JC-Virus Humanes Polyomavirus 2

KG Körpergewicht

KI Kontraindikation

LAD Leukozyten-Adhäsionsdefekt

LAIV Influenza-Lebendimpfstoff

LJ Lebensjahr

MBL Mannose-bindendes Lektin

MHC Major Histocompatibility Complex

MMF

MMR

MMRV Masern/Mumps/Röteln/Varizellen

MP-S Mycophenolat-Natrium

MS Multiple Sklerose

mTOR Mechanistic Target of Rapamycin

MTX Methotrexat

MUG Medizinische Universität Graz

MUI Medizinische Universität Innsbruck

MUW Medizinische Universität Wien

n. d. Nicht definiert

NB-UVB Schmalband-UVB-Therapie

NF-кB Nukleärer Faktor Kappa B

NMDA N-Methyl-D-Aspartat

NT Neutralisationstest

OPA Opsonophagozytose-Antikörper

OPV Orale Poliovakzine

PCV Pneumokokken-Konjugat-Vakzine (Synonym: PNC)

PD Programmed Death

PDGF Platelet-Derived Growth Factor

PI3Kס Phosphatidylinositol-3-Kinase p110 delta

PML Progressive Multifokale Leukenzephalopathie

PNC Pneumokokken-Konjugat-Vakzine (Synonym: PCV)

PPV Pneumokokken-Polysaccharid-Vakzine

PT Pertussis

PUVA Therapie mit Psoralen plus UVA-Bestrahlung

RA
RABA

RFFIT

RKI

RSV

S1P

SCID

SCLE

SLE

SOT

STIKO

SZT

TdaP

$\mathrm{TH}$

TKI

TLR

TNF- $\alpha$

TT

UVA

UVB

VCAM

VEGF

VGKC

VZV

WAS

XLA

YF

ZNS

Radio-Antigen Binding Assay

Rapid Fluorescent Focus Inhibition Test

Robert-Koch-Institut

Respiratory Syncytial Virus

Sphingosin-1-Phosphat

Schwere, kombinierte Immundefizienz

Subakuter kutaner Lupus erythematodes

Systemischer Lupus erythematodes

Transplantation solider Organe

Ständige Impfkommission

Stammzelltransplantation

Impfung gegen Tetanus/Diphtherie/azelluläre Pertussis

T-Helferzelle

Tyrosinkinasehemmer

Toll-Like Receptor

Tumornekrosefaktor alpha

Tetanustoxoid

Ultraviolettes Licht im Frequenzbereich 315-380 nm

Ultraviolettes Licht im Frequenzbereich 280-315 nm

Vaskuläres Adhäsionsmolekül

Vascular Endothelial Growth Factor

Voltage-Gated Potassium Channel (span-

nungsabhängige Kaliumkanäle)

Varicella-Zoster-Vakzine

Wiskott-Aldrich-Syndrom

X-Linked Agammaglobulinemia

Gelbfieber

Zentralnervensystem

\section{Einleitung}

Die vorliegenden Empfehlungen für Impfungen bei Patienten mit Immundefekten bzw. Immunsuppression (ISP) jeglicher Genese verstehen sich als erstmalige Zusammenfassung und State-of the-Art-Darstellung unter Benützung von Empfehlungen diverser internationaler und nationaler Fachgesellschaften und Gremien. Bislang lagen in Österreich keine vereinheitlichten Publikationen vor, die vor dem Hintergrund der steigenden Anzahl an immunsuppressiven Therapien übersichtliche und konsensuelle Empfehlungen zur Impfprävention bei den entsprechenden Risikopopulationen darstellen.

Vorausschickend muss gesagt werden, dass die Datenlage zu Impfungen bei immunsupprimierten Personen sehr unvollständig ist. Daher beruhen viele Impfempfehlungen nur auf theoretischen Überlegungen - so auch jene der verschiedenen medizinischen Fachgesellschaften, die für ihren jeweiligen Bereich Impfempfehlungen für immunsupprimierte Patientengruppen erstellt haben.

In der vorliegenden Publikation wird zum einen versucht, unter Berücksichtigung ev. bereits vorhandener fachspezifischer Leitlinien Impfempfehlungen für die diversen Indikationen zu geben. Zum anderen wird eine systematische Vorgehensweise beim 
Impfen in Abhängigkeit vom Grad der Immunsuppression, die durch die Erkrankung selbst und/oder durchgeführte Therapien entsteht, vorgeschlagen. Zudem wird für verschiedenste Medikamente aufgrund ihrer Wirkmechanismen und pharmakologischen Eigenschaften eine Einschätzung des entstehenden ISPSchweregrads vorgenommen.

Auf diesen Überlegungen aufbauend, werden Impfstrategien für immunsupprimierte Patienten vorgeschlagen und in einer Übersichtstabelle dargestellt. Des Weiteren finden sich in den einzelnen Kapiteln die wichtigsten medizinischen Situationen, Krankheitsbilder und deren Behandlungsschemata, die mit einer Immunsuppression einhergehen können und daher einer differenzierten Vorgehensweise beim Impfen mit inaktivierten und/oder Lebendimpfungen bedürfen. Ein Anspruch auf Vollständigkeit kann und wird alleine aufgrund des sich ständig erweiternden Behandlungsspektrums nicht erhoben.

Diese Empfehlungen sollen dazu beitragen, die Impfversorgung von Risikopersonen $\mathrm{zu}$ verbessern sowie möglichst frühzeitig im Erkrankungs-bzw. Behandlungsprozess mit nötigen Impfungen $\mathrm{zu}$ beginnen, da mit fortschreitender Immunsuppression bestimmte Impfungen kontraindiziert sein können. Allerdings können aufgrund der Komplexität der möglichen Kombinationen von individuellen Risikofaktoren, Komorbiditäten etc. nur allgemeine Empfehlungen gegeben werden. Im Einzelfall sind diese individuellen Faktoren bei der Beratung des Patienten und der Impfentscheidung immer zu berücksichtigen.

Prinzipiell ist anzumerken, dass Impfungen als Primärprävention leider derzeit auch bei Risikopatienten meist kostenpflichtig sind. In Abhängigkeit von der Sozialversicherung ist bei ambulanten Patienten oftmals zumindest ein partieller Kostenersatz möglich. Aufgrund der bestehenden Grundkrankheiten und damit verbundenen erhöhten Infektanfälligkeit wird jedenfalls seitens dieser Expertengruppe eine Kostenübernahme der in der Folge empfohlenen Impfungen durch die Sozialversicherungsträger zur Verhinderung unnötiger und zusätzlicher Therapie- und Hospitalisierungskosten nachdrücklich empfohlen.

\section{Problembereiche bei Risikopatienten/Patienten mit Immundefizienz}

Generell ist anzunehmen, dass Patienten mit Immundefizienz ein erhöhtes Infektionsrisiko haben. Individuelle Patienten bieten äußerst komplexe Voraussetzungen - Grundkrankheit, Alter, Body-Mass-Index, Komorbiditäten, Komedikation und eine Reihe weiterer individueller Faktoren -, welche die Beurteilung des Infektionsrisikos für den jeweiligen Patienten erschweren.

$\mathrm{Zu}$ fordern ist jedoch, dass besonders bei diesen Personen eine entsprechende Impfversorgung sichergestellt wird. So weisen ältere Personen mit rheumatischen oder anderen chronischen Krankheiten ein erhöhtes Risiko für Influenza- oder Pneumokokkenerkrankungen auf. Ebenso ist das Risiko für Herpes zoster bei Patienten mit rheumatoider Arthritis (RA) oder systemischem Lupus erythematodes (SLE) deutlich erhöht. Bei Patienten die z. B. mit TNF-a-Blockern behandelt werden, wurde ein zwei- bis zehnfach höheres Risiko für Tuberkulose (auch extrapulmonale Tb) beschrieben [1].

Gleichzeitig ist aber der Impferfolg aufgrund der bestehenden Immunsuppression bei diesen Personen fraglich; im Falle von Lebendimpfungen ist zudem die Sicherheit hinsichtlich der übermäßigen Vermehrung des Impfantigens (Impfvirus oder Impfbakterium) und eines durch die Impfung getriggerten Erkrankungsschubes fraglich.

Daher ist eine genaue Nutzen-Risikoabschätzung hinsichtlich des Einsatzes von inaktivierten und Lebendimpfstoffen vorzunehmen.

In diesem Zusammenhang muss auch an die Wichtigkeit der Umgebungsprophylaxe aller Personen, die im engen Kontakt zu einem immunsupprimierten $\mathrm{Pa}-$ tienten stehen, erinnert werden.

\section{Wirksamkeit von Impfstoffen}

Bei den Effekten von Impfungen sind zwei Begriffe zu unterscheiden, nämlich die Immunogenität und die Wirksamkeit, also die Protektion selbst.

Die Immunogenität kann anhand der Antikörperantwort überprüft werden. Das bedeutet aber nicht zwangsläufig eine Aussage über die Wirksamkeit, d. h. den tatsächlichen Impfschutz. Bei manchen Impfungen kann die Antikörperantwort als Surrogat für die Wirksamkeit herangezogen werden, nämlich dann, wenn Antikörpertiter (z. B. Erreger-spezifische IgGAntikörper) und Schutzwirkung (durch den Nachweis von funktionell aktiven, neutralisierenden Antikörpern) in entsprechenden Studien korreliert wurden. In diesen Fällen stehen kommerzielle Tests zur Verfügung, die zur Überprüfung der Protektion herangezogen werden können. Es gibt allerdings auch etliche andere Testsysteme, bei denen die gemessenen Antikörperwerte keine Aussage über die Wirksamkeit oder Wirkdauer der Impfung geben (Beispiel: kreuzreaktive, aber nicht schützende IgG-Antikörper bei sequentiellen Flavivirus-Kontakten, die zur Überprüfung der Immunität spezielle Neutralisationstests erfordern).

Tab. 1 zeigt die Impfungen, bei denen eine Titerkontrolle im Sinne einer Überprüfung des Schutzes oder der Schutzdauer sinnvoll sein kann.

\section{Sicherheit}

Hinsichtlich der Sicherheit ist bei immunsupprimierten Patienten zwischen der Verabreichung von Totund Lebendimpfstoffen zu unterscheiden.

Bei der Anwendung von Totimpfstoffen haben immunsupprimierte Patienten kein erhöhtes Risiko bezüglich einer Infektion durch die Impfung (bzw. das 
Tab. 1 Beurteilung des Impferfolgs mittels Titerkontrollen

\begin{tabular}{|c|c|c|c|}
\hline Impfung gegen & Methode & $\begin{array}{l}\text { Akzeptierte Grenzwer- } \\
\text { te }\end{array}$ & Kommentar \\
\hline Diphtherie & $\begin{array}{l}\text { Liganden-Assay, wie } \\
\text { z. B. ELISA }\end{array}$ & $\lg \mathrm{G} \geq 0,1 \mathrm{IE} / \mathrm{ml}$ & - \\
\hline FSME & $\begin{array}{l}\text { Liganden-Assay, wie } \\
\text { z. B. ELISA; NT }\end{array}$ & - & $\begin{array}{l}\text { FSME-IgG-Ak nur aussagekräftig, wenn die FSME-Impfung der einzige Flavivirus- } \\
\text { Kontakt war. Bei Impfung (Gelbfieber, Japan. Enzephalitis) oder Kontakt mit ande- } \\
\text { ren Flaviviren (z. B. Dengue, West-Nil) ist als Spezialdiagnostik ein FSME-NT zur } \\
\text { Messung der funktionell aktiven Antikörper notwendig (Interpretation entsprechend } \\
\text { den jeweiligen NT-Tests) }\end{array}$ \\
\hline Hepatitis B, Hepatitis A & $\begin{array}{l}\text { Liganden-Assay, wie } \\
\text { z. B. ELISA }\end{array}$ & $\begin{array}{l}\text { Anti-Hbs-Ak, HA- } \\
\text { V-AK Serokonversion: } \\
>10 \mathrm{IE} / \mathrm{ml}\end{array}$ & Langzeitschutz Hbs-AK: >100IE/ml; HAV entsprechend Testsystem \\
\hline $\mathrm{HiB}$ & RABA & $\begin{array}{l}\operatorname{lgG} \geq 0,15 \mu \mathrm{g} / \mathrm{ml} \\
\text { "Kurzzeitschutz" } \\
\mathrm{lgG} \geq 1 \mu \mathrm{g} / \mathrm{ml} \text { "Lang- } \\
\text { zeitschutz" }\end{array}$ & - \\
\hline Masern & $\begin{array}{l}\text { Liganden-Assay, wie } \\
\text { z. B. ELISA; NT }\end{array}$ & $\begin{array}{l}\lg \mathrm{g} \text { pos. } \\
\text { (n.d.) }\end{array}$ & Bewertung abhängig vom verwendeten Testsystem \\
\hline Meningokokken & $\begin{array}{l}\text { Liganden-Assay, wie } \\
\text { z. B. ELISA }\end{array}$ & n.d. & $\begin{array}{l}\text { Schutz ist für jeden Serotyp vom Vorhandensein von Antikörpern gegen die jeweili- } \\
\text { gen spezifischen Kapselantigene abhängig. Für serumbakterizide Antikörper (hSBA) } \\
\text { gilt 1:4 als Schutzgrenze (kommerziell nicht erhältlich) }\end{array}$ \\
\hline Mumps & $\begin{array}{l}\text { Liganden-Assay, wie } \\
\text { z. B. ELISA, NT }\end{array}$ & $\begin{array}{l}\lg \mathrm{g} \text { pos. } \\
\text { n.d. }\end{array}$ & Bewertung abhängig vom verwendeten Testsystem \\
\hline Pertussis & $\begin{array}{l}\text { Liganden-Assay, wie } \\
\text { z. B. ELISA }\end{array}$ & n.d. & $\begin{array}{l}\text { Beurteilbar ist nur Seronegativität (<Detektionslimit) bzw. Anstieg von PT-spezifi- } \\
\text { schen AK vor/nach Impfung }\end{array}$ \\
\hline $\begin{array}{l}\text { Pneumokokken (Konju- } \\
\text { gat-Impfstoff) }\end{array}$ & $\begin{array}{l}\text { Liganden-Assay, wie } \\
\text { z. B. ELISA }\end{array}$ & $\lg \mathrm{G}>0,35 \mu \mathrm{g} / \mathrm{ml}$ & $\begin{array}{l}\text { Dieser Grenzwert bezieht sich auf einen ELISA ohne 22F-Präadsorption. ELISAs mit } \\
\text { Präadsorption sind spezifischer. Hier ist von niedrigeren Grenzwerten auszugehen. } \\
\text { Kommerzielle Kits weisen AK gegen ein Pneumokokkengemisch nach - keine } \\
\text { Aussage über einzelne Serotypen möglich; OPA-spezifische Assays sind derzeit } \\
\text { kommerziell nicht erhältlich }\end{array}$ \\
\hline Polio (IPV) & NT & Pos & Bewertung abhängig vom verwendeten Testsystem \\
\hline Röteln & $\begin{array}{l}\text { Liganden-Assay, wie } \\
\text { z. B. ELISA }\end{array}$ & $\begin{array}{l}\text { Laut Grenzwert des } \\
\text { jeweils verwendeten } \\
\text { Testsystems }\end{array}$ & Bewertung abhängig vom verwendeten Testsystem \\
\hline Tetanus & $\begin{array}{l}\text { Liganden-Assay, wie } \\
\text { z. B. ELISA }\end{array}$ & $\lg \mathrm{G} \geq 0,1 \mathrm{IE} / \mathrm{ml}$ & - \\
\hline Tollwut & $\begin{array}{l}\text { RFFIT, Ligan- } \\
\text { den-Assay, wie z. B. } \\
\text { ELISA }\end{array}$ & $\begin{array}{l}\text { RFFIT }>0,5 I E / m l \\
\text { ELISA }>0,125 \text { bzw. } \\
0,5 E U / m l\end{array}$ & - \\
\hline Varizellen & $\begin{array}{l}\text { Liganden-Assay, wie } \\
\text { z. B. ELISA; NT }\end{array}$ & $\lg \mathrm{g} p \mathrm{~s}$ & Bewertung abhängig vom verwendeten Testsystem \\
\hline
\end{tabular}

applizierte Impfstoffantigen); es besteht jedoch die Möglichkeit eines ungenügenden Impfschutzes. Deshalb sollte, falls möglich, eine Kontrolle des Impferfolgs stattfinden. Kombinationsimpfstoffe sind Einzelimpfstoffen vorzuziehen, da sie in der Regel immunogener sind. Bei besonderer Indikation (d. h. erhöhtes Infektionsrisiko) bzw. bei bestimmten Therapien (z. B. hämatopoetische Stammzelltransplantation) kann die Anwendung bestimmter Impfstoffe auch außerhalb des Zulassungsbereichs sinnvoll sein.

Bei Lebendimpfstoffen besteht, abhängig von der immunologischen Restfunktion, das Risiko einer Erkrankung durch das attenuierte, vermehrungsfähige Impfantigen. Deshalb muss diese Art von Impfungen bei immundefizienten Patienten mit größter Vorsicht angewandt werden.
Jede Lebendimpfung beruht auf einem sorgfältig ausgetesteten Gleichgewicht zwischen Immunogenität und Reaktogenität. Das heißt, dass die Attenuierung (die z. B. auf Inaktivierung von Toxinbildung oder anderen Virulenzfaktoren beruht) gerade so weit gehen soll, dass sie unerwünschte Reaktionen verhindert, aber nicht so weit, dass sie die Immunogenität der Impfung zu sehr beeinträchtigt [3]. Dieses subtile Gleichgewicht wird jedoch für gesunde Probanden ermittelt und muss daher auf immunsupprimierte $\mathrm{Pa}$ tienten nicht zutreffen [4].

Kontraindikationen zu Impfungen können entweder auf vorliegender Evidenz oder auf theoretischen Erwägungen beruhen, wenn keine entsprechenden Daten vorliegen. So ist z. B. der orale Polio-Impfstoff (der in unseren Breiten aber nicht mehr zum Einsatz kommt) bei ISP kontraindiziert, weil er auch bei 
Gesunden in seltenen Fällen zu Vakzin-induzierten Paresen geführt hat [5-7]. In den meisten Fällen liegen aber keine ausreichenden Daten über die Verwendung von Lebendimpfungen bei diversen Erkrankungen mit Immunsuppression vor, und daher beruht die Empfehlung auf theoretischen (oftmals auf forensischen) Überlegungen. Z. B. ist die Varizellenimpfung generell bei Kindern mit entzündlichen Darmerkrankungen (IBD) kontraindiziert, die mit 6-Mercaptopurin behandelt werden; Ähnliches gilt für den intranasalen Influenza-Lebendimpfstoff (LAIV) bei ISP.

Ein weiterer Punkt bezüglich Sicherheit von Impfungen bei ISP ist die Frage, ob Impfungen bei diesen Patienten einen Trigger für chronisch-entzündliche Prozesse darstellen können. Derzeit ist die Evidenz eher gering, um für einzelne Impfstoffe einen klaren Zusammenhang mit Erkrankungsschüben von Autoimmunerkrankungen $\mathrm{zu}$ verifizieren oder $\mathrm{zu}$ negieren. Aus den vorliegenden Daten, beispielsweise bei Multipler Sklerose (MS), systemischem Lupus Erythematodes (SLE) oder rheumatoider Arthritis (RA) ergibt sich jedoch, dass Impfungen keinen wichtigen Trigger darstellen und daher verabreicht werden sollten [8-13]. Für bestimmte andere Impfstoffe, vor allem Lebendimpfstoffe, ist die Datenlage unzureichend (z. B. für die Gelbfieberimpfung im Zusammenhang mit MS [13]).

Die individuelle Nutzen-Risiko-Abschätzung ist daher die Grundlage für die Entscheidung, eine bestimmte Impfung zu verabreichen oder eben nicht $\mathrm{zu}$ verabreichen.

\section{Kriterien für die Impfentscheidung}

Die Entscheidung für eine Impfung hängt einerseits von patientenspezifischen, andererseits von impfstoffspezifischen Faktoren ab. Beide werden in Abb. 1 dargestellt.

Hervorgehoben ist hier der Grad der Immunsuppression, der das Hauptkriterium für die Impfempfehlungen der vorliegenden Publikation darstellt.

Wie eingangs erwähnt, müssen jedoch auch die anderen individuellen Patienten- und Impfstoff-spezifischen Kriterien bei der individuellen Impfentscheidung Berücksichtigung finden.

\section{Immunsuppression und Impfungen}

\section{Stadien der Immunsuppression}

Drei Schweregrade der Immunsuppression sind $\mathrm{zu}$ unterscheiden:

1. Erkrankungen/Therapien ohne relevante ISP Grad I

2. Erkrankungen/Therapien mit leichter bis mittelgradiger ISP - Grad II

3. Erkrankungen/Therapien mit hochgradiger ISP Grad III

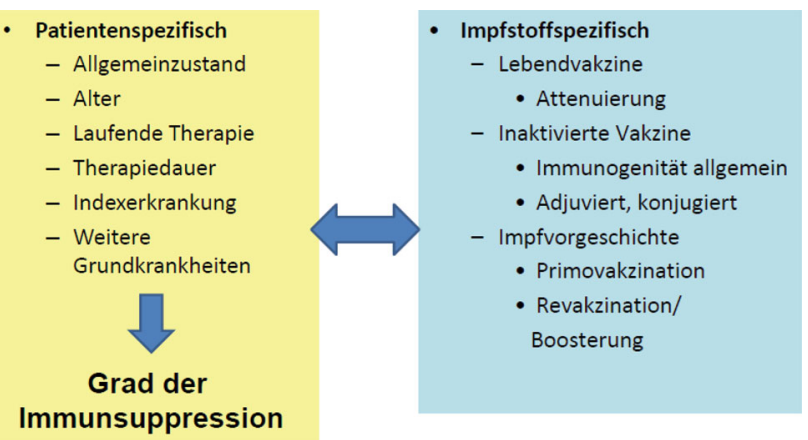

Abb. 1 Kriterien für die Impfentscheidung

Die drei Stadien der Immunsuppression sind mit den wichtigsten Beispielen in Tab. 2 zusammengefasst.

\section{Praktisches Vorgehen}

Im Idealfall sollten alle Impfungen laut dem aktuellen Österreichischen Impfplan vor Beginn einer immunsuppressiven Therapie verabreicht werden, wobei Totimpfungen spätestens zwei Wochen vor Therapiebeginn verabreicht werden sollten, Lebendimpfungen spätestens vier Wochen vor Therapiebeginn. In der Praxis ist jedoch häufig die Situation gegeben, dass eine Entscheidung über die Verabreichung einer Impfung bei bereits bestehender ISP (sei es durch eine Erkrankung oder eine Therapie) getroffen werden muss. Detaillierte Empfehlungen dazu gibt es von der IDSA [7], dem CDC [16], der STIKO/RKI [2] sowie dem Schweizer Bundesamt für Gesundheit [17].

Folgende Vorgangsweisen beim Impfen der beschriebenen Gruppen sollten eingehalten werden:

\section{Erkrankungen/Therapien ohne relevante ISP (Grad I)}

Totimpfstoffe können wie bei gesunden Personen appliziert werden, dies gilt sowohl für Routine- als auch für Reiseimpfungen. Es sind keine Titerkontrollen erforderlich.

Lebendimpfstoffe können wie bei gesunden Personen (unter Einhaltung der angegebenen Zeitabstände, siehe Punkt 4 und Tab. 4) gegeben werden. Bei Autoimmunerkrankungen ohne Therapie können Lebendimpfstoffe verabreicht werden, wenngleich dazu kaum Daten vorhanden sind. Bei HIV-Patienten mit einer CD4-Zellzahl über $500 / \mathrm{mm}^{3}$ muss bezüglich Lebendimpfungen differenziert werden: die Masern-Mumps-Röteln(MMR)-Impfung kann gegeben werden, aufgrund fehlender Daten aber nicht die Vierfachimpfung MMRV (Varizellen). Wenn gegen Varizellen geimpft werden soll, sollten zwei bis drei Monate Abstand zur MMR-Impfung eingehalten werden. Die Impfung gegen Herpes zoster sollte vermieden werden (fehlende Daten), gegen Gelbfieber kann bei zwingender Indikation geimpft werden. 
Tab. 2 Stadien der Immunsuppression

\begin{tabular}{|c|c|}
\hline \multicolumn{2}{|c|}{ 1. Erkrankungen/Therapien ohne relevante Immunsuppression - Grad I } \\
\hline \multirow[t]{3}{*}{ Kortisontherapie $^{\mathrm{a}}$} & Kurzzeittherapie (<2 Wochen) $<20 \mathrm{mg} / \mathrm{Tag}$ \\
\hline & Langzeittherapie: alternierende Tagestherapie mit kurzer HWZ \\
\hline & Inhalative, topische, intraartikuläre oder intrabursale Applikation \\
\hline HIV-Infektion & Patienten mit CD4-Zellen $\geq 500 / \mathrm{mm}^{3}$ bzw. $>25 \%$ bei Kindern \\
\hline \multirow[t]{2}{*}{ Tumorpatienten } & Letzte Chemo $>3$ Monate (bei B-Zell-Therapien $>6$ Mo); Patienten in Remission \\
\hline & SZT >2a ohne immunsuppressive Therapie und ohne GvHD \\
\hline \multicolumn{2}{|c|}{ Autoimmunerkrankungen (SLE, RA, IBD) ohne immunsuppressive bzw. -modulierende Therapie (keine Daten) } \\
\hline Diabetes mellitus & Wenn gut eingestellt (Typ 1 und 2) \\
\hline \multicolumn{2}{|c|}{ 2. Erkrankungen/Therapien mit leichter bis mittelgradiger Immunsuppression - Grad II } \\
\hline HIV-Infektion & Asymptomatische Patienten mit CD4-Zellen von $200-499 / \mathrm{mm}^{3}$ bzw. $15-25 \%$ bei Kindern \\
\hline Kortisontherapie $^{\mathrm{a}}$ & $\begin{array}{l}<20 \mathrm{mg}, \text { aber }>2 \text { Wo bzW. regelmäßige Tagesdosis von }<20 \mathrm{mg} / \mathrm{die} \\
\text { Bei }>20 \mathrm{mg} / \text { die für }<2 \text { Wo: Lebendimpfungen erst } 2 \text { Wochen nach Therapieende } \\
\text { Verabreichung von Depot-Kortison }\end{array}$ \\
\hline \multirow[t]{3}{*}{ Niedrig dosierte Immunsuppressiva } & MTX: $<0,4$ mg/kg/Wo \\
\hline & Azathioprin: $<3 \mathrm{mg} / \mathrm{kg} / \mathrm{Tag}$ \\
\hline & 6-Mercaptopurin: $<1,5 \mathrm{mg} / \mathrm{kg} / \mathrm{Tag}$ \\
\hline \multicolumn{2}{|l|}{ Anatomische oder funktionelle Asplenie } \\
\hline \multicolumn{2}{|l|}{ Chronische Nierenerkrankung } \\
\hline \multicolumn{2}{|l|}{ Chronische Lebererkrankung } \\
\hline \multicolumn{2}{|l|}{ Multiple Sklerose ohne Therapie } \\
\hline Diabetes mellitus & Bei fortgeschrittener Erkrankung und schlechtem Allgemeinzustand \\
\hline \multicolumn{2}{|l|}{ Komplement(MBL)defizienz } \\
\hline \multicolumn{2}{|c|}{ 3. Erkrankungen/Therapien mit hochgradiger Immunsuppression - Grad III } \\
\hline HIV-Infektion & CD4-Zellen $\leq 200 / \mathrm{mm}^{3}$ bzw. $<15 \%$ bei Kindern \\
\hline SZT & $\leq 2 \mathrm{a}$ oder unter immunsuppressiver Therapie oder mit GvHD \\
\hline SOT & $\leq 1 \mathrm{a}$ oder unter immunsuppressiver Therapie oder mit GvHD \\
\hline \multicolumn{2}{|l|}{ Behandlung von Organabstoßung nach SOT } \\
\hline \multicolumn{2}{|c|}{ Akute hämatologische Erkrankung, metastasierte maligne Erkrankung } \\
\hline \multicolumn{2}{|c|}{ CLL } \\
\hline \multicolumn{2}{|c|}{ Rezente Strahlentherapie (Abstand mindestens sechs Wochen nach Radiatio; Bestimmung der Lymphozytenzahl [14, 15]) } \\
\hline \multicolumn{2}{|c|}{ Aplastische Anämie } \\
\hline \multicolumn{2}{|l|}{ Kongenitaler Immundefekt } \\
\hline Kortisontherapie $^{\mathrm{a}}$ & $>20$ mg/Tag für >2 Wo (Lebendimpfung erst 1 Monat nach Therapieende) \\
\hline \multirow[t]{5}{*}{ Transplantations-bedingte Immunsuppressiva } & Ciclosporin \\
\hline & Tacrolimus \\
\hline & Sirolimus \\
\hline & Mycophenolat-mofetil \\
\hline & Mitoxantron \\
\hline \multicolumn{2}{|l|}{ Manche Chemotherapeutika } \\
\hline $\begin{array}{l}\text { Großteil der Biologika (bei Interaktion mit Immunzel- } \\
\text { len) }\end{array}$ & $\begin{array}{l}\text { Z. B. TNF- } \alpha \text {-Blocker (Adalimumab, Certolizumab-pegol, Etanercept, Golimumab, Infliximab), Alemtuzu- } \\
\text { mab, Natalizumab, Rituximab u. v. a. }\end{array}$ \\
\hline
\end{tabular}

Erkrankungen/Therapien mit leichter bis mittelgradiger ISP (Grad II)

Auch in dieser Gruppe können Totimpfstoffe verabreicht werden; es werden jedoch in manchen Fällen, wo dies möglich ist, Titerkontrollen empfohlen.

Patienten mit Asplenie sollten auf jeden Fall gegen Haemophilus influenzae Typ B (HiB), Meningo- kokken (A/C/Y/W-135 und B) und Pneumokokken geimpft werden. Die Impfung gegen Pneumokokken sollte laut Österreichischem Impfplan (Erstimpfung mit Konjugatimpfstoff PNC13, dann nach $\geq 8$ Wochen Auffrischung mit Polysaccharidimpfstoff PPV23) erfolgen. 
consensus report

Tab. 3 Halbwertszeiten und Stärke ${ }^{\mathrm{a}}$ von immunmodulierenden/suppressiven Medikamenten

\begin{tabular}{|c|c|c|c|}
\hline Substanzgruppe/Wirkmechanismus & Substanz & $H W Z^{b}$ & Stärke der ISP \\
\hline Glukokortikoide & Prednisolon & $\begin{array}{l}3,6 \mathrm{~h} \text {; Wirkdauer 12-36 h (Prednison/ } \\
\text { Prednisolon) }\end{array}$ & $\begin{array}{l}\text { III: }>20 \mathrm{mg} / \mathrm{die} \text { oder }>2 \mathrm{mg} / \mathrm{kg} / \mathrm{die} \\
\text { (bei Kindern }<10 \mathrm{~kg} \mathrm{KG} \text { ) } \\
\text { II: }<20 \mathrm{mg} \text {, aber }>2 \text { Wo } \\
\text { I: }<20 \mathrm{mg} / \mathrm{die} \text { für }<2 \text { Wo oder alternierende, } \\
\text { nicht tägliche Gabe } \\
\text { Depotgabe zwischen } 4 \text { und } 120 \mathrm{mg} \text { pro } \\
\text { Verabreichung, je nach Indikation. Daher } \\
\text { Grad II-III }\end{array}$ \\
\hline \multirow[t]{2}{*}{ Calcineurin-Inhibitoren } & Ciclosporin A & $7-19 h$ & III \\
\hline & Tacrolimus & $23-46 \mathrm{~h}$ & Topisch: I, systemisch: III \\
\hline \multirow[t]{2}{*}{ mTOR-Inhibitoren } & Everolimus & $\sim 30 \mathrm{~h}$ & III \\
\hline & Sirolimus & $62 \mathrm{~h}(46-78)$ & III \\
\hline \multirow[t]{8}{*}{ DNS-Biosynthesehemmer } & Azathioprin & $\sim 2 \mathrm{~h}$ & $\begin{array}{l}\text { Niedrig dosiert (<3 mg/kg/Tag): II } \\
\text { Höher dosiert: III }\end{array}$ \\
\hline & Cyclophosphamid & $3-12 \mathrm{~h}$ & III \\
\hline & Leflunomid & $14-15 d$ & III \\
\hline & Teriflunomid & $19 d$ & III \\
\hline & 6-Mercaptopurin & $\sim 2 \mathrm{~h}$ & $\begin{array}{l}\text { Niedrig dosiert (<1,5 mg/kg/Tag): II } \\
\text { Höher dosiert: III }\end{array}$ \\
\hline & Methotrexat & $3-15 h$ & $\begin{array}{l}\text { Niedrig dosiert (<0,4 mg/kg/Woche): II } \\
\text { Höher dosiert: III }\end{array}$ \\
\hline & Mycophenolat & $17-18 \mathrm{~h}$ & $\|-1\|$ \\
\hline & Sulfasalazin & $6-10 \mathrm{~h}$ & I \\
\hline \multirow[t]{5}{*}{ TNF- $\alpha$-Blocker } & Adalimumab & $\sim 14 \mathrm{~d}(10-20)$ & III \\
\hline & Certolizumab-pegol & $\sim 14 \mathrm{~d}$ & III \\
\hline & Etanercept & $\sim 70 \mathrm{~h}$ & III \\
\hline & Infliximab & $7-12 d$ & III \\
\hline & Golimumab & $\sim 14 \mathrm{~d}$ & III \\
\hline Anti-VEGF & Bevacizumab & $\sim 20 \mathrm{~d}(11-50)$ & I \\
\hline \multirow[t]{2}{*}{ Anti-IL-1 } & Anakinra & $4-6 \mathrm{~h}$ & III \\
\hline & Canakinumab & $26 d$ & III \\
\hline Anti-IL-1-Rezeptor & Rilonacept & $\begin{array}{l}\text { 8, } 6 \mathrm{~d} \text { bei Erwachsenen } \\
6,3 \mathrm{~d} \text { bei Kindern }\end{array}$ & III \\
\hline \multirow[t]{2}{*}{ Anti-IL-2 } & Basiliximab & $7-10 d$ & III \\
\hline & Daclizumab & $11-38 d$ & III \\
\hline Anti-IL-6 & Tocilizumab & $23 d$ & III \\
\hline Anti-IL-12/IL-23 & Ustekinumab & $10-126 d$ & III \\
\hline Anti-IL-17A-Rezeptor & Brodalumab & $18-47 d$ & $\| I^{c}$ \\
\hline \multirow[t]{2}{*}{ Anti-IL-17A } & Secukinumab & $18-46 d$ & III \\
\hline & Ixekizumab & $14-18 d$ & III \\
\hline Anti-HER-2 & Trastuzumab & $6 \mathrm{~d}(1-32)$ & I \\
\hline \multirow[t]{5}{*}{ Anti-CD-20 } & Rituximab & $18-32 d$ & III \\
\hline & Obinutuzumab & $30 \mathrm{~d}$ & III \\
\hline & Ofatumumab & $18,5 d$ & III \\
\hline & Ibritumomab-Tiuxetan & $28 \mathrm{~h}$ & III \\
\hline & Ocrelizumab & $8 d$ & III \\
\hline Anti-CD-30 & Brentuximab-Vedotin & $4-6 d$ & III \\
\hline Anti-CD-52 & Alemtuzumab & $6 d$ & III \\
\hline \multirow[t]{2}{*}{ Anti-CD80/CD86 } & Abatacept & $8-25 d$ & $\| I^{d}$ \\
\hline & Belatacept & $8-25 d$ & $\| I^{d}$ \\
\hline S1P-Rezeptor-Modulatoren & Fingolimod & $6-9 d$ & III \\
\hline \multirow[t]{3}{*}{ Tyrosinkinasehemmer (TKI) } & Imatinib & $18 \mathrm{~h}$ & III \\
\hline & Dasatinib & $5-6 \mathrm{~h}$ & III \\
\hline & Nilotinib & $17 \mathrm{~h}$ & III \\
\hline
\end{tabular}


Tab. 3 (Fortsetzung)

\begin{tabular}{|c|c|c|c|}
\hline \multirow[t]{3}{*}{ Substanzgruppe/Wirkmechanismus } & Substanz & $H W Z^{b}$ & Stärke der ISP \\
\hline & Bosutinib & $34 \mathrm{~h}$ & III \\
\hline & Ponatinib & $22 \mathrm{~h}$ & III \\
\hline Bruton-TKI-Inhibitor & Ibrutinib & $4-13 \mathrm{~h}$ & III \\
\hline PI3Kס-Kinase-Inhibitor & Idelalisib & $8 \mathrm{~h}$ & III \\
\hline \multirow[t]{2}{*}{ Integrin-Antagonisten } & Vedolizumab & $25 d$ & 1 \\
\hline & Natalizumab & $12-20 d$ & III \\
\hline Januskinase-Hemmer & Ruxolitinib & $3 \mathrm{~h}$ & III \\
\hline Phosphodiesterase-4-Hemmer & Apremilast & $9 \mathrm{~h}$ & II-III \\
\hline BlyS-Hemmer & Belimumab & $19,4 d$ & III \\
\hline Anti-lgE & Omalizumab & $24-26 d$ & $\|-\| \|^{e}$ \\
\hline Fumarsäure-und Derivate & $\begin{array}{l}\text { Fumarsäure, Fumarat, Dime- } \\
\text { thylfumarat }\end{array}$ & $36 \mathrm{~h}$ & $\mathrm{III}^{\mathrm{f}}$ \\
\hline Retinsäure-Analoga & Acitretin & $50 \mathrm{~h}$ & 1 \\
\hline 2Malariamittel & Hydroxychloroquin & $45 d$ & I \\
\hline Interferone & Beta-Interferone & Einige $\mathrm{h}$ & 1 \\
\hline \multirow{2}{*}{$\begin{array}{l}\text { Nicht restlos geklärter } \\
\text { Wirkmechanismus }\end{array}$} & Glatiramerazetat & $6 d$ & 1 \\
\hline & 5-ASA & $2 \mathrm{~h}$ & 1 \\
\hline \multicolumn{4}{|c|}{$\begin{array}{l}\text { Quellen [7, 16, 20-27]: } \\
\text { 'Ein Teil der hier gegebenen ISP-Graduierung beruht nur auf Expertenmeinungen, da Literatur dazu fehlt. Es muss davon ausgegangen werden, dass die Kombi- } \\
\text { nation von Wirkstoffen zu additivem oder überadditivem Synergismus führen kann. Systematische Untersuchungen fehlen auch dazu. Bei nicht ausreichender } \\
\text { Kenntnis ist davon auszugehen, dass ein Grad III vorliegt } \rightarrow \text { KI Lebendimpfungen } \\
\text { bDie HWZ einer Substanz sagt noch nichts über die Wirkdauer aus, die bei manchen Substanzen aus pharmakodynamischen Gründen sehr viel länger sein kann } \\
\text { (z. B. massive T- und B-Zell-Depletion und Immunsuppression durch Alemtuzumab, die bis zu einem Jahr anhält; Ähnliches gilt für die B-Zell-Depletion durch } \\
\text { Rituximab) } \\
\text { cKeine Lebendimpfungen; normale humorale Antwort auf Totimpfstoffe (Influenza, Meningokokken) dokumentiert } \\
\text { dKeine Lebendimpfstoffe ( } 3 \text { Monate Abstand); Totimpfstoffe möglich } \\
\text { ekeine Hinweise auf profunde Immunsuppression vorhanden; Effekte hinsichtlich Vakzinierung nicht untersucht, die Graduierung folgt daher aus rein theoreti- } \\
\text { schen/forensischen Überlegungen und fehlenden Daten folgend } \\
\text { falle 6-8 Wochen Blutbildkontrolle wegen Reduktion der Leukozyten; daher Graduierung III }\end{array}$} \\
\hline
\end{tabular}

Patienten mit chronischen Erkrankungen des HerzKreislauf-Systems, der Lungen, der Nieren, der Leber, des Gastrointestinaltrakts oder mit Diabetes mellitus sollten auf jeden Fall gegen Influenza, Pneumokokken sowie Hepatitis A und B geimpft werden.

Bezüglich Lebendimpfungen gelten folgende Empfehlungen:

Asymptomatische HIV-Patienten mit CD4-Zellzahlen von $200-499 / \mathrm{mm}^{3}$ (bzw. $15-25 \%$ bei Kindern) können gegen Masern/Mumps/Röteln und Varizellen (monovalent) geimpft werden; für die Verabreichung der MMRV-Kombinationsimpfung fehlen hingegen Daten. Die Impfung gegen Herpes zoster und die Influenza-Lebendimpfung (LAIV) sind wegen mangelnder Daten nicht empfohlen. Gegen Gelbfieber sollten diese Patienten nur geimpft werden, wenn es aufgrund einer zwingenden Reise im Sinne einer Risikoabwägung notwendig ist. Hingegen können Patienten mit einer Kortisontherapie von weniger als zwei Wochen Dauer bzw. mit einer Tagesdosis von weniger als $20 \mathrm{mg}$ eine Gelbfieberimpfung problemlos erhalten.

Bei Asplenie oder Sichelzellanämie sind die Impfungen gegen MMR, MMRV, Varizellen und Zoster möglich, die Influenza-Lebendimpfung ist jedoch wegen fehlender Daten - kontraindiziert.
Bei chronisch-entzündlichen Erkrankungen mit einer niedrig dosierten Dauertherapie kann laut IDSA [7] bei seronegativen Patienten wegen erhöhter Infektionsgefahr eine Varizellenimpfung überlegt werden (dies weicht allerdings von den ebenfalls aus den USA stammenden ACIP-Empfehlungen ab).

\section{Erkrankungen/Therapien mit hochgradiger ISP (Grad III)}

Bei Patienten mit hochgradiger ISP ist die Verabreichung von Totimpfstoffen möglich, der Impferfolg ist jedoch fraglich; Titerkontrollen sind wünschenswert.

Lebendimpfungen sind bei schwerer ISP generell kontraindiziert, es kann jedoch individuelle Ausnahmen von dieser Regel geben, die aber einer strengen Nutzen-Risiko-Evaluierung unterliegen müssen.

\section{Wirkmechanismen immunsuppressiver Medikamente}

Immunsuppressiva sind eine Klasse von Pharmaka, die zur Unterdrückung von Immunreaktionen eingesetzt werden und hauptsächlich zur Prävention von Abstoßungsreaktionen nach Organtransplantationen, bei der Behandlung von Autoimmunerkrankungen, zur Behandlung von chronisch-entzündlichen Erkrankungen und bei antineoplastischer Chemotherapie \pm 
Tab. 4 Zeitraum zwischen Absetzen eines Immunsuppressivums und Lebendimpfung

\begin{tabular}{|c|c|}
\hline Medikament & Zeitraum bis zur Lebendimpfung \\
\hline $\begin{array}{l}\text { Kortikosteroide - kurzzeitig bzw. niedrig dosiert, physiologische Ersatztherapie } \\
\text { oder nicht systemisch }{ }^{\mathrm{a}}\end{array}$ & Kein Abstand erforderlich \\
\hline $\begin{array}{l}\text { Kortikosteroide - systemisch und hoch dosiert }(\geq 2 \text { Wochen })^{b} \\
\text { Interferone }^{c}\end{array}$ & Abstand mindestens 1 Monat \\
\hline $\begin{array}{l}\text { 6-Mercaptopurin } \\
\text { Azathioprin }^{\mathrm{f}} \\
\text { Ciclosporin A } \\
\text { Cyclophosphamid } \\
\text { Mycophenolat } \\
\text { Tacrolimus } \\
\text { Fumarat } \\
\text { Fingolimod }\end{array}$ & Abstand mindestens drei Monate ${ }^{\mathrm{e}}$ \\
\hline $\begin{array}{l}\text { Sulfasalazin } \\
\text { Hydroxychloroquin }\end{array}$ & Kein Abstand erforderlich \\
\hline Methotrexat (MTX) & Abstand mindestens drei Monate ${ }^{g}$ \\
\hline Leflunomid & Abstand mindestens zwei Jahre ${ }^{\mathrm{h}}$ \\
\hline $\begin{array}{l}\text { Abatacept } \\
\text { Adalimumab } \\
\text { Anakinrai } \\
\text { Certolizumab } \\
\text { Golimumab } \\
\text { Infliximab } \\
\text { Natalizumab } \\
\text { Secukinumab } \\
\text { Tocilizumab } \\
\text { Ustekinumab }\end{array}$ & Abstand mindestens drei Monate ${ }^{\mathrm{e}}$ \\
\hline Etanercept & $\begin{array}{l}\text { Abstand mindestens } 3 \text { Monated; in klinisch stabilen Fällen können Lebendimp- } \\
\text { fungen früher ( }>1 \text { Monat nach Absetzen von Etanercept) gegeben werden }\end{array}$ \\
\hline $\begin{array}{l}\text { Rituximab } \\
\text { Alemtuzumab }\end{array}$ & Abstand mindestens 12 Monate \\
\hline \multicolumn{2}{|c|}{ 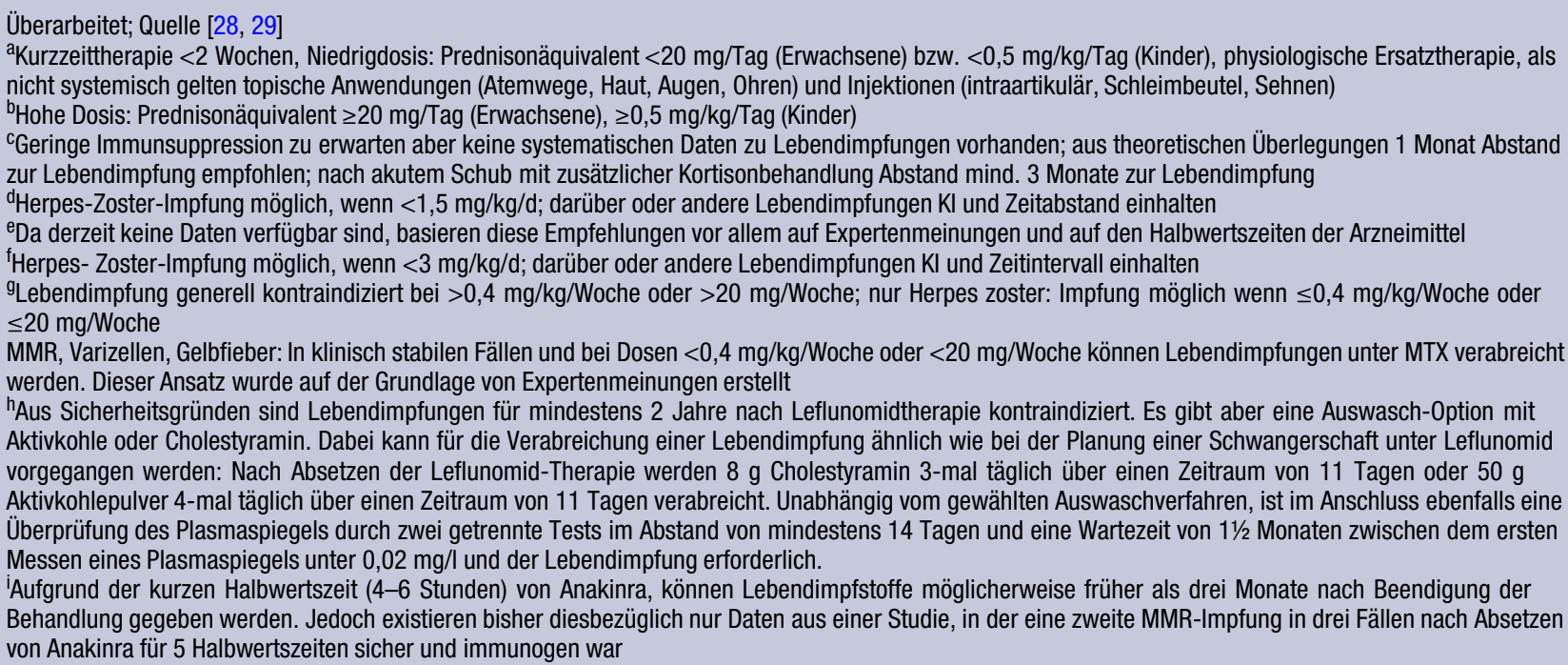 } \\
\hline
\end{tabular}

Bestrahlung (wobei hier die ISP als unerwünschte Wirkung auftritt) verwendet werden.

Heutzutage werden hauptsächlich die folgenden Pharmaka eingesetzt: Glukokortikoide, CalcineurinInhibitoren, mTOR-Inhibitoren, DNS-BiosyntheseHemmer, Tyrosinkinase-Hemmer, immunsupprimierende Antikörper, S1P-Rezeptor-Modulatoren und sogenannte Targeted Therapies. Im Folgenden werden die Wirkmechanismen der Gruppen im Überblick zusammengefasst.

\section{Glukokortikoide}

Glukokortikoide supprimieren die Ausbildung von Zytokinen sowie deren Wirkung, z. B. durch Inhibiti-

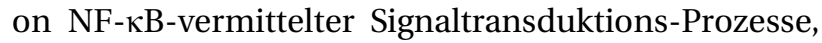
oder können zur Apoptose von u.a. Lymphozyten führen; all dies führt zu einer starken Hemmung zellvermittelter Immunantworten. Im Zellinneren, das nur durch Diffusion erreicht werden kann, führen Glukokortikoide zu hemmenden Wirkungen auf Expression von Signaltransduktions-Molekülen sowie 
$\mathrm{zu}$ direkt hemmenden Effekten. Sie führen auch $\mathrm{zu}$ einer Umverteilung von Lymphozyten. Aufgrund dieser Eigenschaften bieten sich Glukokortikoide - und hier insbesondere Prednisolon - sehr für eine immunsuppressive Begleittherapie bei Organtransplantation oder zur Behandlung von Autoimmunerkrankungen an. Der verzögerte Wirkeintritt beruht auf dem intrazellulären Wirkort, der erst durch die lipophilen Moleküle erreicht werden muss.

Eine Diskrepanz zwischen Plasmahalbwertszeit (siehe auch Tab. 3) und der Wirkhalbwertszeit ist besonders bei Glukokortikoiden augenscheinlich, da sie aufgrund von unterschiedlichen Wirkmechanismen unterschiedlich lange biologisch aktiv sind. Davon abzugrenzen sind Depotpräparate wie das Triamcinolon-Acetonid, das als kristalline Suspension eine Wirkdauer von vier bis sechs Wochen aufweist (und nur nach und nach aus der Kristallform herausgelöst wird); allerdings werden die in Depotpräparaten enthaltenen Kortikosteroide eben nach und nach in den systemischen Kreislauf eingespeist und verteilen sich im Organismus - darauf beruht ihre länger anhaltende und ausgeprägte Wirkung. Aus diesem Grund sollte die Planung einer Immunisierung diesem Umstand Rechnung tragen.

Inhalative Glukokortikoide unterliegen einem besonders schnellen Metabolismus, was auch den Grund für ihre starke lokale und gleichzeitig gering ausgeprägte systemische Wirkung darstellt.

\section{Calcineurin-Hemmer}

Calcineurin führt als Proteinphosphatase über den Umweg der Dephosphorylierung des nukleären Faktors aktivierter T-Zellen und darauffolgender Translokation in den Zellkern zur Steigerung der Transkription und somit der Expression von Zytokinen wie beispielsweise Interleukin 2 (IL-2). Durch Hemmung dieses Prozesses kann die Zytokinproduktion in aktivierten T-Lymphozyten sehr effizient zur Immunsuppression eingesetzt werden. Das zyklische Peptid Ciclosporin wird seit über 30 Jahren in der Organtransplantation erfolgreich eingesetzt; daneben werden noch die neueren, chemisch völlig verschiedenen Makrolide Tacrolimus (systemisch und topisch) und Pimecrolimus (topisch) als Immunmodulatoren verwendet. Während Ciclosporin indirekt über Cyclophilin Calcineurin hemmt, bilden die neueren Substanzen einen Komplex mit FK506-bindendem Protein-12 (FKBP12) und hemmen dadurch Calcineurin.

\section{mTOR-Hemmer}

„Mammalian target of rapamycin“ (mTOR) ist eine Serin-/Threonin-Kinase, die eine wichtige Rolle bei der Regulation der Zellproliferation einnimmt. mTOR stimuliert die Zellproliferation und den Zellzyklus und spielt besonders bei der IL-2-induzierten Stimulati- on der Lymphozytenproliferation eine wichtige Rolle. Strukturell sind die beiden Vertreter der Gruppe, Sirolimus (auch Rapamycin genannt), sein Prodrug Temsirolimus und Everolimus, mit Tacrolimus verwandt. Sie binden ebenfalls an das zytosolische Immunophilin FKBP-12, wobei dieser Komplex dann mTOR inhibiert und damit zu einer Hemmung der durch IL-2 induzierten Proliferation von Lymphozyten führt.

\section{DNS-Biosynthese-Hemmer}

Immunsuppression über effiziente Hemmung der Lymphozytenproliferation kann auch durch Einsatz von DNS-Biosynthese- Hemmstoffen erreicht werden. $\mathrm{Zu}$ dieser Gruppe gehören Azathioprin, Methotrexat, Leflunomid und Mycophenolat-mofetil.

Die Prodrug Azathioprin wird nach Resorption in 6-Mercaptopurin umgewandelt, welches als „falscher Metabolit" die Purin-Nukleotid-Synthese hemmt. Nachdem Azathioprin stärker auf die T- als auf die B-Lymphozyten wirkt, führt es besonders zur Hemmung der zellvermittelten Immunantwort. Mycophenolat-mofetil wirkt ebenso als Prodrug, greift ebenfalls in den DNS-Aufbau - und damit relativ selektiv bei den Lymphozyten - ein. Natrium-Mycophenolat ist im Gegensatz zu Mycophenolat-mofetil keine Prodrug, sondern enthält bereits den aktiven Wirkstoff Mycophenolsäure.

Methotrexat und Leflunomid wirken über die Pyrimidin-Synthesehemmung relativ selektiv auf Lymphozyten und hemmen dadurch deren Wachstum.

\section{Tyrosinkinasehemmer (TKI)}

Wachstumsfaktoren können über Bindung an Rezeptor-Tyrosinkinasen ihre Wirkung entfalten. Bei Rezeptor-Tyrosinkinasen handelt es sich um eine sehr heterogene und große Gruppe: Dazu gehört z. B. die EGF-Rezeptor-Familie (auch ErbB-Familie genannt; z. B. Trastuzumab), die Insulin-Rezeptoren, die PDGF-Rezeptor-Familie und die VEGF-Rezeptoren. Daneben gibt es noch eine Reihe an Rezeptoren, deren Liganden oder Signaltransduktionspfade teilweise noch ungeklärt sind.

Die Aktivierung der Rezeptor-Tyrosinkinasen erfolgt durch Bindung der Liganden an die extrazellulären Domänen. Durch eine darauffolgende Konformationsänderung kommen sich die intrazellulär gelegenen ATP-Bindungsstellen näher und es erfolgt die sogenannte Autophosphorylierung im dimerisierten Rezeptor.

Die immunsupprimierende Wirkung von Tyrosinkinase-Inhibitoren ist allerdings unterschiedlich ausgeprägt, aber im Großen und Ganzen eher geringgradig. Ein Beispiel für keine/geringe immunsuppressive Wirkung ist der VEGF-Rezeptor Blocker Bevacizumab, der das durch das Tumorgewebe mit sezernierten Wachstumsfaktoren getriggerte Wachstum von Blutgefäßen zu seiner eigenen Versorgung unterbindet 
und dessen Angiogenese-hemmende Wirkung im Großen und Ganzen keinen immunsupprimierenden Effekt erzielt.

Im Gegensatz dazu sind TKI mit entsprechender immunsuppressiver Wirkung zu nennen, die die Tyrosinkinasen in Immunzellen inhibieren, wie Ibrutinib, das die Bruton-Tyrosinkinase in B-Zellen und damit die B-Zellantwort hemmt. Zu ähnlich wirkenden Kinasehemmern zählt Idelalisib, das die PI3-Kinasedelta in T- und B-Zellen hemmt und damit sowohl die durch den T- als auch durch den B-Zell-Rezeptor vermittelte Antwort unterdrückt. Weitere Informationen zu TKI finden sich im Punkt Hämatologie.

Bei BCR-ABL-TKI (Imatinib, Nilotinib, Dasatinib, Ponatinib, Bosutinib) muss auch erwähnt werden, dass es bei chronischen Trägern des Hepatitis-B-Virus (HBV) zur Reaktivierung von Hepatitis B gekommen ist, die in einigen Fällen zu besonders fulminanten Verläufen oder Leberversagen führte. Daher muss vor Einleitung der TKI-Therapien auf eine bestehende HBV-Infektion untersucht werden [18].

\section{Immunsupprimierende Antikörper}

T-Zell-Modulation stand zu Beginn der Entwicklung von immunmodulatorischen Antikörpern im Fokus, da die Funktion der T-Zellen als zentraler Vermittler der Immunantwort besonders nach Organtransplantation gehemmt werden sollte. Neben polyvalenten Antiseren wurden auch spezifische, monoklonale Antikörper entwickelt. Allerdings wurde auch der Tumornekrosefaktor alpha (TNF- $\alpha$ ) als Zielstruktur erkannt, der über die Steuerung der Zellaktivität im Immunsystem an entzündlichen Erkrankungen beteiligt ist. Die TNF- $\alpha$-Blocker sind eine heterogene Gruppe von monoklonalen Antikörpern bzw. Fusionsproteinen (Etanercept), die sowohl in Größe als auch im Aufbau unterschiedlich sind: so misst der kleinste, Certolizumab, nur 50 kDa, während die größten um 150 kDa wiegen. Der Grund dafür ist die Reduktion von Certolizumab auf ein reines Fab-Fragment, das auch Vorteile mit sich bringt, wie z. B. das Fehlen einer Komplementaktivierung. Etanercept unterscheidet sich von den anderen TNF- $\alpha$-Blockern: Es bindet lösliches TNF- $\alpha$ mit Hilfe der an IgG1 fusionierten Rezeptorbindungstasche des TNF-Rezeptors und verhindert so dessen Bindung an den endogenen Rezeptor. Anakinra ist ein humaner IL-1-Rezeptor-Antagonist, der die Wirkung von IL- $1 \alpha$ und IL- $1 \beta$ am entsprechenden IL-1-Rezeptor kompetitiv hemmt.

Die gegen den IL-2-Rezeptor (CD25) gerichteten Antikörper Basiliximab und Daclizumab blockieren gezielt die Aktivierung von T-Zellen. Der humane monoklonale Antikörper Ustekinumab bindet seinerseits direkt an die gemeinsame p40-Untereinheit der Zytokine IL-12 und IL-23; dadurch wird die aktivierende Interaktion dieser Zytokine mit den entsprechenden Rezeptoren auf natürlichen Killerzellen und auf naiven T-Lymphozyten unterbunden.
Die monoklonalen Antikörper Secukinumab und Ixekizumab binden IL-17A und unterscheiden sich lediglich in ihrer Immunglobulinklasse, während Brodalumab (das zum Zeitpunkt der Drucklegung allerdings weder von der FDA noch von der EMA zugelassen ist) an den IL-17A-Rezeptor bindet; alle drei Substanzen hemmen IL-17A und unterdrücken so die IL-17-abhängige Entzündungskaskade. Immunsuppressiv wirken auch die Fusionsproteine Abatacept und Belatacept, die Co-aktivierende Proteine in der immunologischen Synapse (zwischen der antigenpräsentierenden Zelle und der T-Zelle) blockieren und damit die T-Zell-Aktivierung verhindern.

Der selektive Adhäsionsmolekül-Inhibitor Natalizumab bindet an die $\alpha 4$-Untereinheit von humanen Integrinen, die auf der Oberfläche aller Leukozyten mit Ausnahme der Neutrophilen in großer Anzahl exprimiert werden. Durch diese Bindung wird die Wechselwirkung mit dem vaskulären Zelladhäsionsmolekül-1 (VCAM-1) und dem Liganden Osteopontin sowie einer alternativ gespliceten Domäne von Fibronektin, dem Connecting Segment-1 (CS-1), blockiert. Hauptsächlich kann durch diese Effekte die Migration von Leukozyten in entzündlich verändertes Gewebe verhindert werden. Bei diesem Antikörper muss aber auch mit unerwünschten Nebenwirkungen gerechnet werden, zu denen $\mathrm{u}$. a. eine progressive multifokale Leukenzephalopathie gehören.

Im Gegensatz dazu ist Vedolizumab ein IntegrinAntagonist ( $\alpha 4 \beta 7$ ) mit selektiver Wirkung im Gastrointestinaltrakt, dem keine systemische immunsuppressive Aktivität nachgesagt wird und der vorwiegend die Migration von T-Zellen in den Darm inhibiert. Allerdings besteht ein erhöhtes Risiko für opportunistische Infektionen bzw. für Infektionen, gegen die der Darm eine schützende Barriere bildet.

Rituximab ist gegen den oberflächlich auf B-Zellen vorkommenden Rezeptor CD20 gerichtet, über den dieser Antikörper u. a. eine Komplement-abhängige Zytotoxizität vermittelt. CD20 reguliert die Initiation des Zellzyklus und kann daher bei chronischentzündlichen Erkrankungen involviert sein. Eine ähnliche Wirkung ruft die Bindung von Alemtuzumab an den auf B- und T-Zellen und weiteren spezialisierten Blutzellen vorkommenden Rezeptor CD52 hervor: Es kommt zu einer Antikörper-mediierten Lyse von maligen entarteten Zellen, aber auch in der Behandlung von Multipler Sklerose hat sich Alemtuzumab als indiziert gezeigt.

Von den Januskinase-Inhibitoren ist bislang lediglich Ruxolitinib bei Polycythaemia vera und Myelofibrose zugelassen; Tofacitinib wurde die Zulassung jedoch verwehrt. Januskinase-Inhibitoren können sowohl zu Immunsuppression als auch zu Infektionsgefahr führen und durch Reaktivieren von Tuberkulose oder auch Hepatitis B eine Bedrohung darstellen.

Ein weiterer monoklonaler Antikörper ist der Angiogenesehemmer Bevacizumab, der das durch das Tumorgewebe mit sezernierten Wachstumsfaktoren 
getriggerte Wachstum von Blutgefäßen zu seiner eigenen Versorgung unterbindet. Allerdings ist dieser monoklonale Antikörper, der zu keinen immunsupprimierenden Effekten führt, nur der Vollständigkeit halber erwähnt. Auch bei dem gegen die extrazelluläre Domäne des humanen epidermalen Wachstumsfaktor-Rezeptors 2 (HER-2) gerichteten Antikörper Trastuzumab, der zelluläre Zytotoxizität bei HER-2 überexprimierenden Zellen induziert, ist eine generelle Immunsuppression nicht anzunehmen.

\section{S1P-Rezeptor-Modulatoren}

Sphingosin-1-Phosphat (S1P) bindet an unterschiedliche S1P-Rezeptoren und fördert dadurch im Immunsystem die Auswanderung von T-Lymphozyten aus Lymphknoten. Fingolimod hemmt die Auswanderung von T-Lymphozyten aus Lymphknoten, weil es als Fingolimod-Phosphat an den S1P1-Rezeptor bindet und diesen internalisiert. Daher bleibt eine Antwort der Lymphozyten auf endogene S1P-Signale aus und sie verbleiben in den Lymphknoten, wodurch entzündliche Prozesse, wie z. B. MS-Schübe eingedämmt werden.

\section{Targeted Therapies}

„Targeted therapies“ werden besonders in der Onkologie eingesetzt (s. auch Punkt 6.4). Zu ihnen gehören monoklonale Antikörper wie z. B. Cetuximab, aber auch „small molecules“, wie die bereits erwähnten Tyrosinkinase-Hemmer, Erlotinib, Gefitinib, Trastuzumab, Afatinib, Apremilast oder Tofacitinib. Das therapeutische Prinzip beruht in der Regel auf der Unterbrechung eines oder mehrerer Signalwege. Die differenziellen Wirkungen verschiedener Biologika auf das Immunsystem sind komplex und bei jedem Biologikum anders. So hat z. B. Cetuximab immunaktivierende Wirkungen (Komplementfixierung, Antikörper-abhängige zelluläre Zytotoxizität [ADCC], MHCExpression, Priming dendritischer Zellen). Eine EGFRInhibition könnte auch zu einer immunsuppressiven Wirkung durch Aktivierung von M2-Makrophagen, die das Tumorwachstum fördern, führen, wie in Modellen des hepatozellulären Karzinoms gezeigt wurde [19].

Insgesamt zeigen Targeted Therapies unterschiedlich ausgeprägte immunsuppressive Wirkungen, bei einzelnen Substanzen kann es sogar eher zu hyperaktiven Reaktionen bzw. chronischen Entzündungen kommen (z. B. akneiforme Hautreaktionen bei EGFRInhibitoren). Für die eher neue Gruppe der Checkpoint-Inhibitoren wie Ipilimumab (Anti-CTLA-4), Nivolumab (Anti-PD-1) etc., die unter anderem zur Melanom-Behandlung eingesetzt werden, gilt, dass es zu keiner wesentlichen Immunsuppression kommt, sondern eher eine Neigung zu Autoimmunphänomenen besteht. Eine theoretisch mögliche Überaktivierung des Immunsystems bei gleichzeitiger Impfung ist hier zu bedenken.
$\mathrm{Zu}$ den gängigen Chemotherapeutika siehe den Punkt Solide Tumoren.

\section{Halbwertszeiten und Stärke der ISP}

Tab. 3 enthält einen Überblick der oben angeführten Pharmaka mit ihren Halbwertszeiten und einer Einteilung in den jeweiligen, durch die Medikation bedingten Grad der ISP. Damit soll den behandelnden Ärzten eine Entscheidungshilfe angeboten werden, um Impfungen bei immunsupprimierten Patienten vorzunehmen; dies soll jedoch nur in Kenntnis der speziellen immunologischen Restfunktion des immunsupprimierten Patienten begonnen werden.

Wenn Kombinationstherapien verabreicht werden, gilt das stärker immunsuppressive Prinzip für den Grad der Abschätzung der ISP.

Die Einteilung nach Halbwertszeiten (HWZ) kann in vielen Fällen als Richtlinie für die Zeitdauer bis zum Erreichen der vollständigen Elimination eines Pharmakons aus dem Organismus (in der Regel 4- bis 6-mal die HWZ) herangezogen werden. Jedoch ist es notwendig, sich mit der Verteilung und dem Wirkmechanismus des jeweiligen Medikaments auseinanderzusetzen, da Akkumulation in tiefen Kompartimenten oder das Triggern von längerlebigen biologischen Prozessen erfolgen kann und somit die biologische Wirkhalbwertszeit nicht mit der Verweildauer im Organismus übereinstimmt.

Nach grundlegenden pharmakokinetischen Überlegungen ist jedoch evident, dass nach $4 \mathrm{HWZ}$ noch 6,25\% und nach 6 HWZ noch 1,56 \% der Ausgangssubstanz im Körper verbleiben - dies kann, je nach Menge, die anfänglich vorhanden war, allerdings noch $\mathrm{zu}$ relevanten Effekten führen. Als ein Beispiel sei angeführt, dass die Makrophagen-Aktivierung auch nach Beenden der TNF-Blockade noch einige Zeit vermindert sein kann.

Daher sind neben dem vorher Gesagten auch die ursprünglich verabreichte Dosis, die Umverteilung und die Metabolisierung von Medikamenten von großer Bedeutung.

\section{Zeitabstände zwischen Behandlungen und Impfungen}

\section{Vor Therapiebeginn}

In den Fällen, in denen die Erkrankung und/oder Behandlung zu schweren Immunsuppressionen führt, sind bevorzugt vor Therapiebeginn die entsprechenden Impfungen (vor allem Lebendimpfungen) durchzuführen.

Inaktivierte Impfstoffe sollen spätestens 2 Wochen vor Therapiebeginn gegeben werden:

- Di/Tet/Pert/Polio,

- Hepatitis A/B,

- Influenza (jährlich), 


\section{consensus report}
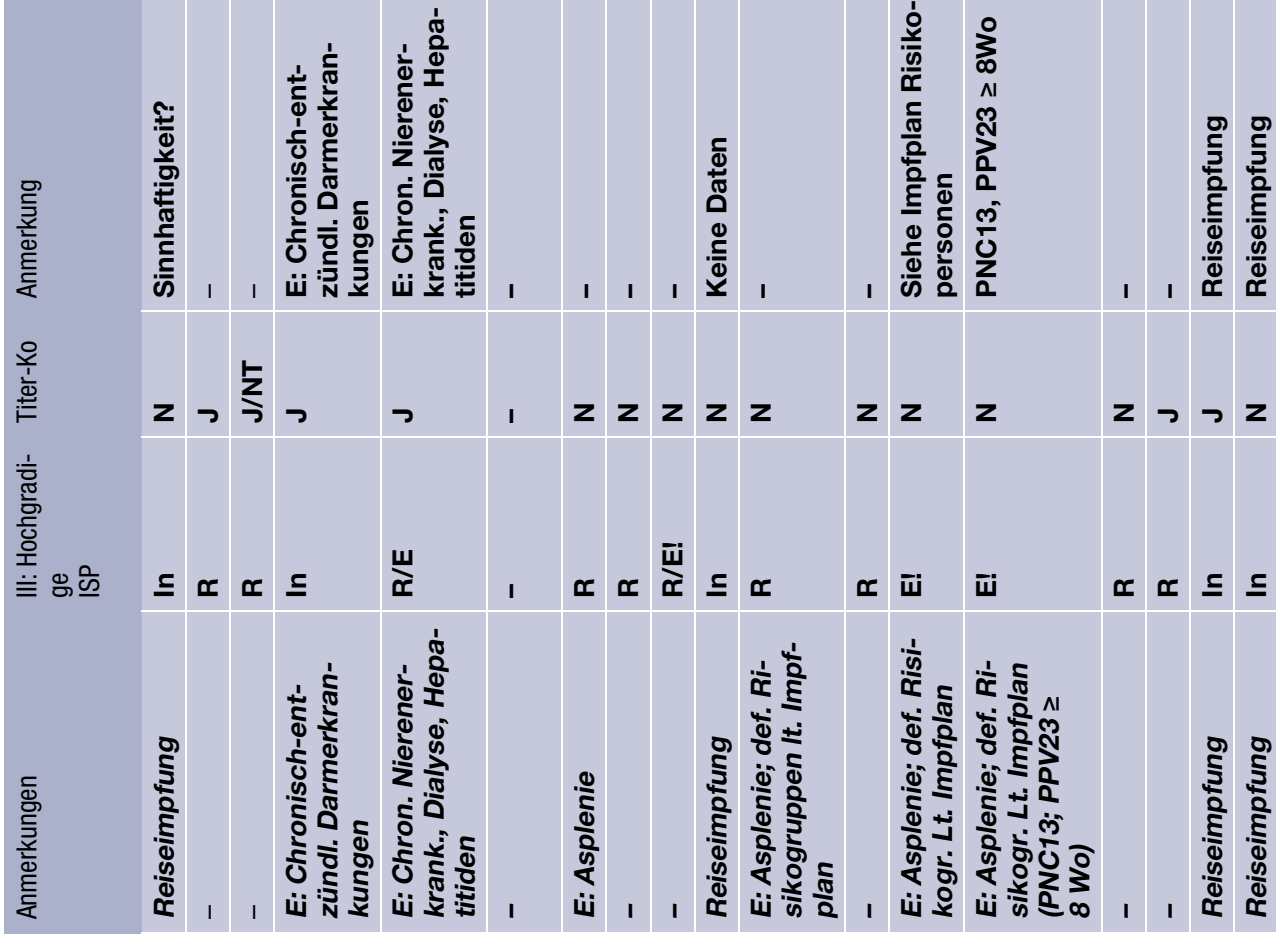

竞
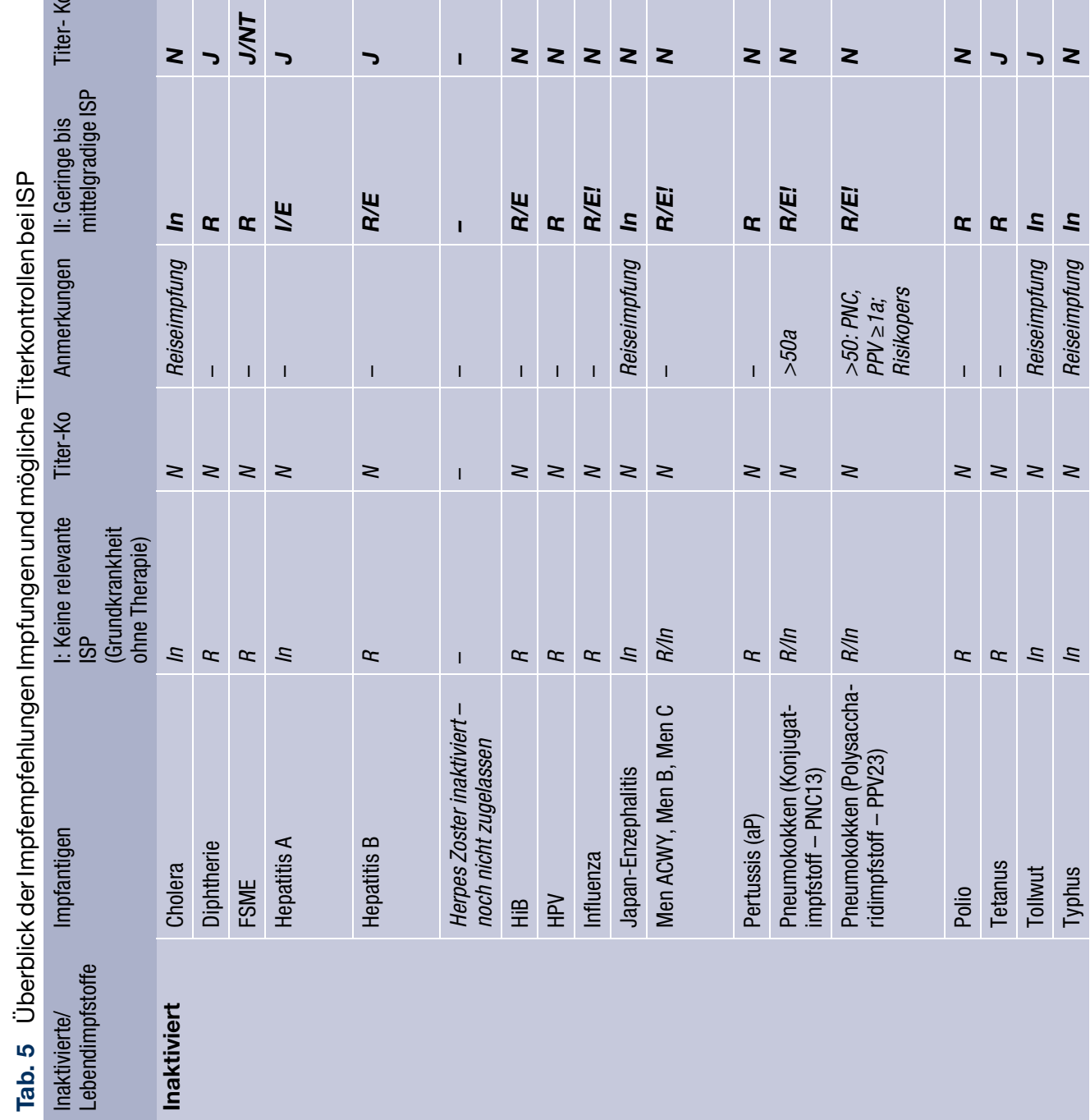


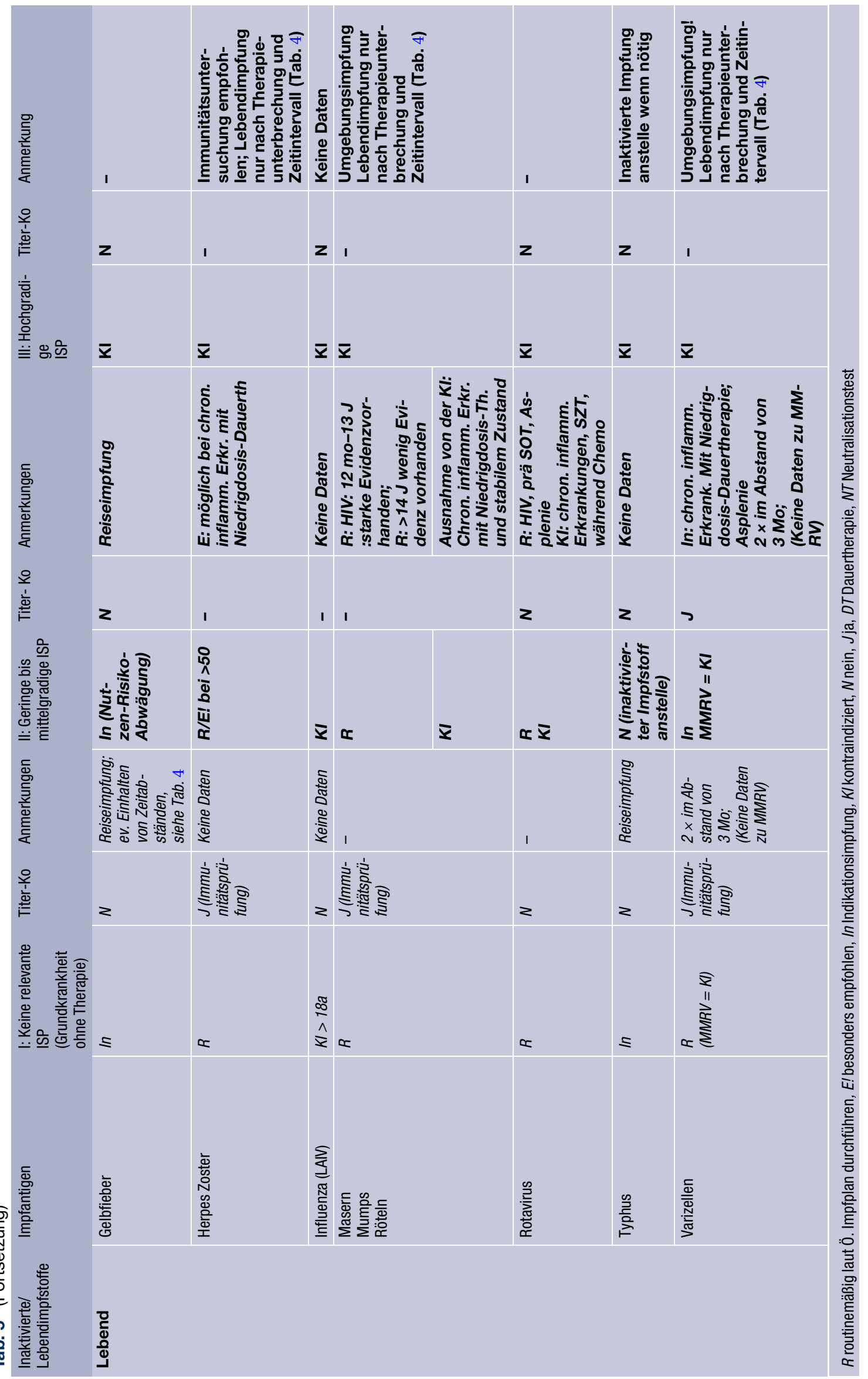


Tab. 6 Angeborene Immundefekte

\begin{tabular}{|c|c|c|c|}
\hline Immundefekt & Krankheit & Häufigkeit & Krankheitsbild \\
\hline \multirow[t]{4}{*}{ B-Zell } & $\begin{array}{l}\mathrm{XLA}=\mathrm{X} \text {-chromosomal vererbte Agammaglo- } \\
\text { bulinämie = Morbus Bruton }\end{array}$ & 1:10.000-1:50.000 & $\begin{array}{l}\text { Manifestation (nur bei Knaben) durch erhöhte Infektionsanfälligkeit } \\
\text { vor allem für bekapselte Bakterien (Pneumokokken, Haemophilus, } \\
\text { Staphylokokken, Streptokokken, aber auch Pseudomonas, Myko- } \\
\text { plasmen) nach Verschwinden der transplazentar erworbenen ma- } \\
\text { ternalen Antikörper im 2. Lebenshalbjahr. Häufig Bronchiektasien; } \\
\text { chronische ZNS-Infektionen durch Viren }\end{array}$ \\
\hline & $\begin{array}{l}\mathrm{CVI}=\text { common variable immunodeficiency = } \\
\text { Variables Immundefektsyndrom }\end{array}$ & 1:25.000-1:60.000 & $\begin{array}{l}\text { Manifestation im 2.-3. Lebensjahrzehnt durch wiederholte Infektio- } \\
\text { nen der Atemwege durch Bakterien, Mykobakterien, Pneumocystis } \\
\text { und Pilze. Verminderte Antikörperbildung auf Impfantigene }\end{array}$ \\
\hline & Selektiver IgA-Mangel & $\begin{array}{l}\text { 1:400-1:600 bei } \\
\text { Kaukasiern }\end{array}$ & Meist ohne Symptome, vermehrt Autoimmunerkrankungen \\
\hline & IgG-Subklassenmangel & $?$ & $\begin{array}{l}\text { Ab dem Kleinkindalter wiederholt bakterielle Infektionen besonders } \\
\text { der Atemwege; bei IgG2-Mangel durch bekapselte Erreger; ev. } \\
\text { Impfversager }\end{array}$ \\
\hline \multirow[t]{5}{*}{ T-Zell } & SCID = Schwerer kombinierter Immundefekt & $1: 25.000$ & $\begin{array}{l}\text { Symptome ab dem 2.-3. Lebensmonat mit rezidivierenden und } \\
\text { chronischen Infektionen (Viren, Candida, Pneumocystis) mit schwe- } \\
\text { rer Gedeihstörung }\end{array}$ \\
\hline & DiGeorge-Syndrom & $?$ & $\begin{array}{l}\text { Thymushypoplasie, Gesichtsdysmorphie, Herzfehler, Hypoparathy- } \\
\text { reoidismus (hypokalzämische Krampfanfälle); T-Zelldefekt nur bei } \\
5 \%-10 \%\end{array}$ \\
\hline & HIGM = Hyper-IgM-Syndrom & $1: 500.000$ & 4 Typen; rezidivierende bakterielle und opportunistische Infektionen \\
\hline & WAS $=$ Wiskott-Aldrich-Syndrom & 1:100.000 bei Knaben & $\begin{array}{l}\text { Meist X-chromosomal rezessiv vererbt; Thrombozytopenie, chroni- } \\
\text { sches Ekzem, rezidivierende Infektionen }\end{array}$ \\
\hline & Ataxia teleangiectatica $=$ Louis-Bar-Syndrom & $1: 40.000$ & $\begin{array}{l}\text { Zerebelläre Ataxie, okulokutane Teleangiektasien, bronchopulmona- } \\
\text { le Infekte; symptomatisch ab dem 2. Lebensjahr }\end{array}$ \\
\hline \multirow[t]{3}{*}{$\begin{array}{l}\text { Komplement } \\
\text { (25 Eiweiße) }\end{array}$} & Komplement-Defekt & $?$ & $\begin{array}{l}\text { Anfälligkeit besonders für Infektion mit Neisserien bei } \\
\text { C5-C8-Defekten (1000-10.000faches Risiko) }\end{array}$ \\
\hline & Properdin-Defekt & $?$ & $\begin{array}{l}\text { X-chromosomal vererbt; stark erhöhte Anfälligkeit für Infektion mit } \\
\text { Neisseria meningitidis (W135, Y) }\end{array}$ \\
\hline & $\begin{array}{l}\text { MBL-Defekt = Mannose-bindendes Lectin- } \\
\text { Defekt }\end{array}$ & $1: 10-1: 20$ & Rezidivierende Infekte im Kleinkindalter durch Bakterien und Pilze \\
\hline \multirow[t]{3}{*}{ Phagozyten } & $\begin{array}{l}\mathrm{CGD}=\text { chronic granulomatous disease }= \\
\text { septische Granulomatose }\end{array}$ & $1: 200.000$ & $\begin{array}{l}\text { Bereits in den ersten Lebensmonaten Pyodermie, Lymphadenitis } \\
\text { und Hepatosplenomegalie; rezidivierende Infektionen durch Bakteri- } \\
\text { en und Pilze }\end{array}$ \\
\hline & LAD = Leukozytenadhäsionsdefekt & 1:10 Mio & $\begin{array}{l}\text { Verzögerter Abfall der Nabelschnur, nekrotisierende Infektionen } \\
\text { durch Bakterien und Pilze mit massiver Leukozytose }\end{array}$ \\
\hline & Myeloperoxidase-Mangel & $1: 2.000$ & Meist keine Symptome, manchmal disseminierte Candidiasis \\
\hline
\end{tabular}

- FSME,

- Pneumokokken (PNC13, PP23 nach >8 Wo),

- Meningokokken (4 valent und B),

- Hib,

- HPV.

Lebendimpfstoffe sollen spätestens 4 Wochen vor

Therapiebeginn gegeben werden:

- MMR (Kontrolle od. Impfen),

- Varizellen ggf. Herpes zoster,

- LAIV (bei Kindern und Jugendlichen von 2 bis 18a).

\section{Bei schon laufender Therapie}

In den Fällen, wo Dauertherapien bereits laufen, müssen in Abhängigkeit von der Art und der Dosierung der Medikationen folgende Abstände zu den Lebendimpfungen eingehalten werden (Tab. 4). Die Therapie kann 4 Wochen nach Lebendimpfung fortgesetzt werden.

An dieser Stelle sei nochmals auf die Wichtigkeit der Umgebungsprophylaxe, i. e. ausreichender Impf- status bei allen Kontaktpersonen inkl. HCWs, hingewiesen, da es in vielen Fällen schwer möglich sein wird, eine immunsuppressive Therapie für einige Monate auszusetzen ohne das Risiko eines Erkrankungsschubes zu provozieren. Abgesehen davon ist bei jeder Therapieumstellung, die zu einer höheren ISP führen kann, daran zu denken, ob wichtige Lebendimpfungen (wie gegen MMR, Varizellen) vor Therapieumstellung durchgeführt werden können, bzw. zu kontrollieren, ob eine entsprechende Immunität besteht.

\section{Überblick über Impfempfehlungen in Abhängig- keit vom Grad der Immunsuppression}

In der folgenden Tab. 5 sind alle in Österreich zugelassenen inaktivierten Impfstoffe und Lebendimpfstoffe gelistet. Hier werden in Abhängigkeit, ob die Erkrankung und/oder Behandlung zu keiner relevanten (Grad I), einer leichten bis mittelgradigen (Grad II) oder einer schweren Immunsuppression (Grad III) führen, angegeben, ob die jeweiligen Impfungen ver- 
Tab. 7 Impfempfehlungen bei angeborenen Immundefekten

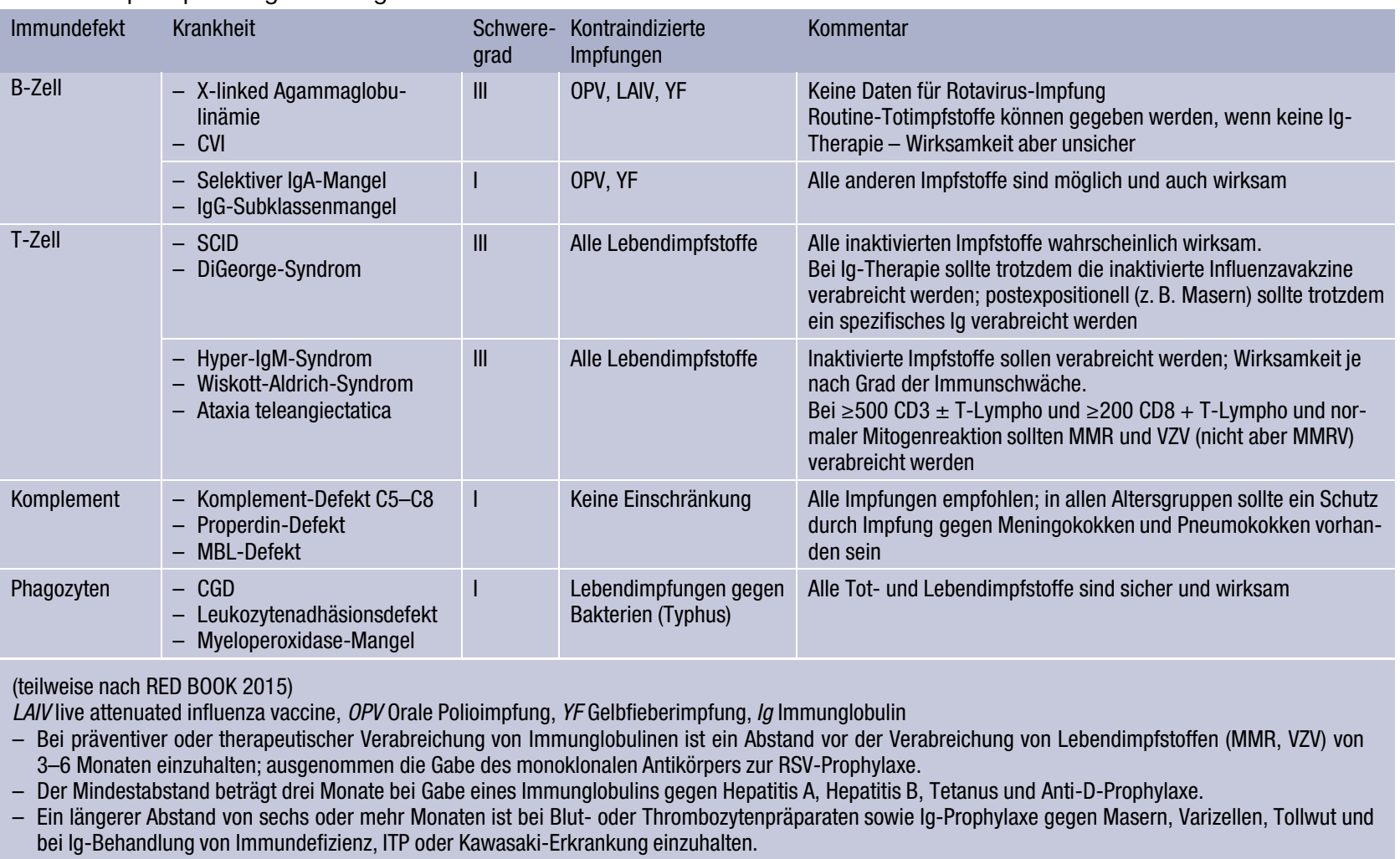

abreicht werden können oder nicht. Des Weiteren wird angegeben, ob eine Titerkontrolle möglich bzw. sinnvoll ist.

\section{Detaillierte Impfempfehlungen bei Immunsup- pression nach klinischen Indikationen/ Erkrankungen}

Allgemein ist an dieser Stelle zu bemerken, dass im Zweifelsfall (bzw. bei fehlenden Daten zu Behandlungsschemata) vorwiegend aus forensischen Gründen eine Grad-III-Immunsuppression anzunehmen ist.

\section{Angeborene Immundefekte}

Neben der ISP im Rahmen von erworbenen Erkrankungen und deren medikamentösen Therapien, die in der Folge ausführlicher besprochen werden, gibt es auch eine Reihe - zumeist seltener - angeborener Immundefekte, die zu einer Immunschwäche führen.

Tab. 6 gibt einen Überblick der wichtigsten angeborenen Immundefekte, geordnet nach dem dominierenden Immundefekt. Tab. 7 enthält die dazu gehörigen Impfempfehlungen.

\section{Chronische Nierenerkrankungen/Dialysepatienten}

Chronische Nierenerkrankungen (chronic kidney disease, CKD), ungeachtet der Ätiologie, beeinflussen sowohl das angeborene als auch das adaptive Im- munsystem. Infektionen sind die zweithäufigste Todesursache bei CKD [30]. Impfungen sind in dieser Patientengruppe gängige Empfehlung [31], jedoch ist die „vaccine effectiveness“ bei diesen Patienten deutlich reduziert, was auf mehrere Ursachen zurückzuführen ist: Veränderungen des angeborenen Immunsystems (,innate immunity“), hier v.a. der dendritischen Zellen (Verminderung der Zytokinausschüttung und damit Reduktion antigen-spezifischer Antworten, Antigenpräsentation [32]!), aber auch des adaptiven Immunsystems, d.h. der T-Lymphozyten (sowohl T-Helfer als auch zytotoxische) und B-Lymphozyten (Immunglobulin-Produktion und Switch der IgG-Subklassen) [33]. Insbesondere die funktionelle Beeinträchtigung der dendritischen Zellen wird heute als eine der Hauptursachen sowohl für die erhöhte Infektanfälligkeit als auch für die verminderte Impfantwort angesehen [33]. Die Beeinträchtigung der Immunantwort ist klar stadienabhängig (G1 bis G5; entsprechend der Klassifizierung der Guidelines der „Kidney Disease Improving Global Outcomes Work Group 2012“, wobei Patienten mit den Stadien G3b [GFR 30-44]), G4 (GFR 15-29) und G5 (GFR < 15; Nierenversagen; „end stage renal disease“ - ESRD) die deutlichste und klinisch relevanteste Immunsuppression bei Impfantworten aufweisen, während Patienten mit den Stadien G1 bis G3a zumindest im Hinblick auf die Hepatitis-B-Immunantwort vergleichbar wie gesunde Kontrollen antworten [34].

Besonders erwähnenswert ist auch, dass die Ausbildung Antigen-spezifischer T-Memory-Zellen bei 
CKD-Patienten (CD4+; ebenfalls stadienabhängig) beeinträchtigt ist; insbesondere die mangelhafte Generierung Virus-spezifischer $\mathrm{CD}^{+}$-Effektorzellen zusammen mit geringerer Produktion von IL-2 und IFN$\gamma$ vermindert die protektive Kapazität bei wiederholter Antigenexposition [35].

Diese Daten legen nahe, dass CKD-Patienten bereits bei beginnender Erkrankung so gut wie möglich durchimmunisiert werden sollten, da mit dem stadienweisen Fortschreiten der Erkrankung mit immer schlechterem Impferfolg zu rechnen ist und zusätzlich durch begleitende immunsupprimierende Therapie in den Spätstadien der Nierenerkrankungen weitere Unsicherheiten hinsichtlich des Impferfolgs entstehen.

Alle inaktivierten Impfstoffe des Österreichischen Impfplanes gelten als indiziert bei Personen mit CKD und ESRD; es bestehen keine Einschränkung in Bezug auf die Arzneimittelsicherheit für diese Gruppe, hinsichtlich der Indikation existieren aber teilweise besondere Empfehlungen:

Da besonders die Impfung gegen Hepatitis $\mathrm{B}$ infolge erhöhten HBV-Risikos (3,3 \% Prävalenz für HBsAg-Träger mit chronischer Hepatitis B bei CKD versus $<2 \%$ in der Normalbevölkerung Europas [36]) für Patienten mit CKD relevant ist, gilt ihr neben den anderen Impfungen des Erwachsenenalters spezifisches Augenmerk. Die Serokonversionsraten nach Hepatitis-B-Impfung bei CKD-Patienten liegen zwischen 30 und $80 \%$, abhängig vom Impfstoff und der Impfstrategie [37]. Stadium der Erkrankung, männliches Geschlecht und höheres Lebensalter oder Diabetes mellitus tragen zusätzlich zur schlechten Immunantwort auf die Hepatitis-B-Impfung bei, zielgerichtete Erfassung solcher Patienten im frühen Erkrankungsstadium hingegen trägt maßgeblich zum Impferfolg bei, ebenso wie die Verwendung von Impfstoffen mit höherer Antigenkonzentration (HBVax-Pro ${ }^{\circledR} 40 \mu \mathrm{g}$ oder doppelte Dosis Engerix $\left.\mathrm{B}^{\circledR}\right)$ [38, 39]. Drittgenerationsimpfstoffe (Pre-S1/S2 und S-Protein) sind trotz vielversprechender klinischer Studien [40] nach wie vor nicht erhältlich, alternative Verabreichungsformen (intradermale Injektion) bieten hingegen nur geringen Zusatznutzen [33].

Um die Immunantwort bei CKD- und ESRD-Patienten zu verbessern, wurden Studien mit Parallelapplikation verschiedener Medikationen zusammen mit der Impfung gegen Hepatitis B durchgeführt. Zur Verbesserung der Funktion dendritischer Zellen wurde GM-CSF, Levamisol (ein Anthelmintikum, das jedoch zu Agranulozytose führen kann und für den Humanbereich nicht mehr zugelassen ist) und ein TLR9-Agonist (Heplisav ${ }^{\circledR}$ ) eingesetzt, für die Verbesserung der T-Zell-Effektormechanismen und Memory-Induktion CpG-Oligonukleotide und Levamisol. Alle verwendeten Komponenten waren bei Spätstadium-Patienten in der Lage, die Immunantwort $\mathrm{zu}$ verbessern, haben aber bis dato nicht Eingang in die routinemäßige Verwendung gefunden [33].
Andere Impfstoffe sind bei CKD-Patienten weit weniger gut untersucht [33].

Die Immunantwort auf Hepatitis-A-Vakzinen scheint weit weniger stark beeinträchtigt $\mathrm{zu}$ sein als jene auf Hepatitis B. Die Verwendung der Kombinationsimpfung Hepatitis A + B (Twinrix ${ }^{\circledR}$ ) bietet kaum Vorteile. Die Indikation für die Hepatitis-A-Impfung weicht von jener der Normalbevölkerung nicht ab.

Influenzaimpfungen haben insbesondere für ESRD-Patienten belegbare Vorteile; die Immunantwort scheint nur unwesentlich beeinträchtigt zu sein und der klinische Schutz vergleichbar mit jenem, der in der allgemeinen Population erreichbar ist. Die Indikation für die Influenzaimpfung wird betont.

Das US Renal Data System hat über den Zeitraum 2001-2010 die Inzidenz von Pneumokokkenpneumonien und invasiven Pneumokokkenerkrankungen (IPD) untersucht und Streptococcus pneumoniae als den weitaus häufigsten Erreger von ambulant erworbener Pneumonie („Community-Acquired Pneumonia“ - CAP) bei Dialyse- und Transplantat-Patienten identifiziert. Diese Patientengruppen weisen auch ein 14- bis 16-fach erhöhtes Risiko auf, an Sekundärkomplikationen nach CAP zu versterben [41]. Patienten mit Nierenerkrankungen im Spätstadium haben allerdings den Nachteil, dass sie schlechter auf nichtkonjugierte Pneumokokkenimpfstoffe antworten, während die Antwort auf Konjugatimpfstoffe weitgehend unbeeinträchtigt bleiben dürfte. Auch die Dauer der Immunität scheint gegenüber der normalen Bevölkerung reduziert $\mathrm{zu}$ sein. Trotzdem besteht eine klare Impfempfehlung für die Pneumokokkenimpfung [42].

Die Immunantwort auf Tetanus/Diphtherie/inaktivierte Polio/Pertussis ist kaum untersucht. Alle erhobenen Daten deuten zwar auf eine kaum beeinträchtigte Primärantwort hin, deutlich verkürzt dürfte aber die Immunitätsdauer und dies insbesondere betreffend das Diphtherie-Antigen sein [43]. Die Indikation steht außer Streit.

Impfungen gegen Meningokokkenmeningitits sollen entsprechend Impfplan durchgeführt werden, es bestehen keine Sicherheitsbedenken, allerdings auch keine Daten zur vaccine efficacy.

Die FSME-Impfung wird gemäß einem Positionspapier der WHO als sicher auch bei Immunsupprimierten angesehen, lediglich der Impferfolg kann in Abhängigkeit vom Grad der Immunsuppression variieren [44]. Demgemäß besteht eine Impfempfehlung bei Indikation auch für CKD-Patienten.

$\mathrm{Zu}$ weiteren inaktivierten Impfstoffen, insbesondere reisemedizinisch verwendeten Vakzinen, gibt es keine Literatur. Es ist aber davon auszugehen, dass CKD-Patienten im fortgeschrittenen Erkrankungsstadium nur eingeschränkt reisetauglich sind und daher v. a. Reiseimpfungen mit spezieller Indikation, wie z. B. Japan-Enzephalitis oder Tollwut, nur selten indiziert sein werden. Dialysepatienten, die auf speziell ausgerüsteten Kreuzfahrtschiffen auf Reisen betreut 
werden, haben deshalb auch nur eine eingeschränkte Impfindikation.

Für alle Impfungen mit Totimpfstoffen gilt, dass v. a. bei ESRD und bei Stadium G4 jedenfalls die Möglichkeit der Überprüfung des Impferfolges bei Vorhandensein eines validen Tests in Evidenz gehalten werden soll.

Auch zu Lebendimpfungen gibt es kaum Daten für CKD-Patienten. Es ist davon auszugehen, dass bei entsprechender Indikation jedoch kein erhöhtes Sicherheitsrisiko aus der Applikation einer Lebendimpfung resultiert, während CKD-Patienten im Falle einer korrespondierenden Erkrankung sicher mit schwereren Verläufen zu rechnen haben. Die Influenza-Lebendimpfung gilt auf Grund inaktivierter Alternativ-Impfstoffe als kontraindiziert, die Gelbfieberimpfung soll nur bei zwingender medizinischer Indikation durchgeführt werden (hohes Erkrankungsrisiko im Reiseland) [33].

Kinder mit CKD werden hinsichtlich der Impfempfehlungen analog den Erwachsenen behandelt [45]. MMR und VZV können bei CKD-Patienten, die keine zusätzliche immunsuppressive Therapie erhalten, gegeben werden, allerdings wird eine Immunitätsprüfung empfohlen. Auch die Impfung gegen Rotavirus wird empfohlen, allerdings ohne ausreichende Evidenz und unter den gleichen Prämissen wie MMR.

Impfungen für Patienten mit Nierentransplantation fallen unter die Kategorie „Immunsuppression bei SOT“. Bei CKD-Patienten, die neben ihrer Grundkrankheit auch noch eine immunsuppressive Therapie erhalten (z. B. Kortikosteroide), gelten zusätzlich zu den Vorgaben durch die Grundkrankheit die durch die Therapie vorgegebenen Regeln und Vorsichtsmaßnahmen.

\section{Diabetes mellitus}

Patienten mit Diabetes mellitus haben ein höheres Risiko für Infektionen, wobei vermutlich die Hemmung der Immunantwort durch Hyperglykämie im Vordergrund steht: Chemotaxis und Adhärenz der neutrophilen Granulozyten an Gefäßendothelien, Opsonisierung, intrazelluläre bakterizide Aktivität und zelluläre Immunantwort sind bei erhöhten Blutzuckerwerten eingeschränkt: zum Beispiel sezernieren LPSstimulierte Makrophagen weniger TNF- $\alpha$ und IL-1 in diabetischen Mäusen als in Kontrollmäusen [46]. In der Lunge von diabetischen Mäusen ist die Rekrutierung von neutrophilen Granulozyten langsamer, da der entsprechende Mediator („macrophage inflammatory protein 2“) in geringerem Ausmaß produziert wird [47]. Hyperglykämie hemmt die Produktion von IL-10 von myeloischen Zellen und von TNF- $\alpha$ und Interferon- $\gamma$ von T Zellen [48]. Die Bindung von Oligosacchariden durch C-Lektin wird durch hohe Glukosekonzentrationen kompetitiv gehemmt, was sich auf viele Funktionen des Immunsystems auswirkt [49].
Darüber hinaus spielen auch Neuropathien, Gefäßschäden und Kolonisierung von Haut und Schleimhäuten mit pathogenen Keimen eine Rolle für die erhöhte Infektanfälligkeit bei Diabetes mellitus. Im Vordergrund stehen dabei Fußinfektionen, Hautund Weichteilinfektionen (nekrotisierende Fasziitis, Pilzinfektionen), Harnwegsinfekte und Cholezystitis. Weiters haben Infektionen im Allgemeinen bei Diabetikern einen schwereren und längeren Verlauf, und das Infektionsrisiko korreliert meist mit der Höhe des Blutzuckers. Daher senkt eine gute Einstellung des Diabetes und vor allem das Vermeiden von Blutzuckerwerten > $200 \mathrm{mg} / \mathrm{dl}$ das Risiko von Infektionen.

Bezüglich Impfungen gibt es keine Einschränkungen, sondern die meisten Impfungen werden sogar besonders empfohlen, da ein gut eingestellter Diabetes (Typ 1 und 2) als Erkrankung mit nicht relevanter Immunsuppression betrachtet wird. Daher können neben den Totimpfstoffen auch alle Lebendimpfungen verabreicht werden. Besonders empfohlen wird für Diabetiker die jährliche Grippeimpfung. Die Impfung gegen Hepatitis B wird für Diabetiker empfohlen: es konnte ein erhöhtes Infektionsrisiko über Blutzuckermessungen in Pflegeeinrichtungen in den USA gezeigt werden [50]. Die Pneumokokkenimpfung sollte unabhängig vom Alter verabreicht werden. Zur Effektivität von Impfungen bei Diabetes gibt es kaum Daten. Es wurde in zwei Studien gezeigt, dass die Grippeimpfung bei Diabetikern unter 65 Jahre eine vergleichbare Wirkung hat wie in der älteren Bevölkerung mit oder ohne Diabetes [51, 52].

\section{Solide Tumoren}

Das Gebiet der Onkologie und der derzeit gängigen Therapien ist überaus umfang- und facettenreich, sodass dieses Thema den Rahmen dieser Publikation sprengen würde und einer eigenen Abhandlung bedürfte. Besonders hinsichtlich der Beurteilung des Grads der Immunsuppression lässt die Vielfalt der Tumorentitäten und stadienabhängigen Therapiekombinationen und der Mangel an entsprechenden Daten derzeit keine hilfreichen Schlüsse zu. Dennoch wird hier versucht, überblicksmäßig die Wirkmechanismen einiger der sehr gängigen Therapiegruppen und deren Einfluss auf das Immunsystem (supprimierend oder stimulierend) $\mathrm{zu}$ beschreiben und die daraus resultierenden gängigen Impfempfehlungen zu erklären.

Traditionelle Chemotherapeutika haben zytotoxische Effekte, die vor allem sich schnell teilende (maligne und normale) Zellen betreffen, etwa im Knochenmark, im Gastrointestinaltrakt und in den Haarfollikeln. Die Immunsuppression bei Chemotherapie ergibt sich aus der Myelosuppression und dem daraus resultierenden Abfall an Blutzellen aller Zelllinien, insbesondere jedoch der Leukozyten. Daraus resultiert die Empfehlung, während einer Chemotherapie sowie zumindest sechs Monate nach deren 
Abschluss keine Lebendimpfstoffe $\mathrm{zu}$ verabreichen. Dies betrifft konkret die Impfungen gegen MMR bzw. deren Einzelkomponenten, weiters Gelbfieber, Typhus oral und Varizellen bzw. Herpes Zoster und die nasale Grippeimpfung (LAIV).

Die Wirksamkeit von Totimpfstoffen kann reduziert sein, sie können jedoch während Therapien verwendet werden. Dies betrifft u. a. Diphtherie, Tetanus, Pertussis, Influenza (außer LAIV), Hepatitis A und B, Pneumokokken, Tollwut, Cholera, Typhus, Meningokokken, FSME und Japan-Enzephalitis.

Eine differenzierte Betrachtung der Auswirkungen verschiedener Chemotherapeutika auf unterschiedliche Zelltypen des Immunsystems zeigt jedoch, dass es nicht nur immunsuppressive, sondern auch entgegengesetzte Wirkungen gibt. Diese ergeben sich sowohl aus einer direkten Wirkung von Chemotherapeutika auf Immunzellen als auch durch indirekte Wirkung, vermittelt durch den Tod der Krebszellen [53]. So zeigt z. B. Doxorubicin fördernde Wirkungen auf neutrophile Granulozyten [53]. Paclitaxel wiederum kann die Infiltration von Makrophagen in den Tumor fördern, die wiederum CD8-T-Zellen durch Ausschüttung von IL10 hemmen können [53]. Chemotherapeutika können auch direkt Immunzellen beeinflussen. So ist z. B. gezeigt worden, dass 5-FU und Doxorubicin die Apoptose von myeloiden Suppressorzellen hervorrufen können [53]. Dies wiederum verstärkt die Aktivität von CD8-positiven zytotoxischen T-Zellen. Irinotecan wiederum kann stark immunsuppressiv wirken, indem es die Vermehrung von myeloiden Suppressorzellen verursacht [53]. Welche Auswirkungen diese differenziellen Effekte allerdings auf das Angehen von Impfungen haben, ist derzeit nicht bekannt.

Tab. 8 zählt einige gängige Chemotherapeutika auf, deren Wirkmechanismen im nachfolgenden Text beschrieben sind.

Diese verschiedenen Klassen von Chemotherapeutika rufen den Tod der Krebszellen durch verschiedene Mechanismen hervor. Interkalantien positionieren sich zwischen zwei DNA-Strängen und bewirken deren kovalente Bindung, sodass die Zellteilung verunmöglicht wird. Platin-Zytostatika verursachen ebenfalls kovalente Quervernetzungen der DNA und verhindern somit deren Verdoppelung. Alkylanzien verursachen chemische Veränderungen in der DNA, die sowohl zu Mutationen als auch zur Hemmung der DNA-Replikation führen. Topoisomerase-Inhibitoren hemmen eine Klasse von wichtigen Enzymen, die für die Struktur der DNA essenziell sind und sowohl die Gentranskription als auch die DNA-Replikation hemmen. Mitosehemmer binden an Eiweißstränge, sogenannte Mikrotubuli, die für die korrekte Aufteilung der Chromosomen auf zwei Tochterzellen notwendig sind, und verhindern somit die Zellteilung. Auf ähnliche Weise wirken Taxane, die Zytoskelettmoleküle hemmen, sodass keine korrekte Zellteilung erfolgen kann. Antimetaboliten werden als falsche Bausteine in Nukleinsäuren (DNA oder RNA) eingebaut und
Tab. 8 Gängige Chemotherapeutika

\begin{tabular}{|l|l|}
\hline Doxorubicin & Interkalantium \\
\hline Epirubicin & Interkalantium \\
\hline Farmorubicin & Interkalantium \\
\hline Mitomycin & Interkalantium \\
\hline Eribulin & Mikrotubuli-Inhibitor \\
\hline Vinblastin & Mikrotubuli-Inhibitor \\
\hline Vincristin & Mikrotubuli-Inhibitor \\
\hline Vinorelbin & Mikrotubuli-Inhibitor \\
\hline Fotemustin & Nitrosoharnstoff \\
\hline Carboplatin & Platinzytostatikum \\
\hline Cisplatin & Platinzytostatikum \\
\hline Oxaliplatin & Platinzytostatikum \\
\hline Bortezomib & Proteasom-Inhibitor \\
\hline Cabazitaxel & Taxan \\
\hline Docetaxel & Taxan \\
\hline Paclitaxel & Taxan \\
\hline Etoposid & Topoisomerasehemmer \\
\hline Irinotecan & Topoisomerasehemmer \\
\hline Topotecan & Topoisomerasehemmer \\
\hline Cyclophosphamid & Alkylans \\
\hline Procarbazin & Alkylans \\
\hline Dacarbazin & Alkylans \\
\hline Capecitabin & Antimetabolit \\
\hline 5-Fluorouracil (5-FU) & Antimetabolit \\
\hline Gemcitabin & Antimetabolit \\
\hline Methotrexat & Antimetabolit \\
\hline Quelle: Sibilia & \\
\hline
\end{tabular}

verhindern somit deren korrekte Funktion. Dies hat sowohl Auswirkungen auf die DNA-Replikation als auch auf den allgemeinen Zellstoffwechsel. Durch die verschiedenen Wirkmechanismen der Zytostatika ergeben sich auch verschiedene Formen des Zelltods von Krebszellen. So kann der Zelltod programmiert (Apoptose) oder chaotisch (Nekrose) verlaufen oder als Mischung der beiden (Nekroptose). Diese können sich wiederum indirekt positiv oder negativ auf die Immunantwort auswirken. Dadurch sind Zellen des hämatopoetischen Systems und auch Immunzellen verschieden betroffen, und der Grad der durch die Chemotherapeutika verursachten Immunsuppression kann somit stark variieren. Nachdem die direkten und indirekten Auswirkungen dieser Therapeutika auf das Immunsystem noch nicht ausreichend erforscht sind, empfiehlt es sich, mit einer Impfung (vorwiegend mit Lebendimpfungen) mindestens drei bis sechs Monate nach Therapie abzuwarten. Wenn jedoch im Zuge einer Chemotherapie geimpft wird, so sollten die Impfungen tunlichst am Beginn eines Chemotherapiezyklus verabreicht werden, weil dann ein besseres Ansprechen vorliegt als zu einem späteren Zeitpunkt, wie dies für die Influenza-Impfung gezeigt wurde [54].

Revakzinierungen nach Chemotherapie sind prinzipiell empfehlenswert, weil es durch die Behandlung 


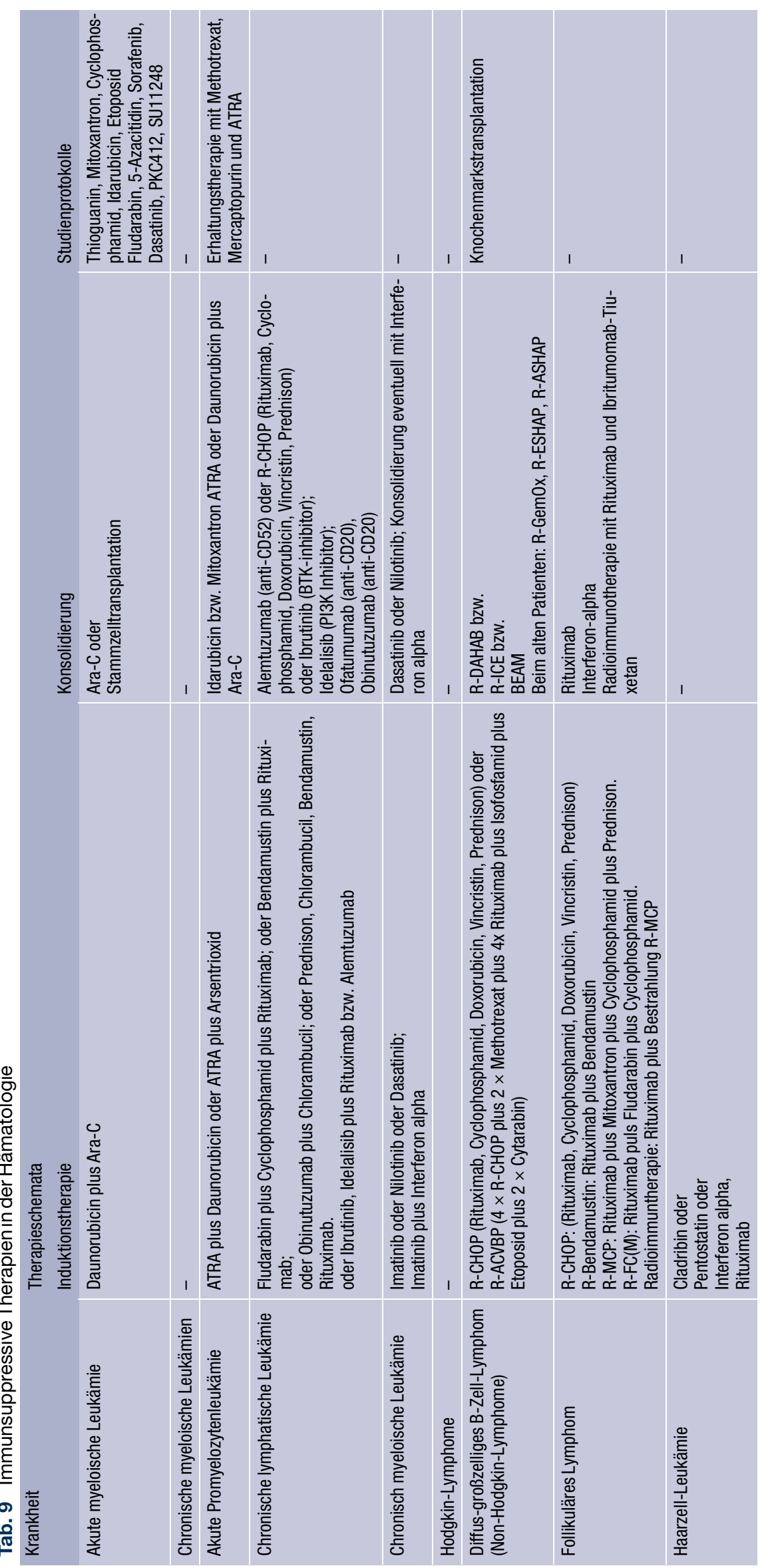




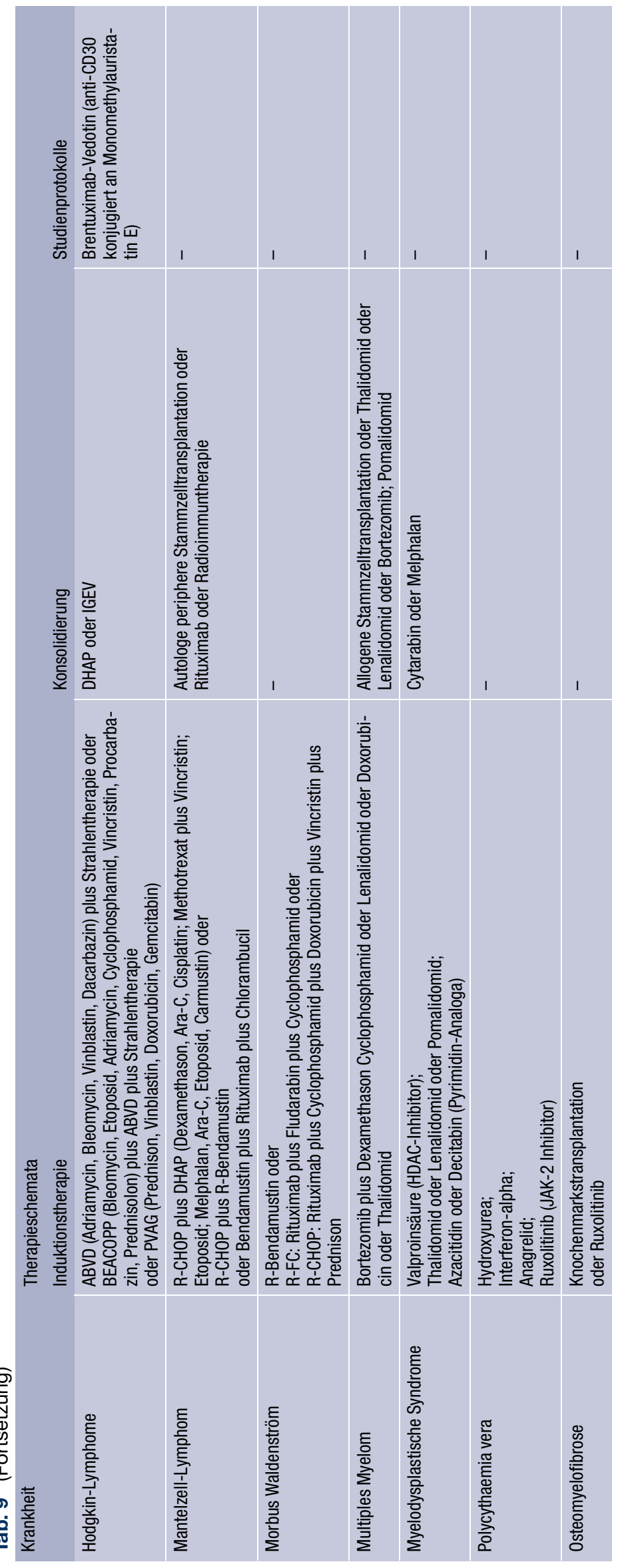


zu einem Immunitätsverlust kommen kann, wie dies für die Impfungen gegen Diphtherie/Tetanus, Haemophilus influenzae oder Masern bei Kindern mit akuter Leukämie beschrieben wurde [55].

Zum Thema der „targeted therapies“ siehe den Punkt Targeted Therapies.

\section{Hämatologie}

Im Bereich der hämatologischen Erkrankungen sind in Bezug auf Impfungen vor allem die chronischen Leukämien von Bedeutung, da die akuten Leukämien fast immer mit massiven myeloablativen Therapieschemata behandelt werden (Tab. 9), die wenig Spielraum für Impfungen lassen; weiters sind hier auch Lymphome (Hodgkin und Non-Hodgkin) sowie myeloproliferative und myelodysplastische Syndrome zu berücksichtigen.

Die chronisch-lymphatische Leukämie (CLL) wird im Prinzip mit vier Gruppen von Substanzen behandelt: 1. Purin-Analoga (z. B. Fludarabin, Pentostatin), 2. Alkylanzien (z. B. Chlorambucil, Cyclophosphamid, Bendamustin), 3. Monoklonalen Antikörpern (z. B. Rituximab, Ofatumumab, Alemtuzumab), 4. Molekularen Inhibitoren (z. B. Ibrutinib, Idelalisib). Diese Substanzen werden in den verschiedensten Kombinationen verabreicht.

Für Impfungen von Bedeutung ist die Verwendung von CD20-Antikörpern wie Rituximab oder Ofatumumab, die über zumindest drei verschiedene Mechanismen gleichzeitig wirken und zu einer B-Zell-Depletion führen [56]. Wichtig ist, dass ein Impfansprechen unter einer Anti-CD20-Therapie nicht gegeben ist, weil die Antikörper-bildenden B-Zellen fehlen [57, 58]. Darüber hinaus kann eine Anti-CD20-Therapie zu einer Reaktivierung von Hepatitis B führen, die nicht selten fulminant verläuft [59]. Weiters kann eine Anti-CD20Therapie - wie auch andere immunsuppressive Therapien mit monoklonalen Antikörpern - sporadisch zum Auftreten einer progressiven multifokalen Leukenzephalopathie (PML) durch Reaktivierung des JCVirus führen [60].

Für Patienten, die mit Anti-B-Zell-Antikörpern (Rituximab bzw. auch dem Anti-CD52-Antikörper Alemtuzumab) behandelt werden, wird daher empfohlen, dass Impfungen vor Therapiebeginn oder mindestens 6 Monate nach Therapieende im Falle von Boosterimpfungen bzw. 12 Monate nach Therapieende im Falle von Primovakzinierung (und jedenfalls bei Lebendimpfungen) durchgeführt werden $[7,58]$.

Small Molecule Inhibitors wie Idelalisib oder Ibrutinib inhibieren die Signalübertragung über den B-ZellRezeptor. Ihre Verwendung ist mit einem erhöhten Infektionsrisiko verbunden [61]. Impfungen unter diesen Substanzen sind daher vermutlich wirkungslos bzw. nicht zu empfehlen.

Die chronisch-myeloische Leukämie (CML) kann kurativ nur durch eine Stammzelltransplantation behandelt werden. Eine Kontrolle der Erkrankung ist je- doch mittels bestimmter Tyrosinkinasehemmer (TKI) möglich, eine palliative Therapie kann mit zytotoxischen Medikamenten durchgeführt werden. TKI der ersten (Imatinib) oder zweiten Generation (Dasatinib, Nilotinib, Bosutinib) stellen heute die Initialtherapie für alle neu an CML erkrankten Patienten dar.

Imatinib hat vielfältige Wirkungen auf das Immunsystem. So ist z. B. das gehäufte Auftreten von Varicella-Zoster-Infektionen unter Imatinib bei CMLPatienten beschrieben [62], weiters eine Hemmung der T-Zell-Proliferation und -Aktivierung [63], eine Hemmung der Expansion von zytotoxischen Memory-T-Zellen [64], eine Reaktivierung von Hepatitis B [65] und eine Hemmung der B-Zell-Immunantwort [66]. Andererseits inhibiert Imatinib auch die Freisetzung bestimmter Viren (Poxviridae), was eventuell sogar einen neuen Ansatz der antimikrobiellen Therapie darstellen könnte [67].

Dasatinib inhibiert in der Maus Virusantigen-spezifische CD4- und CD8-T-Zell-Antworten sowie die Aktivität natürlicher Killerzellen [68]. Bei mit Dasatinib behandelten CML-Patienten wurden Immunsuppression und atypische Infektionen beobachtet [69].

Weder für die Therapie mit Imatinib, Dasatinib oder andere TKI liegen valide Studien zu Lebendoder Totimpfstoffen vor. Lebendimpfungen sind unter TKI, die die Wirkung von Immunzellen beeinträchtigen, nicht empfohlen (im Gegensatz zu TKI, die keine systemische Immunsuppression bewirken siehe Punkt 3.5). Empfehlungen, wie lang man nach Beendigung einer TKI-Therapie mit Impfungen noch zuwarten sollte, variieren zwischen einem und drei Monaten [16].

\section{Hämatopoetische Stammzelltransplantation (SZT)}

Die Dauer der hochgradigen Immunsuppression nach SZT ist sehr stark variabel und hängt vom Transplantat (für allogene länger als für autologe), dem Spender und der Art der Stammzellengewinnung sowie von möglichen Komplikationen nach der SZT, wie der „Graft-versus-Host-Disease“ und deren Behandlung, ab. Die Impfempfehlungen gelten für Patienten mit autologer und allogener SZT.

\section{Impfempfehlung für Spender und Empfänger VOR $S Z T$}

Spender: Die Immunität des Spenders kann auf den Empfänger übertragen werden. Es hat sich gezeigt, dass die Impfungen des Spenders günstige Auswirkungen auf die Immunität des Empfängers nach SZT haben.

Immunkompetente Spender sollten gemäß den offiziellen Empfehlungen des Österreichischen Impfplans geimpft sein. Allerdings soll innerhalb eines Zeitfensters von vier Wochen vor der Stammzellengewinnung keine Lebendimpfung (z. B. MMR, MMRV, Varizellen, Herpes zoster) verabreicht werden, da hier 
keine Daten zur Sicherheit des Empfängers vorliegen es kann nicht mit absoluter Sicherheit ausgeschlossen werden, dass ein vermehrungsfähiger Vakzineerreger auf den Empfänger übertragen wird. Eine Impfung des Spenders mit einer Vakzine, die für den Spender selbst nicht indiziert ist, sondern ausschließlich der Immunität des Empfängers dienen soll, ist aus ethischen Gründen nicht empfohlen.

Empfänger: Es ist bekannt, dass die vorhandene Immunität des Empfängers oft auch bis einige Monate nach der SZT erhalten bleiben kann [70-72]. Impfungen, die kurz nach der SZT verabreicht werden, erzielen jedoch nur suboptimale Immunantworten. Indem man seronegative Patienten rechtzeitig vor der SZT immunisiert, kann möglicherweise ein Schutz bis nach der SZT bestehen bleiben. Daher sollen Empfänger alle Impfungen gemäß den offiziellen Empfehlungen im Österreichischen Impfplan für immunkompetente Personen vor der SZT, basierend auf Alter sowie Impf- und Expositionsanamnese, erhalten, so sie nicht bereits immunsupprimiert sind. Lebendimpfstoffe dürfen nur mit $>4$ Wochen und Totimpfstoffe mit $>2$ Wochen Abstand zum Beginn der Konditionierung verabreicht werden.

Nicht immune SZT-Kandidaten im Alter von $>12$ Monate sollten zwei Dosen eines Varizellen-Impfstoffes erhalten, sofern noch ein Zeitrahmen von mindestens vier Wochen bis zum Start der Konditionierung vorhanden ist und sie nicht bereits immunsupprimiert sind. Sind Empfänger bereits vor SZT immunsupprimiert, sollen sie, wenn es hinsichtlich der erwähnten Zeitfenster für Tot- und Lebendimpfstoffe noch möglich ist, vor der Konditionierung alle noch fehlenden, nicht kontraindizierten Impfungen gemäß Impfplan erhalten.

\section{Impfempfehlung für Patienten NACH SZT}

In den allermeisten Fällen kommt es in der Zeit nach der SZT zu einem rapiden Abfall antigenspezifischer Antikörper-Titer, weshalb die Patienten wieder empfänglich für Erkrankungen (z. B. Tetanus, Polio, Masern) sind [73]. Mit Ausnahme von Influenza und Pneumokokken-Erkrankungen wurde jedoch nur eine begrenzte Anzahl von impfpräventablen Erkrankungen nach SZT beobachtet, weshalb die Bewertung dieser reduzierten Antikörper hinsichtlich klinischer Relevanz schwierig ist. Daher sollten Patienten nach einer SZT immer wie Personen, die noch nie zuvor geimpft wurden, betrachtet werden, ungeachtet dessen, ob ihr Spender oder sie selbst vor der SZT Impfungen erhalten hatten oder nicht.

In der Regel gilt, dass inaktivierte Impfstoffe sechs Monate nach SZT verabreicht werden können. Hierfür wird eine „Grundimmunisierung“ bestehend aus drei Dosen, die grundsätzlich in einmonatigen Abständen geimpft werden, als sicher und bestmöglich schützend angesehen. Die bei immunkompetenten Gesunden häufig beobachteten Lokalreaktionen tre- ten bei Immunsupprimierten nur selten auf. Sofern eine Boosterimpfung empfohlen wird, ist diese zumeist 18 Monate nach SZT (bzw. 12 Monate nach der ersten Dosis nach SZT) empfohlen [74].

Nach ein bis zwei Jahren ist das Immunsystem grundsätzlich wieder voll funktionstüchtig und Lebendimpfungen können ab 24 Monaten nach SZT gegeben werden (s. Tab. 10).

Sollte nach der SZT Unsicherheit bezüglich des Impferfolgs bestehen, empfiehlt sich eine Bestimmung der spezifischen Antikörper vor und einen Monat nach der primären Impfserie sowie nach dem Booster. Es gilt auch, passiv transferierte Antikörper durch verabreichte Immunglobuline zu berücksichtigen; ebenso, dass nicht für jede impfpräventable Erkrankung Schutzkorrelate bekannt sind (siehe Tab. 1). Grundsätzlich ist davon auszugehen, dass ein vierfacher Anstieg der spezifischen Antikörper als ausreichend für eine Immunantwort anzusehen sind.

\section{Graft-versus-Host-Disease (GvHD)}

Patienten mit einer GvHD können eine Immunantwort auf proteinbasierte Impfstoffe erzielen. Das Risiko einer Exazerbation einer GvHD ist entsprechend vorliegender Erfahrungen als gering anzusehen. Bei GvHD-Patienten sind Impfstoffe auf PolysaccharidBasis ineffektiv, weshalb hier auch dem konjugierten PNC13-Impfstoff gegenüber dem PPV23-Impfstoff (Polysaccharid-Impfstoff) der Vorzug zu geben ist.

Besteht hinsichtlich des Impferfolges Unsicherheit, empfiehlt sich auch hier die Bestimmung spezifischer Antikörper vor und nach Impfung.

CAVE: Lebendimpfstoffe dürfen nicht bei Patienten mit aktiver GvHD oder bestehender Immunsuppression verabreicht werden.

Grundsätzlich soll eine Impfung mit Totimpfstoffen bei Patienten mit bestehender aktiver oder überstandener chronischer GvHD ungeachtet ihres Schweregrades nicht verschoben werden. Speziell die Impfprophylaxe gegen Pneumokokken und Haemophilus influenzae Typ B sowie gegen Influenza sollten aufgrund des hohen Risikos lebensbedrohlicher Infektionen gerade in dieser Patientengruppe möglichst zeitgerecht durchgeführt werden.

In Abwesenheit gesicherter Daten ist bei Patienten unter hochdosierter Kortikoidtherapie (Erwachsene: Prednison >0,5 mg/kg KG) als Teil einer Kombinationstherapie oder unter einer Behandlung mit drei Immunsuppressiva sowie unter laufender Therapie mit immunsuppressiven monoklonalen Antikörpern (z. B. Rituximab, Alemtuzumab) anzunehmen, dass die Immunantwort minimal ist. In diesen Fällen wird empfohlen, die Impfung zu verschieben.

Optimalerweise wird eine Impfung durch eine immunsuppressive Therapie nicht länger als drei Monate hinausgezögert [74]. 
Tab. 10 Impfungen nach SZT

\begin{tabular}{|c|c|c|c|c|}
\hline Impfstoff & $\begin{array}{l}\text { Alter bzw. } \\
\text { Zielpopulation }\end{array}$ & Anzahl an Dosen & $\begin{array}{l}\text { Frühester Zeitpunkt (Zeitrahmen) für } \\
\text { Impfung und Booster nach SZT }\end{array}$ & Anmerkungen \\
\hline $\begin{array}{l}\text { Diphtherie } \\
\text { Tetanus } \\
\text { Pertussis }\end{array}$ & $\begin{array}{l}\text { Kinder, Jugendliche, } \\
\text { Erwachsene }\end{array}$ & $\begin{array}{l}3 \times \mathrm{DTaP} \\
\text { Booster }\end{array}$ & $\begin{array}{l}6 \text { Monate } \\
18 \text { Monate }\end{array}$ & $\begin{array}{l}\text { Diphtherie, Tetanus, Pertussis, } \\
\text { Polio, Hib, (HepB) auch als } \\
\text { Kombinationsimpfung in allen } \\
\text { Altersgruppen }\end{array}$ \\
\hline Polio (IPV) & - & $\begin{array}{l}3 \times \\
\text { Booster }\end{array}$ & $6(-12)$ Monate & Bei DTaP-Applikation \\
\hline Hib (konj.) & - & $\begin{array}{l}3 \times \\
\text { Booster }\end{array}$ & $\begin{array}{l}6(-12) \text { Monate } \\
18 \text { Monate }\end{array}$ & Bei DTaP-, IPV-Applikation \\
\hline $\begin{array}{l}\text { Masern } \\
\text { Mumps } \\
\text { Röteln }\end{array}$ & $\begin{array}{l}\text { Masern-seronegative } \\
\text { Kinder, Jugendliche, } \\
\text { Erwachsene }\end{array}$ & $2 \times$ & $\begin{array}{l}24 \text { Monate nach SZT } \\
\text { und } \\
8-11 \text { Monate nach letzter i. v. Im- } \\
\text { munglobulin(IVIG)-Gabe }\end{array}$ & $\begin{array}{l}\text { Voraussetzung: weder GvHD } \\
\text { noch bestehende Immunsup- } \\
\text { pression }\end{array}$ \\
\hline Varizellen & $\begin{array}{l}\text { Varizellen-seronegative } \\
\text { Patienten }\end{array}$ & $2 \times$ & $\begin{array}{l}24 \text { Monate } \\
\text { und } \\
\text { 8-11 Monate nach letzter IVIG- } \\
\text { Gabe (oder früher im Fall eines } \\
\text { Ausbruchs) }\end{array}$ & $\begin{array}{l}\text { Voraussetzung: weder GvHD } \\
\text { noch bestehende Immunsup- } \\
\text { pression } \\
\text { Als Einzelimpfung (nicht als } \\
\text { MMRV) }\end{array}$ \\
\hline \multirow[t]{2}{*}{ Pneumokokken } & $\begin{array}{l}\text { PNC13: Kinder, Erwach- } \\
\text { sene }\end{array}$ & $3 \times$ & $3(-6)$ Monate & \multirow{2}{*}{$\begin{array}{l}\text { Anschließend nach } 3 \times \text { PNC13: } \\
\text { PPV23, so keine GvHD } \\
\text { bzW. } \\
\text { PNC13 bei GvHD }\end{array}$} \\
\hline & $\begin{array}{l}\text { PPV23 (ab } 2 \text { Jahren) } \\
\text { bzw. bei GvHD: Boostern } \\
\text { mit PNC13 }\end{array}$ & $1 \times$ (als 4. Dosis) & $12(-18)$ Monate & \\
\hline Influenza-Totimpfstoff & Alle $\geq 6$ Monate & $1 \times$ jährlich & $\begin{array}{l}6 \text { Monate } \\
4 \text { Monate bei Epidemie It. offizieller } \\
\text { Verlautbarung }\end{array}$ & $\begin{array}{l}\text { Lebendimpfstoff ist kontraindi- } \\
\text { ziert! } \\
\text { Inaktivierter Impfstoff: Bevor- } \\
\text { zugt } 2 \text { Dosen im Abstand von } \\
4 \text { Wochen (für alle Altersgrup- } \\
\text { pen analog zur Erstimpfung bei } \\
\text { Kindern) }\end{array}$ \\
\hline $\begin{array}{l}\text { Meningokokken } \\
\text { Men C (konj.; optional } \\
\text { MCV4 [A,C, W, Y konj.] })^{\mathrm{a}}\end{array}$ & Kinder, Jugendliche & $3 \times$ & $6(-12)$ Monate & $\begin{array}{l}\text { Alternativ kann statt 3. Teilimp- } \\
\text { fung auch MCV4 }{ }^{\mathrm{b}} \text { (ACWY konj.) } \\
\text { in Erwägung gezogen werden }\end{array}$ \\
\hline Men B & $\begin{array}{l}>6 \text { Monate-2 Jahre } \\
>2 \text { Jahre }\end{array}$ & $\begin{array}{l}3 \times \\
2 \times\end{array}$ & 6-12 Monate $^{\mathrm{a}}$ & Keine Daten vorhanden \\
\hline Hepatitis B & $\begin{array}{l}\text { Kinder, Jugendliche, } \\
\text { Erwachsene }\end{array}$ & $\begin{array}{l}3 \times \\
\text { Booster }\end{array}$ & $\begin{array}{l}6(-12) \text { Monate } \\
18 \text { Monate }\end{array}$ & $\begin{array}{l}\text { Wenn post vacc. Anti-HBs-Kon- } \\
\text { zentration }<10 \mathrm{mlU} / \mathrm{ml} \text {, dann } \\
\text { zweite 3-Dosen Serie (evtl. } \\
\text { Anti-HBs-Testung schon nach } \\
\text { der ersten dieser } 3 \text { Dosen) }\end{array}$ \\
\hline Hep A & $\begin{array}{l}\text { Kinder, Jugendliche, } \\
\text { Erwachsene }\end{array}$ & $\begin{array}{l}\text { Falls nur Hep. A: } 2 \times \\
\text { Falls Kombiimpfung mit } \\
\text { Hep. B: } \\
3 \times+ \text { Booster }\end{array}$ & $6(-12)$ Monate & Impfung in Erwägung ziehen \\
\hline FSME & $\begin{array}{l}\text { Kinder, Jugendliche, } \\
\text { Erwachsene }\end{array}$ & $\begin{array}{l}3 \times \\
\text { Booster }\end{array}$ & $\begin{array}{l}6(-12) \text { Monate }^{\mathrm{a}} \\
18 \text { Monate }\end{array}$ & - \\
\hline HPV & $\begin{array}{l}\text { Kinder, Jugendliche, } \\
\text { Erwachsene }\end{array}$ & $\begin{array}{l}3 \times \\
\text { Grundimmunisierung } 3+1 \\
\text { für alle Altersgruppen }\end{array}$ & $6(-12)$ Monate $^{\mathrm{a}}$ & $\begin{array}{l}\text { Impfung in Erwägung ziehen } \\
\text { mit mindestens 4fach HPV-Vak- } \\
\text { zine }\end{array}$ \\
\hline
\end{tabular}

\section{Impfstoffe im Einzelnen}

Influenza kann bei SZT-Patienten sehr schwere Verläufe zur Folge haben und weist eine Mortalität von $10-15 \%$ bei nicht antiviral Behandelten auf.

Diesen Patienten wird daher lebenslang eine jährliche Influenzaimpfung (Totimpfstoff) empfohlen, da Todesfälle durch Influenza selbst mehrere Jahre nach einer SZT beschrieben sind.
Pneumokokken: Besonders diese Patientengruppe trägt ein signifikant höheres Risiko für invasive Pneumokokkeninfektionen, bedingt durch funktionalen Hyposplenismus als Folge der Konditionierung (z. B. durch Ganzkörperbestrahlung), chronische GvHD und „rekonvaleszentes“ Immunsystem. Polysaccharid-Impfstoffe sind gewöhnlich im ersten Jahr nach der SZT unwirksam, insbesondere bei chronischer GvHD. Deshalb wird nach SZT eine möglichst frühzeitige Verabreichung konjugierter Impfstoffe emp- 
fohlen, selbst wenn dies zu einer kürzeren Präsenz protektiver Antikörperkonzentrationen führt. Um den Schutz dennoch zu optimieren, wird eine vierte Dosis mit PPV23 zwölf Monate nach SZT empfohlen, um die Serotypen-Abdeckung auszuweiten. Sollten Patienten eine GvHD aufweisen, ist die vierte Dosis mit PNC13 (statt PPV23) durchzuführen.

Haemophilus influenzae Typ B: Auch hier drohen schwerwiegende Infektionen bei Stammzell-Transplantierten. Der früheste empfohlene Zeitpunkt für diesen Konjugat-Impfstoff nach SZT ist besonders zu beachten, da binnen sechs Monaten nach SZT keine ausreichende Immunität ausgebildet werden kann.

Diphtherie/Tetanus/Pertussis: Hier ist hinsichtlich der Diphtherie- und Pertussis-Komponente zwischen Kombinationsimpfstoffen mit hohem (DTaP) bzw. mit niedrigem Gehalt ( $d$ Ta $p$ ) Gehalt an Antigenen zu unterscheiden. Obwohl erstere für die Grundimmunisierung empfohlen werden, können sie in dieser Patientenpopulation auch abweichend von der Fachinformation angewendet werden, da SZT-Patienten wie Ungeimpfte anzusehen sind und daher auch von keiner erhöhten Reaktogenität auszugehen ist. Deshalb sollten nach einer SZT DTaP-hältige Impfstoffe unabhängig vom Alter des Patienten für die DreiDosen-Serie herangezogen werden. Später kann mit dieser oder alternativ auch mit einer dTaP-hältigen Vakzine geboostert werden [74]. Nachfolgende Auffrischungsimpfungen sind gemäß Österreichischem Impfplan durchzuführen.

Hepatitis B: SZT-Patienten sind besonders gefährdet, da einerseits Hepatitis-B-naive Patienten bei Infektion während der Immunsuppression eine chronische Hepatitis B erwerben können und es andererseits bei Patienten, die vorab HBs-Ag-positiv waren, nach SZT zu einer Reaktivierung kommen kann.

Alle Patienten, die negative Hepatitis-B-Marker aufweisen, einschließlich solcher, die vor SZT immunisiert wurden, sollen nach der SZT geimpft werden.

Patienten mit durchgemachter Hepatitis B (AntiHBs- und Anti-HBc-positiv) und solche, die vor SZT nur Anti-HBc-positiv sind, sollten spätestens zu Beginn der Konditionierung mit Nukleosid/NukleotidAnaloga behandelt werden. Die Impfung erfolgt dann wie bei seronegativen Patienten.

Ist für einen seronegativen Empfänger ein HBsAg-positiver Spender vorgesehen, soll der Empfänger wenn möglich bereits vor der SZT geimpft werden und ein Hepatitis-B-Immunglobulin in Kombination mit „Nukleotid/Nukleosid-Analoga“ erhalten, wobei explizit Lamivudin empfohlen wird [74, 75].

Präliminäre Daten zeigten, dass es zu schlechteren Response-Raten bei Empfängern einer SZT im Vergleich zu Gesunden kam. Es wird daher nach SZT eine Bestimmung der Anti-HBs-Konzentration nach Imp- fung empfohlen, um beurteilen zu können, ob weitere Dosen notwendig sind.

Masern/Mumps/Röteln: Die meisten Patienten werden nach SZT bezüglich Masern seronegativ; es wurden Fälle von schweren und tödlich verlaufenden Masernerkrankungen berichtet. Erwachsene, die vor der SZT eine natürliche erworbene Maserninfektion durchgemacht hatten, bleiben oft mehrere Jahre nach SZT gegen Masern immun. Diese Patienten sollten unbedingt serologisch überprüft und nur im Fall einer Masern-Seronegativität geimpft werden.

Da Lebendimpfstoffe nicht früher als 24 Monate nach SZT gegeben werden dürfen, kann in der Zwischenzeit eine Immunglobulingabe (IVIG) bei MMRseronegativen Personen - besonders Frauen im gebärfähigen Alter - notwendig sein.

In diesen Fällen muss beachtet werden, dass Immunglobuline (IVIG) und andere Blutprodukte Antikörper gegen Masern, Varizellen und andere Impfantigene enthalten können und es möglich ist, dass diese mit einer Masernimpfung und/oder anderen Lebendimpfungen interferieren. Aus diesem Grund ist ein Abstand der Impfung von acht Monaten (IVIGDosis: $400 \mathrm{mg} / \mathrm{kg} \mathrm{KG}$ ) oder elf Monaten (IVIG-Dosis: $2 \mathrm{~g} / \mathrm{kg} \mathrm{KG)} \mathrm{zur} \mathrm{IVIG-Verabreichung} \mathrm{erforderlich.} \mathrm{Im}$ Falle eines Masernausbruchs kann eine Impfung zu einem früheren Zeitpunkt als acht bis elf Monate nach IVIG durchgeführt werden.

Es gilt daher in jedem Fall eine Wartezeit von 24 Monaten für die MMR-Impfung nach SZT; zusätzlich ist ein Abstand von acht bis elf Monaten (oder früher in Ausbruchssituationen) nach letzter IVIGGabe zu berücksichtigen. Eine weitere Voraussetzung für die sichere Anwendung ist, dass keine immunsuppressive Therapie verabreicht wird und keine GvHD vorliegt.

Varizellen: Hier gelten im Wesentlichen dieselben Kriterien für seronegative Patienten wie für die Masern-Impfung. Die Impfung kann frühestens 24 Monate nach SZT erfolgen, ohne weitere immunsuppressive Therapie oder Vorliegen einer GvHD [74].

Herpes zoster: Der Zoster-Impfstoff hat eine 14-fach höhere Antigenmenge als der Varizellen-Impfstoff. Die Impfung wird nicht empfohlen, da es keine Daten zur Sicherheit bei SZT-Patienten gibt.

HPV: Es gibt speziell für SZT-Patienten keine Daten; jedoch sind genitale HPV-Erkrankungen eine typische Spätkomplikation einer allogenen SZT, die bei ca. einem Drittel der Langzeit-Überlebenden auftritt. Ebenso stellt eine länger andauernde immunsuppressive Therapie aufgrund einer chronischen GvHD ein erhöhtes Risiko für die Entwicklung HPV-induzierter squamöser intraepithelialer Läsionen dar [76, 77]. Die Impfung kann jedoch für diese Patienten in Erwägung gezogen werden und ein regelmäßiges HPV-Screening 
wird speziell empfohlen (Kostenübernahme durch Sozialversicherungsträger zur Zeit nicht geklärt).

FSME: Gerade in Österreich, wo FSME endemisch vorkommt, hat diese Impfung besondere Bedeutung. Daher wird sie in der Tabelle entsprechend empfohlen, auch wenn nur begrenzte Daten von Patienten nach Herztransplantation vorliegen [78].

Rotaviren: Hier handelt es sich um einen viralen Lebendimpfstoff, der ausschließlich innerhalb der ersten sechs Lebensmonate indiziert (je nach Impfstoff soll die Impfserie spätestens mit 32 Lebenswochen abgeschlossen sein) und daher nach SZT kontraindiziert ist.

\section{Umgebungsprophylaxe}

(Haushalts-)Kontaktpersonen und medizinische Betreuer von SZT-Patienten sollten über einen entsprechenden Schutz gemäß den Empfehlungen des Österreichischen Impfplans sowie den erweiterten Empfehlungen „Impfungen für MitarbeiterInnen des Gesundheitswesens“ [79] verfügen.

Besonders wichtig ist hier ein Schutz der Kontaktpersonen vor Masern, Mumps, Röteln, Varizellen/ Zoster, Influenza (inaktiviert; jährlich), Polio (IPV) und Hepatitis A.

Sollten Kontaktpersonen nach der Varizellen/ Zoster-Impfung Hautläsionen aufweisen, ist ein enger Kontakt zum Patienten so lange zu vermeiden, bis diese Läsionen wieder abgeklungen sind.

Sollten Säuglinge (z. B. Geschwister) mit einem Rotaviren-Impfstoff geimpft worden sein, darf für die Dauer von vier Wochen nach Impfung kein Kontakt des Patienten mit Windeln dieses Kindes stattfinden.

\section{Transplantation solider Organe (SOT)}

Kandidaten für eine Organtransplantation sowie Empfänger von Organtransplantaten haben ein erhöhtes Risiko für Infektionskrankheiten. Daher muss dafür gesorgt werden, dass alle SOT-Kandidaten, aber auch alle Familien-und Kontaktpersonen inkl. HCW, über einen kompletten Impfstatus vor Transplantation verfügen. Da das Impfansprechen bei Personen mit zunehmendem Organversagen deutlich reduziert sein kann, ist es wichtig, diese Personen bereits zu einem möglichst frühen Zeitpunkt ihrer Erkrankung (chronische, aber stabile Grundkrankheit) impfmäßig entsprechend $\mathrm{zu}$ versorgen; spätestens beim ersten Besuch in einer Transplantationsklinik muss der Impfstatus überprüft bzw. aktualisiert werden, und bei Listung zur Transplantation müssen Impfnachweis und Antikörpertiter (s. Tab. 1) vorliegen.

Lebende Organspender sollen alle Impfungen entsprechend dem Österreichischen Impfplan erhalten haben. Lebendimpfungen (MMR, V Zoster) sollen innerhalb von vier Wochen vor Organentnahme nicht mehr durchgeführt werden. Impfungen beim Spender, die nur zum Nutzen des Empfängers dienen, werden generell nicht empfohlen.

\section{Allgemeines}

Abgesehen von der Tatsache, dass alle Impfungen entsprechend dem Österreichischen Impfplan vor Transplantation gegeben/aufgefrischt werden sollen, sind alle inaktivierten Impfungen auch nach SOT sicher. Inaktivierte Impfungen sollen frühesten zwei Monate nach Transplantation mit initialer Hochdosis-Immunsuppression (durchschnittlich 3-6 Monate nach SOT und mit Beginn der Erhaltungsdosis von Immunsuppressiva) appliziert werden. Einzige Ausnahme ist die inaktivierte Influenzaimpfung, die bereits einen Monat nach Transplantation (in Abhängigkeit von der Influenzasaison) gegeben werden kann [7, 80].

Der fragliche Impferfolg soll durch Titerkontrollen (möglichst laut Tab. 1, frühestens 4 Wochen nach Impfung) überprüft werden. Es gibt keine Hinweise, dass Impfungen bei Transplantierten zu Organabstoßungen oder GvHD führen [80, 81].

Lebendimpfungen sind nach SOT prinzipiell kontraindiziert. Alle nötigen Lebendimpfungen, besonders MMR sowie V, sollen spätestens vier Wochen vor Transplantation appliziert werden.

\section{Impfempfehlungen VOR SOT}

SOT-Kandidaten (Kinder wie Erwachsene) sollen alle laut Österreichischem Impfplan empfohlenen Impfungen erhalten (Augenmerk auf Komplettierung von Grundimmunisierungen bzw. Boosterimpfungen).

Inaktivierte Impfungen (besonders wichtige Beispiele):

Influenza: Da Influenza bei allen Patienten mit fortgeschrittenem Organversagen einen schwerwiegenden Verlauf nehmen kann, wird die inaktivierte Influenzaimpfung allen SOT-Kandidaten (ab dem Alter von 6 Monaten) dringend empfohlen.

Pneumokokken: Ebenso haben SOT-Kandidaten ein erhöhtes Risiko für invasive Pneumokokkenerkrankungen. Die Impfempfehlung entspricht jener für Risikopatienten im Österreichischen Impfplan: im 1. LJ Grundimmunisierung mit PNC13: 0, 8 Wo, 9-12 Mo und ab 3. LJ: 1x PPV23; 2.-5. LJ: PNC13: 0, 8 Wo und ab 3. Lj: $1 \times$ PPV23; >6 Jahre: $1 \times$ PNC13 und nach $\geq 8$ Wo: $1 \times$ PPV23.

Haemophilus influenzae: Kinder werden entsprechend dem Impfplan mit dem Sechsfach-Impfstoff geimpft. Da bei Erwachsenen in der Regel protektive Hib-Antikörper vorhanden sind, ist eine Hib-Impfung generell vor SOT nicht nötig.

Hepatitis B: Patienten mit chronischem Nierenversagen, Dialysepatienten, aber auch Patienten mit fortgeschrittenem Leberversagen zeigen ein deutlich schlechteres Ansprechen auf die Hepatitis-B-Impfung. 
Daher gelten die im Kapitel 6.2 beschriebenen Hepatitis-B-Impfstrategien mit höherer Dosis (40-80 $\mu \mathrm{g}$ ), mehreren Dosen und Verwendung eines Impfstoffs mit stärkerem Adjuvans.

Sollte bei seronegativen Empfängerkandidaten eine Transplantation mit einem HBs-Ag-positiven Transplantat geplant sein, so sollte zusätzlich zur Hepatitis-B-Impfung eine Prophylaxe mit Hepatitis-B-Immunglobulin und dem nukleosidischen Reverse-Transkriptasehemmer Lamivudin vor Transplantation geplant werden. Diese Vorgehensweise wurde bei Lebertransplantat-Empfängern beschrieben [82].

Hepatitis A: Eine Impfung gegen Hepatitis A ist besonders bei Patienten mit chronischen Lebererkrankungen durchzuführen. Da bei diesen Patienten das Impfansprechen deutlich reduziert sein kann, sollte möglichst im Frühstadium einer chronischen Lebererkrankung geimpft werden, bevorzugt mit einem Hepatitis-A/B-Kombinationsimpfstoff.

HPV: Transplantierte Patienten zeigen ein deutlich höheres Risiko, an HPV-bedingten Kondylomen, Zervix-Karzinom oder anderen HPV-assoziierten Malignomen zu erkranken. Daher soll die HPV-Impfung entsprechend den Empfehlungen für Kinder >9 Jahre und Erwachsene durchgeführt werden (bevorzugt mit dem tetravalenten bzw. ab Zulassung mit dem 9-valenten Impfstoff).

Lebendimpfungen: Sämtliche Lebendimpfungen sollen spätestens vier Wochen vor SOT appliziert worden sein, da das Risiko einer Posttransplantationserkrankung durch die Impfung bei den meisten Lebendimpfungen nicht klar definiert ist. Darüber hinaus werden die meisten Patienten nach Transplantation mit Chemoprophylaxe gegen Herpes simplex oder CMV abgeschirmt, was einen negativen Einfluss auf das Angehen von Impfungen wie z. B. gegen Varizellen/Zoster haben kann.

MMR: Die MMR-Impfung soll laut den Empfehlungen des Österreichischen Impfplans allen seronegativen Personen zweimal im Mindestabstand von vier bis acht Wochen gegeben werden, sofern die Patienten nicht bereits vor SOT unter immunsuppressiver Therapie stehen und die Transplantation nicht innerhalb von vier Wochen nach Impfung geplant ist. Die Impfung kann bei kindlichen SOT-Kandidaten bereits ab 6-11 Lebensmonate durchgeführt werden.

Varizellen/Zoster: Die Varizellen-Impfung wird besonders für Transplantationskandidaten empfohlen, weil eine Erkrankung einen schwerwiegenden Verlauf bei Transplantierten nehmen kann. Generell soll die Impfung allen seronegativen SOT-Kandidaten, die nicht bereits unter Immunsuppression stehen, gegeben werden (ab dem 6.-11. Lebensmonat möglich).
Zwei Dosen sollten im Abstand von drei Monaten gegeben werden.

Varizellen-positive, erwachsene SOT-Kandidaten (>50 Jahre) sollten eine Zoster-Impfung erhalten (vorausgesetzt, dass sie nicht unter immunsuppressiver Therapie stehen und die Transplantation in mehr als vier Wochen geplant ist) aufgrund eines erhöhten Risikos eines Post-Transplantations-Zosters.

Rotavirus: Die Rotavirus-Impfung sollte allen Säuglingen, bei denen eine SOT geplant ist, mit zwei Lebensmonaten (unter Umständen ab sechs Lebenswochen) gegeben werden. Die Impfserie sollte spätestens mit sechs Lebensmonaten abgeschlossen sein. Die Impfung ist bei älteren Kindern oder Erwachsenen nicht indiziert.

\section{Impfempfehlungen NACH SOT (unter} immunsuppressiver Therapie)

Alle altersentsprechenden inaktivierten Standardimpfungen können frühesten zwei bis sechs Monate nach SOT (nach initialer Hochdosis-Immunsuppression) gegeben werden (im Idealfall handelt es sich nach Transplantation nur um Auffrischungsimpfungen, da sämtliche Primärvakzinierungen vor SOT durchgeführt werden sollten).

Es empfiehlt sich, wie anfangs erwähnt, jedoch dort, wo Titerkontrollen möglich sind, diese durchzuführen, um ein adäquates Angehen der Impfungen zu kontrollieren und ggf. wiederholte Impfungen durchzuführen.

Die Influenza-Impfung kann, wie bereits erwähnt, im Falle eines Influenzaausbruchs bereits einen Monat nach SOT geben werden.

Alle Lebendimpfungen, wie z. B. MMR, sollen $z u$ keinem Zeitpunkt nach SOT geimpft werden (entsprechende Umgebungsprophylaxe ist bei seronegativen SOT-Empfängern daher besonders wichtig: Gabe von Immunglobulin im Expositionsfall möglich). Keinerlei Daten liegen zur Rotavirus-Impfung bei Transplantierten vor.

Als einzige Ausnahme kann die Varizellen-Impfung bei Kindern nach Leber -oder Nierentransplantation genannt werden. Hier wurde gezeigt, dass diese Impfung drei Jahre nach Transplantation sicher war und zu einer Seroprotektion geführt hat [83].

Impfung von Kontaktpersonen/Umgebungsprophylaxe Familienmitglieder, alle Kontaktpersonen sowie das Gesundheitspersonal sollen einen kompletten Impfstatus haben. Besonders zu erwähnen ist die jährliche Influenza-Impfung, sowie MMR- und Varizellen-Impfung.

\section{Asplenie}

Patienten mit anatomischer oder erworbener Asplenie haben lebenslang ein erhöhtes Infektionsrisiko, besonders mit bekapselten Bakterien, intrazellulären 
Bakterien und Protozoen. Unter den bekapselten Bakterien können vor allem Pneumokokken, Meningokokken aber auch Haemophilus influenzae $\mathrm{zu}$ sehr schweren Krankheitsverläufen führen. Das Infektionsrisiko ist in den ersten beiden Jahren nach Splenektomie besonders hoch (etwa $30 \%$ treten im ersten Jahr und $50 \%$ im zweiten Jahr auf). Das lebenslange Risiko beträgt etwa $5 \%$. Gefürchtet ist die „overwhelming post-splenectomy infection“, die innerhalb von Stunden zu einer irreversible Sepsis mit Multiorganversagen führen kann. Die Letalität beträgt $50 \%$. Das Risiko für diese Form der Infektion ist bei anatomischer Asplenie am geringsten, bei funktioneller Asplenie, aufgrund von Sichelzellanämie (homozygot) oder Thalassämien am höchsten.

Unabhängig von der Ursache für eine Splenektomie (anatomisch oder funktionell) bzw. bei Patienten mit Sichelzellanämie sollen folgende Impfungen unbedingt erfolgen:

Pneumokokkenimpfung. Impf-Vorgehensweise entsprechend den Empfehlungen des Österreichischen Impfplans für die jeweilige Altersgruppe - sequentielle Impfung mit PNC13 und nach $\geq 8$ Wochen PPV23. Derzeitige Empfehlungen zur Wiederholung des Zyklus sind alle fünf Jahre (laut IDSA [7]).

Meningokokkenimpfung: Impfung mit dem tetravalenten Impfstoff (A, C, W135, Y) entsprechend dem für das Alter empfohlenen Impfschema. Auffrischungsimpfung alle fünf Jahre. Meningokokken-B-Impfung, entsprechend den altersangepassten Empfehlungen (bezüglich Auffrischungsimpfungen dzt. noch keine Daten - ev. wie beim tetravalenten MeningokokkenImpfstoff alle fünf Jahre).

Gegen Hib sollen alle Patienten über fünf 5 Jahren zumindest einmal geimpft werden. Weitere Auffrischungsimpfungen im Erwachsenenalter dürften aufgrund einer entsprechenden Immunität nicht nötig sein [7].

Zeitpunkt der Impfungen vor/nach Splenektomie (laut IDSA [7]): Optimaler Zeitpunkt für die Impfungen ist 2 Wochen vor Splenektomie (besonders wenn eine immunsuppressive Therapie geplant ist).

Wenn dies nicht erfolgen konnte, sollte 2 Wochen nach Splenektomie geimpft werden (Impfungen zeitnah zur Operation führen zu niedrigen Impftitern; laut IDSA [7]), aber jedenfalls noch vor Spitalsentlassung!

Bei Patienten, die wegen einer immunsuppressiven Therapie nicht geimpft werden können, muss eine entsprechende Antibiotikaabschirmung durchgeführt werden.

Alle anderen Impfungen entsprechend dem Österreichischen Impfplan sollen ebenso durchgeführt werden, bevorzugt vor Splenektomie und immunsuppressiver Therapie.

\section{Rheumatologie}

Das Spektrum der Erkrankungen aus dem rheumatischen Formenkreis ist vielfältig, und einige dieser autoimmun-mediierten Erkrankungen gehen per se mit einem höheren Infektionsrisiko einher [84]. Darüber hinaus wird dieses Risiko durch die zur Behandlung eingesetzten immunsuppressiven Medikation erhöht [85]. Daher sind Impfungen unverzichtbar im Behandlungskonzept entzündlich-rheumatischer Erkrankungen sowie anderer Autoimmunerkrankungen. Jedoch kann auch der Impferfolg sowohl durch die Erkrankung selbst als auch durch deren Therapie negativ beeinflusst werden. Wie bei allen Betroffenen mit Autoimmunerkrankungen, ist eine genaue Impf-Anamnese in der Erstellung des Behandlungskonzepts unerlässlich. Auch wenn es derzeit keine ausreichende Evidenz dafür gibt, dass Impfungen den Krankheitsverlauf ungünstig beeinflussen, so lauten internationale Empfehlungen, am besten in Phasen einer kontrollierten Krankheitsaktivität zu impfen. Die theoretische Überlegung, dass eine immunogene Stimulation durch einen Impfstoff auch zu einer Aktivierung der Autoimmunreaktion und damit Provokation einer vermehrten Krankheitsaktivität führt, kann derzeit nicht ausgeschlossen werden. Besondere Vorsicht ist auch beim Einsatz von Lebendimpfstoffen erforderlich. Letztere sollten grundsätzlich bei Patienten mit entzündlich-rheumatischen Erkrankungen unter immunsuppressiver Therapie vermieden werden. Die Task Force der „European League Against Rheumatism“ (EULAR) sieht aber die Vakzinen gegen MMR sowie Varizellen/Herpes zoster davon ausgenommen; die Impfstoffe können im Einzelfall bei Patienten unter milder immunsuppressiver Therapie in Erwägung gezogen werden. Sofern es die Krankheitsaktivität zulässt, ist eine Reduktion oder Pause der immunmodulatorischen Medikation vor Lebendimpfungen zu erwägen [29, 86].

In der Behandlung entzündlich-rheumatischer Erkrankungen kommen neben Glukokortikoiden eine Vielzahl von krankheitsmodulierenden Medikamenten (Disease Modifying Antirheumatic Drugs DMARDs) und einige Biologicals (Tab. 11) zum Einsatz. Für einige Substanzen gibt es Studien zur Wirksamkeit von Impfungen unter der jeweiligen Therapie bzw. auch bei verschiedenen Krankheitsbildern. In den meisten Studien ist zwar der Impferfolg sowohl unter konventionellen DMARDs als auch unter TNF-Inhibitoren unbeeinflusst, in manchen fanden sich aber im Vergleich zu Gesunden leicht verminderte Immunantworten. Jedoch sollten Impfungen idealerweise vor Beginn einer B-Zell-depletierenden Therapie erfolgen.

Pneumokokken und Influenza: Patienten mit autoimmun bedingten rheumatischen Erkrankungen zeigten ein höhere Morbidität und Mortalität für Influenza [85]. Methotrexat als Monotherapie oder in Kombination mit TNF-Inhibition kann die Antikörperbildung nach Pneumokokken-Impfungen von RAPatienten vermindern [87-89]. Hingegen waren in Kohorten von Patienten mit Psoriasis-Arthritis kei- 
Tab. 11 Erkrankungen und Therapieschemata in der Rheumatologie

\begin{tabular}{|c|c|c|}
\hline \multicolumn{3}{|c|}{ Immunsuppressive Medikamente in der Rheumatologie } \\
\hline $\begin{array}{l}\text { Konventionelle } \\
\text { DMARDs }\end{array}$ & Biologika & „Small molecules“ \\
\hline MTX & $\begin{array}{l}\text { TNF Inhibitoren: } \\
\text { Infliximab } \\
\text { Etanercept } \\
\text { Adalimumab } \\
\text { Golimumab } \\
\text { Certolizumab }\end{array}$ & Tofacitinib ${ }^{a}$ \\
\hline Leflunomid & Abatacept (CTLA4-lg) & Apremilast \\
\hline Sulfasalazin & Tocilizumab (Anti-IL6) & - \\
\hline (Hydroxy-)Chloroquin & $\begin{array}{l}\text { Rituximab (Anti-CD20) } \\
\text { Belimumab (Anti-BLyS) }\end{array}$ & - \\
\hline Azathioprin & $\begin{array}{l}\text { IL-1-Inhibitoren } \\
\text { Anakinra } \\
\text { Rilonacept } \\
\text { Canakinumab }\end{array}$ & - \\
\hline Mycophenolat & $\begin{array}{l}\text { Ustekinumab (An- } \\
\text { ti-IL-12/23) }\end{array}$ & - \\
\hline Calcineurin-Inhibitoren & - & - \\
\hline Cyclophosphamid & - & - \\
\hline
\end{tabular}

ne negativen Effekte von TNF- $\alpha$-Blockern auf den Impferfolg $\mathrm{zu}$ beobachten. Abatacept (CTLA-4-Ig) dürfte ebenso einen negativen Einfluss auf eine Influenza- oder Pneumokokken-Impfantwort bei RAPatienten haben, für Tocilizumab (Anti-IL-6) scheint dem bislang nicht so, jedoch in Kombination mit MTX wurde aber eine Abschwächung der Antikörperantwort auf PPV23 beschrieben [90-93]. Azathioprin beeinträchtigte den Erfolg einer Influenza-Impfung bei einigen Patienten mit SLE. Insgesamt ist die Datenlage zum Einfluss diverser DMARDs auf die Impfantwort teilweise widersprüchlich. Die stärkste Hemmung der humoralen Immunantwort auf Impfungen findet sich unter einer Therapie mit Rituximab (Anti-CD20) [93, 94]. Dies wurde für Influenza-Vakzinen vor allem in den ersten drei Monaten nach der Gabe von Rituximab beobachtet, bei PneumokokkenImpfungen sogar bis zu 28 Wochen danach [95-98]. Daher sollte eine Impfung den Empfehlungen folgend sechs Monate nach (Bemerkung: 6 Monate gilt für Totimpfstoffen oder Boosterimpfungen; für Primovakzinierung oder Lebendimpfstoffe gilt ein Abstand von 12 Monaten [29]) und vier Wochen vor der nächsten Rituximab-Gabe erfolgen [86].

Hepatitis B: Die Effektivität von Hepatitis B-Impfungen wurden bei verschiedenen Erkrankungen untersucht [85]. Beim Großteil der Patienten wurde ungeachtet der zugrundeliegenden Erkrankung sowohl unter Kortikosteroiden wie auch konventionellen DMARDs ein Impferfolg beobachtet. Nur TNF$\alpha$-Blocker beeinträchtigen die Immunantwort auf die HBV-Vakzine massiv [99]
Tetanustoxoid (TT): Impfungen mit TT scheinen bei Patienten mit entzündlich-rheumatischen Erkrankungen sicher und erfolgreich zu sein. Auch 24 Wochen nach einer Gabe von Rituximab konnte eine ausreichende Antikörperbildung beobachtet werden [97]. Nachdem Rituximab die Effektivität von TT-Vakzinen bei kürzer zurückliegender Gabe beeinträchtigen könnte, empfiehlt das Expertenkomitee der EULAR, Patienten mit größeren oder kontaminierten Wunden, die innerhalb der letzten 24 Wochen eine solche Therapie erhalten haben, auch passiv mit TetanusImmunglobulin zu immunisieren [86].

Mumps, Masern, Röteln (MMR): Alle Studien zu MMR-Impfungen wurden bei jugendlichen Patienten mit entzündlich rheumatischen Erkrankungen durchgeführt. Es fand sich generell gute Immunogenität unabhängig von Kortikosteroiden oder DMARDs. In einer großen retrospektiven Analyse von Patienten mit juveniler idiopathischer Arthritis und gesunden Kontrollen wurden niedrigere Antikörper-Konzentrationen und Seroprotektionsraten gegen Mumps und Röteln, aber nicht gegen Masern erhoben [100, 101].

Herpes zoster (HZ): Patienten mit RA haben per se ein höheres Risiko an Herpes zoster zu erkranken [102]. Darüber hinaus wird dieses Risiko sowohl bei der RA als auch bei anderen Erkrankungen durch die Behandlung mit Kortikosteroiden oder konventionellen DMARDs, insbesondere Cyclophosphamid, Azathioprin oder Leflunomid, erhöht [103]. Mycophenolat ist diesbezüglich geringer prädisponierend, für MTX hat sich dieses Risiko bisher nicht gezeigt [85, 104, 105]. Auch TNF- $\alpha$-Blocker begünstigen in unterschiedlichem Ausmaß HZ, ebenso wurden höhere Erkrankungsraten unter Tofacitinib berichtet [106-108]. Eine Impfung sollte den Expertenmeinungen folgend nur unter geringer Immunsuppression und auch nur bei VZV-Antikörper-positiven Patienten erfolgen, um eine primäre Infektion durch den Impfstamm zu vermeiden.

Humanes Papilloma-Virus (HPV): HPV-Infektionen treten bei Patienten mit SLE häufiger auf als bei gesunden Vergleichskollektiven, auch in Hinblick auf den Risikostamm HPV-16 [85, 109, 110].

\section{Biologika in der Schwangerschaft}

Generell gibt es wenig Daten zur Verabreichung von Biologika in der Schwangerschaft. Am ehesten liegen noch Daten zu TNF $\alpha$-Blockern bei Patientinnen mit entzündlichen Darmerkrankungen vor. TNF $\alpha$-Blocker können laut einem Statement des World Congress of Gastroenterology während der Konzeption (auch beim männlichen Partner) und im ersten und zweiten Trimenon der Schwangerschaft verabreicht werden, wenn es absolut notwendig ist $[111,112]$. Die FDA hat die TNF $\alpha$-Blocker in die Risikokategorie B (kein Risi- 
ko für den Fötus) eingeordnet [113]. Infliximab und Certolizumab sind auch mit dem Stillen vereinbar; Daten zu Adalimumab fehlen hier [111].

Im dritten Trimenon sind TNF $\alpha$-Blocker kontraindiziert, weil - zumindest nach der 30. Schwangerschaftswoche - hohe Mengen des Medikaments diaplazentar auf den Fötus übergehen [112].

Kinder, die intrauterin einem Biologikum ausgesetzt waren, sollten nach dem normalen Schema geimpft werden - Ausnahme sind Lebendimpfungen während der ersten sechs Monate (Rotavirusimpfung) [111]. Lebendimpfungen bei Kindern, die in utero Biologika-exponiert waren, dürfen in den ersten 6 Monaten nicht gegeben werden bzw. sollen erst dann gegeben werden, wenn kein Biologikum mehr im Blut nachweisbar ist [112].

Daten zur Gabe von Rituximab, Abatacept, Anakinra, Tocilizumab und Belimumab in der Schwangerschaft sind sehr limitiert, und die Verabreichung dieser Substanzen in der Schwangerschaft und/oder Stillzeit ist daher zur Zeit nicht empfohlen [112] (zum Teil sehr lange Wirkdauer beachten!).

\section{Gastroenterologie/entzündliche Darmerkrankungen}

Patienten mit entzündlichen Darmerkrankungen (IBD) sind ohne Therapie durch die Krankheit allein nicht immunsupprimiert [114]. Eine Immunsuppression bei diesen Patienten entsteht durch eine Therapie mit Kortikosteroiden (Lebenszeitwahrscheinlichkeit $80 \%$ ), Immunsuppressiva (Lebenszeitwahrscheinlichkeit $40 \%$ ) oder TNFa-Blockern (Lebenszeitwahrscheinlichkeit $20 \%$ ), gelegentlich auch durch Malnutrition (heute selten) und ev. durch Komorbiditäten oder höheres Lebensalter [114, 115].

Durch die genannten Therapeutika sind IBD-Patienten einem erhöhten Risiko für impfpräventable Erkrankungen ausgesetzt [116]. Daten aus Deutschland zeigen jedoch, dass - anhand der Impfungen gegen Hepatitis B, Influenza und Pneumokokken insgesamt 60 bis über $80 \%$ aller IBD-Patienten nicht geimpft sind [117]. Auf Grund der hohen Lebenszeitwahrscheinlichkeit für eine dauerhafte immunsuppressive Therapie nach Diagnose einer chronischentzündlichen Darmerkrankung sollten Patienten bereits zu Beginn und möglichst vor Etablierung einer solchen Therapie dem Impfplan gemäß immunisiert werden.

IBD-Patienten, die nur Aminosalizylate und/oder Probiotika erhalten, gelten nicht als immunsupprimiert und können daher alle Impfungen, einschließlich Lebendimpfungen erhalten.

Patienten unter Kortikosteroiden, Azathioprin bzw. 6-Mercaptopurin, Methotrexat oder TNFa-Blockern gelten als immunsupprimiert und sollten keine Lebendimpfungen erhalten [114]. Eine Therapie mit Vedolizumab (Integrin-Antagonist) ist laut Label ebenfalls in diese Gruppe einzureihen [118]. Besondere Bedachtnahme gilt der langen Halbwertszeit thera- peutischer Antikörper und den möglichen längeren Nachwirkungen einer Antimetabolitentherapie (Azathioprin, 6-Mercaptopyrin, Methotrexat). Bei beiden Medikamentengruppen gilt eine Schutzperiode von drei Monaten nach Absetzten, in der keine Lebendimpfungen verabreicht werden sollen.

Patienten, die unter kombinierter Immunsuppression (i. v. Steroide, Ciclosporin A, Infliximab) stehen, sollten keine Impfungen bekommen [114].

Für Lebendimpfungen wie z. B. Masern sollte bei IBD-Patienten folgendermaßen vorgegangen werden: Wenn keine Hinweise für Immunität bestehen (IgGpositiv bzw. zwei dokumentierte Impfdosen), so sollte der Patient, sofern er noch nicht immunsupprimiert ist, geimpft werden. Frühestens vier Wochen nach der zweiten Impfdosis kann die immunsuppressive Therapie begonnen werden. Ist der Patient bereits immunsupprimiert und wahrscheinlich nicht immun, so sollten zumindest seine Haushaltskontakte geimpft werden, soweit erforderlich.

Was das Varicella-Zoster-Virus (VZV) angeht, so finden sich bei $77 \%$ aller IBD-Patienten messbare Antikörpertiter, was deutlich weniger ist als in der Allgemeinbevölkerung [119]. Unter immunsuppressiver Kombinationstherapie ist das Risiko für eine disseminierte VZV-Infektion erhöht [120]. Deshalb sollten alle immunkompetenten IBD-Patienten spätestens einen Monat vor Beginn oder frühestens drei Monate nach Ende der ISP gegen VZV geimpft werden, sofern keine Immunität vorliegt [114].

Für Totimpfstoffe gibt es folgende IBD-spezifische Daten: Die Impfung gegen Hepatitis B scheint bei diesen Patienten auch dann schlechter anzugehen als in der Normalbevölkerung, wenn keine ISP vorliegt [121, 122]. Eine zweite Impfung bzw. höhere Antigendosen erhöhen jedoch die Serokonversionsrate [121]. Titerkontrollen nach HBV-Impfung werden empfohlen, auch dann, wenn die Impfung vor Beginn der ISP erfolgt ist [114]. Eine Impfung gegen HPV erreichte hingegen in einer kleineren Studie in einer IBDKohorte eine gute, mit Gesunden vergleichbare Immunogenität [123]. Bei der Influenza-Impfung findet sich für IBD-Patienten eine reduzierte Immunogenität [124]. Es sollte jedoch gegen Influenza geimpft werden. Die Verwendung der Influenza-Lebendimpfung (LAIV) sollte vermieden werden [114].

Die Pneumokokkenimpfung zeigt bei nicht immunsupprimierten IBD-Patienten ein normales Ansprechen, bei immunsupprimierten Patienten, insbesondere jenen unter TNF $\alpha$-Blockern ist das Ansprechen jedoch signifikant geringer [125]. Deshalb sollten diese Patienten möglichst vor Beginn der ISP gegen Pneumokokken geimpft werden [114].

Vedolizumab verändert nicht das immunologische Ansprechen auf parenterale, wohl aber auf oral verabreichte Vakzinen, was aufgrund des Wirkmechanismus auch plausibel ist [126]. Mangels anderslautender Daten verbietet das Label unter Vedolizumab die Verabreichung von Lebendimpfstoffen. 
Tab. 12 Immunsuppressive Therapien bei IBD

\begin{tabular}{|c|c|}
\hline Erkrankung & Therapeutika \\
\hline \multirow[t]{6}{*}{ Morbus Crohn } & 5-Aminosalicylate (nicht immunsuppressiv) \\
\hline & Steroide \\
\hline & Thiopurine (Azathioprin, 6-Mercaptopurin) \\
\hline & TNF- $\alpha$-Blocker (Infliximab, Adalimumab, Golimumab) \\
\hline & Methotrexat \\
\hline & $\begin{array}{l}\text { Monoklonale Antikörper gegen Integrine (alpha4 be- } \\
\text { ta7) }\end{array}$ \\
\hline \multirow[t]{6}{*}{ Colitis ulcerosa } & 5-Aminosalicylate (nicht immunsuppressiv) \\
\hline & Steroide \\
\hline & Thiopurine (Azathioprin, 6-Mercaptopurin) \\
\hline & TNF- $\alpha$-Blocker (Infliximab, Adalimumab, Golimumab) \\
\hline & $\begin{array}{l}\text { Monoklonale Antikörper gegen Integrine (alpha4, } \\
\text { beta7) }\end{array}$ \\
\hline & Calcineurin-Inhibitoren (Ciclosporin) \\
\hline
\end{tabular}

Tab. 13 Impfempfehlungen für IBD-Patienten

\begin{tabular}{l|l}
$\begin{array}{l}\text { Generelle Empfeh- } \\
\text { lung }\end{array}$ & Folgend dem Nationalen Impfplan \\
\hline Bei Erstdiagnose & $\begin{array}{l}\text { VZV (falls keine Immunität) } \\
\text { Hepatitis B (falls seronegativ) } \\
\text { Influenza (unter Vermeidung von Lebendvakzinen) } \\
\text { HPV (entsprechend den Altersempfehlungen) }\end{array}$ \\
\hline $\begin{array}{l}\text { Vor Immunsup- } \\
\text { pression }\end{array}$ & $\begin{array}{l}\text { Pneumokokken (PNC13 gefolgt von PPV23 nach 8 Wo- } \\
\text { chen, Revakzination mit PPV23 nach 5 Jahren [114]) }\end{array}$ \\
Jährlich & Influenza
\end{tabular}

Eine Übersicht immunsuppressiver Therapien bei IBD bringt Tab. 12, spezielle Impfempfehlungen für IBD-Patienten Tab. 13.

\section{Dermatologie}

Neben Kortikosteroiden spielen verschiedene Biologika mit immunsuppressiver Wirkung in der Dermatologie bei einer großen Anzahl von Erkrankungen eine Rolle. Hauptindikationen sind chronisch-entzündliche Erkrankungen wie Psoriasis und Hidradenitis suppurativa, allergische Erkrankungen wie atopische Dermatitis und chronische Urtikaria; weiters Kollagenosen, blasenbildende Dermatosen und seltene autoinflammatorische Syndrome. Monoklonale Antikörper werden in der Behandlung des metastasierenden Melanoms eingesetzt, entweder adjuvant (Interferon alfa) oder als spezifische Immuntherapie (PD-1-Inhibitoren, Anti-CTLA-4 Antikörper). Zum Einsatz kommen die TNF $\alpha$-Blocker Adalimumab, Etanercept und Infliximab, weiters Interferon alfa, Ipilimumab (AntiCTLA-4), Ustekinumab (Anti-IL-12/IL-23), Omalizumab (Anti-IgE), Rituximab (Anti-CD20) sowie die IL17A-Inhibitoren Secukinumab und Ixekizumab.

Aufgrund der Natur und der Prognose der meisten hier in Frage kommenden dermatologischen Erkrankungen ist es in der Regel möglich, vor Beginn der immunsupprimierenden Therapie notwendige Impfungen durchzuführen.
Die Hauptindikation für eine schwere ISP in der Dermatologie ist die Therapie der mittelschweren und schweren Psoriasis. Hier werden an systemischen Therapien heute vor allem Acitretin, Ciclosporin, Fumarsäureester und Methotrexat (MTX) verwendet. Das Retinoid Acitretin wirkt nicht immunsuppressiv; es besteht daher keine Kontraindikation gegen Impfungen. Unter Ciclosporin sollten Lebendimpfungen vermieden werden. Die Impfungen gegen Pneumokokken und gegen Herpes zoster (bei positiver Varizellenanamnese/serologie) sollten älteren Patienten vor Therapiebeginn verabreicht werden, da das Impfansprechen unter Therapie reduziert sein kann. Fumarsäureester sind in Österreich zur Therapie der Psoriasis nicht zugelassen, während in Deutschland Dimethylfumarat das meistverordnete Präparat zur Therapie der Psoriasis ist. Impfungen sind nicht kontraindiziert, und unerwünschte Wirkungen im $\mathrm{Zu}$ sammenhang mit Impfungen wurden nicht berichtet. Dimethylfumarat wirkt immunmodulatorisch, kann allerdings zu einer deutlichen Lymphopenie $(<500 / \mu \mathrm{l})$ führen, und wenige Fälle von progressiver multifokaler Leukenzephalopathie (PML) wurden beschrieben [127]. Patienten unter MTX sollten keine Lebendimpfungen erhalten. Inaktivierte Impfstoffe können unter MTX eine reduzierte Wirksamkeit aufweisen [128]. Für die Durchführung von Routineimpfungen bei Psoriasispatienten gibt es detaillierte Empfehlungen [29, 129] bzw. siehe Tab. 4 .

Ein neues Medikament gegen Psoriasis ist der PDE4-Inhibitor Apremilast [130-132]. In der ESTEEM1-Zulassungsstudie waren Lebendimpfungen während des Beobachtungszeitraums gestattet [133]. Spezifische Impfempfehlungen der Fachgesellschaften liegen noch nicht vor.

Laut europäischen Empfehlungen scheinen TNFaBlocker die Wirksamkeit der Impfung gegen Influenza A nicht zu vermindern; diese Daten stammen allerdings aus Studien bei Patienten mit rheumatoider Arthritis und nicht aus Untersuchungen an Psoriasispatienten. Abhängig von der Grundkrankheit kann hingegen die Impfantwort gegen Influenza B und Pneumokokken unter TNF $\alpha$-Blockern vermindert sein. Patienten unter TNF $\alpha$-Blockern sollten keine Lebendimpfungen erhalten. Abhängig von der HWZ sollten TNF $\alpha$-Blocker durchschnittlich drei Monate vor einer Lebendimpfung abgesetzt (siehe Tab. 4) und frühestens zwei bis drei Wochen [134], in der Regel aber vier Wochen nach Lebendimpfung später wieder begonnen werden. Entsprechend Tab. 4 sollte mindestens ein Abstand von vier HWZ vor einer Lebendimpfung eingehalten werden; das ergibt für die meisten Biologika einen Abstand von drei Monaten. Säuglinge, die in utero eine Exposition gegenüber TNF $\alpha$-Blockern hatten, dürfen bis sechs Monate nach der Geburt keine Lebendimpfstoffe erhalten bzw. erst dann, wenn Biologika im Blut nicht mehr nachweisbar sind [111-113, 128]. 
Tab. 14 Immunsuppressive Therapien in der Dermatologie

\begin{tabular}{|c|c|c|c|}
\hline \multirow[t]{2}{*}{ Krankheit } & \multicolumn{3}{|l|}{ Therapieschemata } \\
\hline & 1. Wahl & 2. Wahl & 3. Wahl \\
\hline $\begin{array}{l}\text { Chronische Plaque- } \\
\text { Psoriasis }\end{array}$ & $\begin{array}{l}\text { (Abhängig vom Schweregrad) } \\
\text { topische Steroide, } \\
\text { topische Vitamin D Analoga (nicht immunsuppressiv), } \\
\text { topische Calcineurininhibitoren; } \\
\text { Fototherapien: NB-UVB, PUVA; } \\
\text { Methotrexat } \\
\text { Ciclosporin } \\
\text { Fumarsäureester (in Österreich nicht zugelassen) } \\
\text { Secukinumab }\end{array}$ & $\begin{array}{l}\text { (Bei KI oder Therapieversagen von } \\
\text { 1. Wahl) } \\
\text { Apremilast, } \\
\text { Adalimumab, Etanercept, Infliximab, } \\
\text { Ustekinumab, } \\
\text { Secukinumab } \\
\text { Ixekizumab }\end{array}$ & $\begin{array}{l}\text { Acitretin (nicht immunsup- } \\
\text { pressiv) } \\
\text { Acitretin in Kombination mit } \\
\text { PUVA (Re-PUVA) }\end{array}$ \\
\hline Atopische Dermatitis & $\begin{array}{l}\text { (Abhängig vom Schweregrad) } \\
\text { topische Steroide, } \\
\text { topische Calcineurininhibitoren; } \\
\text { UVA1-, NB-UVB Fototherapie, } \\
\text { systemische Kortikosteroide }\end{array}$ & Ciclosporin & $\begin{array}{l}\text { Azathioprin, } \\
\text { Mycophenolat-mofetil, Me- } \\
\text { thotrexat }\end{array}$ \\
\hline $\begin{array}{l}\text { Hidradenitis suppurati- } \\
\text { va }\end{array}$ & $\begin{array}{l}\text { Kortikosteroide intraläsional } \\
\text { Clindamycin, Rifampicin (nicht immunsuppressiv) } \\
\text { Adalimumab }\end{array}$ & Infliximab & - \\
\hline $\begin{array}{l}\text { Kutaner Lupus erythe- } \\
\text { matodes }\end{array}$ & $\begin{array}{l}\text { (Abhängig vom Schweregrad) } \\
\text { topische Steroide (nur bei Einzelläsionen; DLE), Hydroxychlo- } \\
\text { roquin (SCLE), Mepacrin } \\
\text { systemische Kortikosteroide }\end{array}$ & $\begin{array}{l}\text { Methotrexat } \\
\text { Dapson } \\
\text { Thalidomid (DLE) }\end{array}$ & $\begin{array}{l}\text { Mycophenolatmofetil (MMF)/ } \\
\text { Mycophenolat-Natrium } \\
\text { (MP-S), } \\
\text { Hochdosierte intravenöse } \\
\text { Immunglobuline, Ciclosporin }\end{array}$ \\
\hline Pemphigus vulgaris & $\begin{array}{l}\text { Systemische Kortikosteroide, Kombinationstherapien: Korti- } \\
\text { kosteroide plus Mycophenolatmofetil } \\
\text { Kortikosteroide plus Azathioprin } \\
\text { Kortikosteroide plus Cyclophosphamid }\end{array}$ & $\begin{array}{l}\text { Rituximab, } \\
\text { Hochdosierte intravenöse Immunglo- } \\
\text { buline, Immunapherese }\end{array}$ & - \\
\hline Bullöses Pemphigoid & $\begin{array}{l}\text { (Abhängig vom Schweregrad) topische Steroide, systemi- } \\
\text { sche Kortikosteroide als Monotherapie oder in Kombination } \\
\text { mit Azathioprin, Dapson, Methotrexat, Doxycyclin, Mycophe- } \\
\text { nolat-mofetil }\end{array}$ & $\begin{array}{l}\text { Hochdosierte intravenöse Im- } \\
\text { munglobuline, Immunadsorption/ } \\
\text { Plasmapherese, } \\
\text { Rituximab }\end{array}$ & $\begin{array}{l}\text { Cyclophosphamid, Omalizu- } \\
\text { mab }\end{array}$ \\
\hline
\end{tabular}

Unter einer Therapie mit Ustekinumab sind Totimpfungen erlaubt und das Impfansprechen ist nicht eingeschränkt [135]. Lebendimpfungen sind unter Ustekinumab kontraindiziert. Ist eine Lebendimpfung notwendig, soll Ustekinumab zwölf Wochen vorher abgesetzt und frühestens zwei Wochen nach Impfung wieder begonnen werden [128].

Für den erst kürzlich zugelassenen IL-17A-Blocker Secukinumab wurde gezeigt, dass er bei gesunden Probanden die Impfantwort gegen Influenza und Meningokokken nicht beeinflusst [136].

Tab. 14 gibt einen Überblick immunsuppressiver Therapien in der Dermatologie.

\section{HIV-Infektion}

Die unbehandelte HIV-Infektion führt zu einer kontinuierlich progredienten Immundefizienz, die in erster Linie durch den Verlust und die Dysfunktion von CD4-positiven T-Lymphozyten charakterisiert ist. Die opportunistischen Infektionen bei fortgeschrittener HIV-Infektion sind daher primär Folge der defekten zellulären Immunität. Entsprechend der Abnahme der CD4-Zellzahl werden verschiedene Stadien der Immundefizienz definiert: bei einer CD4-Zellzahl ab $500 / \mathrm{mm}^{3}$ liegt keine wesentliche Immundefizienz vor, bei einer CD4-Zellzahl unter $200 / \mathrm{mm}^{3}$ wird von einer schweren Immundefizienz ausgegangen. Bei dieser ist das Risiko für opportunistische Erkrankungen (AIDS) beträchtlich. Bei Kindern wird anstelle der absoluten Zellzahl der relative Anteil von CD4-Zellen unter den T-Lymphozyten herangezogen, da Kinder generell hohe CD4-Zellzahlen haben. Eine CD4-Prozentzahl unter $14 \%$ bedeutet eine schwere Immundefizienz, bei über $25 \%$ ist die Immunfunktion weitgehend normal.

Neben der defekten zellulären Immunantwort kommt es bei fortschreitender HIV Infektion auch zu einer B-Zell-Dysfunktion und eingeschränkter humoraler Immunantwort [137].

Die Behandlung der HIV-Infektion erfolgt durch eine Kombinationstherapie von meist drei Substanzen mit verschiedenen antiretroviralen Angriffspunkten. Während früher die Behandlungsindikation in Abhängigkeit von der CD4-Zellzahl gestellt wurde, wird seit 2015 der Beginn der HIV-Therapie in jedem Stadium der Infektion empfohlen. Unter antiretroviraler Behandlung steigen die CD4-Zellen meist auf Normalwerte an. Damit ist der Zeitraum, in dem eine schwere Immundefizienz und AIDS-Erkrankungen vorliegen, begrenzt, sofern die HIV-Infektion diagnostiziert und behandelt wird. Bei einer CD4Zellzahl unter $200 / \mathrm{mm}^{3}$ werden neben der antiviralen Therapie auch medikamentöse Prophylaxen gegen opportunistische Infektionen durchgeführt. Impfungen sind in dieser Phase weniger wirksam.

Die meisten vorliegenden Daten zum Impferfolg bei HIV-infizierten Patienten beziehen sich auf die 
Immunogenität; zur Effektivität/Protektivität der Impfungen existieren weniger Daten. Die Impfantworten sind bei HIV-Infizierten in der Regel niedriger und dauern weniger lange an als bei Gesunden. In frühen Stadien der Infektion bzw. nach Immunrekonstitution und Virussuppression unter antiretroviraler Therapie sind die Antikörperantworten besser. Empfehlungen zu Formulierung, Dosis und Applikationsschema von Impfungen können bei HIV-Infektion von jenen für die Allgemeinbevölkerung abweichen, um die Impfantwort $\mathrm{zu}$ optimieren. Lebendimpfstoffe sind bei CD4-Zellen unter $200 / \mathrm{mm}^{3}$ bzw. $14 \%$ kontraindiziert.

Totimpfstoffe sind bei HIV-Patienten generell sicher und können in allen Stadien der Infektion gegeben werden. In manchen Fällen kann auch bei schwerer Immunsuppression eine protektive Immunität erreicht werden; allerdings ist bei $\mathrm{zu}$ erwartender suboptimaler Impfantwort auf die initiale Impfung eine neuerliche Impfung nach Immunrekonstitution bzw. eine Kontrolle der Impftiter empfohlen. Da mittlerweile die antiretrovirale Therapie in allen Stadien der HIV-Infektion empfohlen wird, kann das Aufschieben von manchen Impfungen bis zum Erreichen der Virussuppression und Immunrekonstitution erwogen werden, um eine bestmögliche Impfantwort zu erreichen (z. B. Pneumokokken). Wiederholte Titerkontrollen werden bei HIV-infizierten Patienten nach Hepatitis-B-Impfung empfohlen mit dem Ziel, gegebenenfalls durch Booster-Impfungen die HBsAntikörper-Titer über 10IU/l zu halten. Titerkontrollen sind auch bei anderen Impfungen (z. B. FSME, Hepatitis A) zu erwägen.

Manche Lebendimpfstoffe sind bezüglich ihrer Sicherheit ausreichend belegt und können HIV-infizierten Personen verabreicht werden, wenn die CD4Zellzahl über $200 / \mathrm{mm}^{3}$ bzw. über $14 \%$ liegt und keine aktuelle AIDS-Erkrankung besteht. Dies gilt für MMR, VZV und Gelbfieber. Bei Patienten mit einer CD4Zellzahl unter $200 / \mathrm{mm}^{3}$ bzw. unter $14 \%$ dürfen keine Lebendimpfungen verabreicht werden, da es keine Daten zur Sicherheit gibt und ein erhöhtes Risiko von Vakzine-assoziierten Infektionen zu erwarten ist. Immer kontraindiziert sind folgende Lebendimpfungen (da Alternativen vorhanden sind oder der Nutzen beschränkt ist): Intranasale Influenza (LAIV), Cholera oral (zur Zeit nicht verfügbar) und Typhus oral (Ty21a).

HIV-positive Kinder bzw. HIV-exponierte Säuglinge sollen grundsätzlich alle im Österreichischen Impfplan empfohlenen Impfungen erhalten. Die jährliche Influenzaimpfung (Totimpfung) wird auch für Haushaltkontakte (v. a. von Kindern bis 6a) empfohlen. Lebendimpfungen wie Varizellen und MMR dürfen nur bei einer CD4-Prozentzahl von > $14 \%$ verabreicht werden. Die MMRV-Vierfachimpfung sollte nicht gegeben werden, da sie bei HIV-Infektion derzeit nicht evaluiert ist. Rotavirus-Impfungen sind möglich. Nutzen und Risiko sollen dabei abgewogen werden, da es we- nig Daten zur Sicherheit gibt. Da die Impfstämme von Rotaviren beträchtlich attenuiert sind, ist vermutlich keine erhöhte Toxizität bei HIV-positiven Säuglingen zu erwarten. Meningokokken-Impfungen können wie bei HIV-negativen Kindern verabreicht werden.

Bei Erwachsenen soll die Impfung gegen Influenza altersunabhängig erfolgen. Besonders empfohlen werden HIV-Patienten weiters die Impfungen gegen Pneumokokken (altersunabhängig), gegen Hepatitis B (die bei HIV-Infektion schwerer verläuft) und gegen HPV (ggf. auch über 26a, weil das Risiko für HPV-Infektionen und assoziierte Karzinome bis zu 40mal höher ist als in der Normalbevölkerung). Bei entsprechender Indikation kann auch gegen Hepatitis A, Meningokokken, Haemophilus influenzae B, MMR und Varizellen (bei fehlender Immunität und Zellzahl über $200 / \mathrm{mm}^{3}$ ) sowie gegen Zoster (bei Zellzahl über $200 / \mathrm{mm}^{3}$ ) geimpft werden. Die Sicherheit der Zoster-Lebendimpfung (Zostavax ${ }^{\circledR}$ ) wurde in einer Studie gezeigt [138], bisher wurde allerdings keine generelle Impfempfehlung ausgesprochen. Dies wird sich ändern, wenn ein Totimpfstoff zur Verfügung steht.

Bei den Reiseimpfungen kann bei HIV-infizierten Personen in höherem Alter ( $>60 \mathrm{a})$ eine vierte Impfdosis für Japan-Enzephalitis erwogen werden. In diesem Alter ist bei der Gelbfieberimpfung das Risiko von Nebenwirkungen erhöht, daher sollte die Indikation sehr streng gestellt werden. Umgekehrt wird die Empfehlung zur Impfung gegen Rabies und Typhus bei HIV-positiven Reisenden eher großzügig ausgesprochen.

Es sind keine negativen Auswirkungen von Impfungen auf den Verlauf der HIV-Infektion beschrieben. In manchen Studien wurde nach Impfung (z. B. Tetanus, Influenza) ein transienter Anstieg der Viruslast beobachtet, der jedoch ohne klinische Relevanz war. Zu Nebenwirkungen nach Varizellen-Impfung bei Erwachsenen mit HIV gibt es keine systematischen Daten; bei Kindern hingegen ist die Sicherheit dokumentiert

Tab. 15 Abweichungen von den allgemeinen Impfempfehlungen bei HIV-Infektion

\begin{tabular}{|c|c|}
\hline \multirow[t]{3}{*}{$\begin{array}{l}\text { Mehrere Dosen } \\
\text { (Grundimmunisierung) }\end{array}$} & $\begin{array}{l}\text { Hepatitis A: } 3 \text { Dosen bei CD4-Zellen } \\
<200 / \mathrm{mm}^{3}\end{array}$ \\
\hline & FSME: 4 Dosen bei CD4-Zellen $<200 / \mathrm{mm}^{3}$ \\
\hline & Japan-Enzephalitis: 4 Dosen bei Alter $>60 a$ \\
\hline Frühere Booster & Typhus: nach 2a bei CD4-Zellen <200/mm³ \\
\hline Titerkontrollen & $\begin{array}{l}\text { Hepatitis B: jährlich (bei geringer Impfantwort } \\
\text { und Expositionsrisiko) }\end{array}$ \\
\hline \multirow[t]{2}{*}{ Höhere Dosen } & Hepatitis B: $40 \mu \mathrm{g}$ \\
\hline & Influenza (intradermal, Adjuvans) \\
\hline \multirow[t]{2}{*}{ Großzügigere Empfehlung } & Typhus \\
\hline & Rabies \\
\hline $\begin{array}{l}\text { Zurückhaltendere Emp- } \\
\text { fehlung }\end{array}$ & Gelbfieber bei Alter $>60 \mathrm{a}$ \\
\hline Kontraindiziert & $\begin{array}{l}\text { Lebendimpfungen bei CD4-Zellen }<200 / \mathrm{mm}^{3} \\
\text { und/oder AIDS-Erkrankung }\end{array}$ \\
\hline
\end{tabular}


Tab. 16 Immunsuppressive Therapien in der Neurologie

\begin{tabular}{|c|c|c|c|}
\hline \multirow[t]{2}{*}{ Erkrankung } & \multirow[t]{2}{*}{ Schubtherapie } & \multirow{2}{*}{$\begin{array}{l}\text { Intervalltherapie } \\
\text { Basistherapie }\end{array}$} & \multirow{2}{*}{$\begin{array}{l}\text { Intervalltherapie } \\
\text { Eskalation }\end{array}$} \\
\hline & & & \\
\hline Multiple Sklerose & Kortikosteroide & $\begin{array}{l}\text { B-Interferone } \\
\text { Glatiramer-Azetat } \\
\text { Dimethylfumarat } \\
\text { Teriflunomid }\end{array}$ & $\begin{array}{l}\text { Fingolimod } \\
\text { Natalizumab } \\
\text { Alemtuzumab } \\
\text { Mitoxantron } \\
\text { Rituximab } \\
\text { Ocrelizumab }\end{array}$ \\
\hline Neuromyelitis optica & $\begin{array}{l}\text { Kortikosteroide } \\
\text { Plasmapherese }\end{array}$ & - & $\begin{array}{l}\text { Azathioprin } \\
\text { Mycophenolatmofetil } \\
\text { Rituximab } \\
\text { Mitoxantron } \\
\text { Cyclophosphamid }\end{array}$ \\
\hline Akute Disseminierte Enzephalomyelitis & $\begin{array}{l}\text { Kortikosteroide } \\
\text { Plasmapherese }\end{array}$ & - & Cyclophosphamid \\
\hline $\begin{array}{l}\text { Erkrankungen durch Auto-Antikörper gegen Transmitter, Rezep- } \\
\text { toren oder lonenkanäle (z. B. NMDA-R; VGKC-Komplex; AMPA-R, } \\
\text { GABA-R) }\end{array}$ & - & $\begin{array}{l}\text { Langzeit-Steroidtherapie } \\
\text { i. v. Immunglobuline } \\
\text { Plasmapherese }\end{array}$ & $\begin{array}{l}\text { Rituximab } \\
\text { Cyclophosphamid }\end{array}$ \\
\hline $\begin{array}{l}\text { CD8+ T-Zell-vermittelte Erkrankungen (z. B. Paraneoplastische } \\
\text { Syndrome; Rasmussen-Enzephalitis) }\end{array}$ & - & Langzeit-Steroidtherapie & Tacrolimus \\
\hline Neurosarkoidose & - & Langzeit-Steroidtherapie & $\begin{array}{l}\text { Methotrexat, Azathioprin, } \\
\text { Mycophenolatmofetil } \\
\text { Ciclosporin A } \\
\text { Cyclophosphamid, } \\
\text { Infliximab, Rituximab }\end{array}$ \\
\hline Zerebrale Vaskulitis & - & Langzeit-Steroidtherapie & $\begin{array}{l}\text { Azathioprin } \\
\text { Methotrexat } \\
\text { Infliximab } \\
\text { Rituximab }\end{array}$ \\
\hline Guillain-Barré-Syndrom (GBS) & $\begin{array}{l}\text { i. v. Immunglobulin } \\
\text { Plasmapherese }\end{array}$ & - & - \\
\hline Chronische Inflammatorische Polyneuropathie (CIDP) & $\begin{array}{l}\text { Glukokortikoide } \\
\text { i. v. Immunglobuline } \\
\text { Plasmapherese }\end{array}$ & $\begin{array}{l}\text { i. v. Immunglobuline } \\
\text { Langzeit-Steroidtherapie }\end{array}$ & - \\
\hline Demyelinisierende Neuropathie bei IgM-Paraproteinämie & - & $\begin{array}{l}\text { i. v. Immunglobuline } \\
\text { Plasmapherese }\end{array}$ & $\begin{array}{l}\text { Rituximab? } \\
\text { Immunsuppression? }\end{array}$ \\
\hline
\end{tabular}

[139, 140]. Bei Auftreten von „Impfvarizellen“ sollte Aciclovir/Valaciclovir gegeben werden.

Tab. 15 zeigt die Abweichungen von den allgemeinen Impfempfehlungen bei HIV-Patienten.

\section{Neurologie}

Abgesehen von systemischen Autoimmunerkrankungen sowie hämatologischen Erkrankungen, die jeweils das Nervensystem mitbetreffen können, wird eine therapeutische Immunsuppression bei Autoimmunerkrankungen angewandt, die für das Nervensystem spezifisch sind. Dies sind die Multiple Sklerose (MS), die Neuromyelitis optica, die akute disseminierte Enzephalomyelitis, andere seltene Erkrankungen wie Vaskulitiden, Sarkoidose, M. Behcet u. a. sowie das Guillain-Barré-Syndrom und andere entzündliche Erkrankungen des peripheren Nervensystems.

Für die immer wieder geäußerte Behauptung, Impfungen könnten eine MS verursachen, gibt es keinerlei Beweise [13, 141]. Eine Induktion von MS-Schüben ist aufgrund der Immunstimulation theoretisch denkbar, es gibt jedoch dafür keine Beweise aus epidemiologischen Daten [141], sondern lediglich Fallberichte.
Allerdings besteht eine Assoziation von MS-Schüben mit aktiven Infektionserkrankungen [142-144].

Bei MS werden inaktivierte Impfstoffe als weitgehend sicher angesehen. Dies gilt für Patienten unter folgenden Therapien: Beta-Interferone, Teriflunomid, Glatiramer-Azetat, Fingolimod, Natalizumab ( $\alpha 4$-Integrin-Inhibitor), Fumarat, Alemtuzumab (Anti-CD52) und Mitoxantron.

Lebendimpfungen werden hingegen im Allgemeinen nicht empfohlen. Dies gilt insbesondere für Patienten unter Alemtuzumab, Natalizumab und Rituximab (Anti-CD20). Bei Patienten mit hoch wirksamer immunsuppressiver Therapie kann die Effektivität von Impfungen reduziert sein - daher sollte der Impferfolg nach durchgeführter Impfung kontrolliert werden. Innerhalb von vier bis sechs Wochen nach Beginn eines Erkrankungsschubes sollten keine Impfungen verabreicht werden.

Was die Impfantwort angeht, so ist bei MS-Patienten unter Beta-Interferon und wahrscheinlich auch unter Natalizumab und Alemtuzumab [145] eine normale Impfantwort (auf inaktivierte Impfstoffe) $\mathrm{zu}$ erwarten. Unter Mitoxantron und Glatiramer-Aze- 
tat scheint zumindest auf die Influenza-Impfung ein vermindertes Ansprechen vorzuliegen [146].

Bezüglich Natalizumab fand sich in einer randomisierten, offenen Studie bei 60 Patienten mit schubförmiger MS kein signifikanter Unterschied in der humoralen Immunantwort auf ein Recall-Antigen (TetanusToxoid), und es wurde lediglich eine etwas langsamere und reduzierte humorale Immunantwort auf ein Neoantigen („Keyhole Limpet Hemocyanin“ = KLH) bei Patienten beobachtet, die im Vergleich zu einer unbehandelten Kontrollgruppe über sechs Monate mit Natalizumab behandelt wurden [147]. Lebendimpfstoffe wurden nicht untersucht.

Hingegen ist die Impfantwort unter Rituximab und Mycophenolat-mofetil reduziert [148, 149]. Während einer Therapie mit Mycophenolat-mofetil sollten keine Lebendimpfungen erfolgen. Auch andere Impfungen können zu Problemen führen oder einen unzureichenden Schutz bieten und sollten daher nur nach sorgfältiger Indikationsstellung erfolgen. Die diesbezüglichen Daten stammen weitestgehend aus der Rheumatologie und der Nephrologie [150-152].

Bei einer geplanten Therapie mit Natalizumab, Alemtuzumab oder Rituximab sollte zunächst der Impfstatus überprüft werden und eine Abwägung zwischen Infektions- und Impfrisiko erfolgen. Dann sollten Impfungen idealerweise vier bis sechs Wochen vor Therapiebeginn erfolgen. Unter Alemtuzumab sollten während und bis zwölf Monate nach der Therapie keine Lebendimpfstoffe gegeben werden.

Tab. 16 gibt einen Überblick immunsuppressiver Therapien in der Neurologie.

Open access funding provided by Medical University of Vienna.

Interessenkonflikt Dieses Projekt wurde durch die Medizinische Universität Wien ohne jegliches externe Sponsoring durch die Pharmaindustrie finanziert. An der Medizinischen Universität Wien wird durch das geltende Antikorruptionsgesetz ( $\$ \$ 304 \mathrm{ff}$ StgB) sowie die Richtlinien für Ethik in Wissenschaft und Forschung (Good Scientific Practice) wissenschaftlich korrektes Verhalten und Transparenz vorgegeben. Alle Autoren haben unentgeltlich an diesem Projekt mitgearbeitet. U. Wiedermann: In den letzten fünf Jahren: Wissenschaftliche Kooperationsprojekte (Investigator-initiated Studies, Phase III/IV Studien) mit Pfizer, Novartis/GSK, Imugene. Scientific Officer/Scientific Advisory Board von Imugene (Biotech Australia). A. Eser: Beratung und Vortragstätigkeit MSD, Abbvie und Janssen. H. Holzmann: In den letzten fünf Jahren - Vorträge, die Impfthemen inkludierten organisiert von Abbott, Roche und DiaSorin. H. Kollaritsch: In den letzten fünf Jahren - Mitglied im Expertenteam eines FSME-Impfstoffes der Firma Novartis. Principal Investigator in mehreren Vakzinestudien (experimentelle Produkte) von Novartis und Baxter. Vorträge zu Impfthemen mit und ohne Produktbezug - finanziert von Baxter, Novartis, Sanofi Pasteur MSD, Wyeth/Pfizer und GSK. Übernahme der Kosten für Kongressreisen und Tagungsgebühren von wissenschaftlichen Veranstaltungen - finanziert von Baxter, Novartis, Sanofi Pasteur MSD, Wyeth/Pfizer und GSK. M. Köller: Vortrags- und Beratungshonorare von abbvie, Amgen, Astellas, Lilly, Novartis, Pfizer, Roche, Sandoz. M. Kundi: In den letzten fünf Jahren - Mitglied von Expertenteams für Baxter, Pfizer und Greenhills. I. Mutz: Honorar für Vorträge zu Impfthemen (Baxter, Novartis, Sanofi Pasteur MSD, Wyeth/Pfizer und GSK);Honorar für Beratungstätigkeit als Mitglied von Data Safety Monitoring Committees (Baxalta, CureVac, Pfizer). W. Pickl: In den letzen fünf Jahren, Beratung und Vortragstätigkeit mit und ohne Produktbezug - Firma Novartis; Shareholder Biomay AG. E. Riedl: In den letzten fünf Jahren - Mitglied in Advisory Boards und/oder Prüfarzt in klinischen Studien und/oder Vortragstätigkeit und/oder Übernahme der Kosten für Kongressreisen und Tagungsgebühren von wissenschaftlichen Veranstaltungen und/oder Beratertätigkeit für AbbVie, Amgen, Celgene, Eli-Lilly, Janssen, Maruho, Merck/MSD, Novartis, Wyeth/Pfizer; Förderung von Forschungsprojekten an der Medizinischen Universität Wien durch AbbVie, Wyeth/Pfizer. H. Sitte: Honorare für Seminare und Consulting von AbbVie, Amgen, Astra Zeneca, Astropharma, Lundbeck, MSD, Pfizer, Ratiopharm, Roche, Sanofi-Aventis, Serumwerk Bernburg und Shire (vergangene 5 Jahre). W. Zenz: In den letzten fünf Jahren - Mitglied im Expertenteam Independent Data Safety Monitoring Committee eines FSME-Impfstoffes der Firma Baxter. Vorträge zu Impfthemen mit und ohne Produktbezug - finanziert von Baxter, Novartis, und Pfizer (Gesamtsumme weniger als $3 \%$ des jährlichen Bruttoeinkommens). Übernahme der Kosten für Kongressreisen und Tagungsgebühren von wissenschaftlichen Veranstaltungen - finanziert von Baxter, Novartis, Sanofi Pasteur MSD, Wyeth und GSK. Förderung von Forschungsprojekten an der Medizinischen Universität Graz (Leitung Prof. Zenz) durch Novartis, GSK und Pfizer. (Gesamtsumme der industriellen Förderung etwa $2 \%$ der Summe, die aus öffentlichen Geldern eingeworben wurde). K. Zwiauer: In den letzten fünf Jahren - Mitglied in Advisory Boards zu verschiedenen Impfstoffen der Firmen Baxter, GSK, Novartis, Sanofi Pasteur, Pfizer. Vorträge zu Impfthemen - finanziert von Baxter, GSK, Novartis, Sanofi Pasteur, Pfizer. Übernahme der Kosten für Kongressreisen und Tagungsgebühren von wissenschaftlichen Veranstaltungen - finanziert von Baxter, GSK, Novartis, Sanofi Pasteur, Pfizer. P. Falb, M. Kitchen, H. Lassmann, M. Sibilia, F. Thalhammer und B. Tucek geben an, dass kein Interessenkonflikt besteht.

Open Access Dieser Artikel wird unter der Creative Commons Namensnennung 4.0 International Lizenz (http:// creativecommons.org/licenses/by/4.0/deed.de) veröffentlicht, welche die Nutzung, Vervielfältigung, Bearbeitung, Verbreitung und Wiedergabe in jeglichem Medium und Format erlaubt, sofern Sie den/die ursprünglichen Autor(en) und die Quelle ordnungsgemäß nennen, einen Link zur Creative Commons Lizenz beifügen und angeben, ob Änderungen vorgenommen wurden.

\section{Literatur}

1. Salgado E, Gomez-Reino JJ. The risk of tuberculosis in patients treated with TNF antagonists. Expert Rev Clin Immunol.2011;7(3):329-40.

2. Robert-Koch-Institut. Hinweise zu Impfungen bei Patienten mit Immundefizienz. Epidemiol Bull. 2005;39: Sonderdruck.

3. Galen JE, Curtiss R 3rd. The delicate balance in genetically engineering live vaccines. Vaccine. 2014;32(35):4376-85.

4. Centers for Disease Control and Prevention (CDC). General recommendations on immunization - recommendations of the Advisory Committee on Immunization Practices (ACIP). MMWR Recomm Rep. 2011;60(2):1-64. 
5. Oishi M, et al. Vaccine-associated paralytic poliomyelitis showing biphasic motor paresis. Rinsho Shinkeigaku. 2012;52(10):744-9.

6 . Shibazaki K, et al. Acute disseminated encephalomyelitis associated with oral polio vaccine. Intern Med. 2006;45(20):1143-6.

7. Rubin LG, et al. 2013 IDSA clinical practice guideline for vaccination of the immunocompromised host. Clin Infect Dis. 2014;58(3):e44-e100.

8. Chalmers A, et al. Immunization of patients with rheumatoid arthritis against influenza: a study of vaccine safety and immunogenicity. J Rheumatol. 1994;21(7):1203-6.

9. Holvast A, et al. Effect of a second, booster, influenza vaccination on antibody responses in quiescent systemic lupus erythematosus: an open, prospective, controlled study. Rheumatology (Oxford). 2009;48(10):1294-9.

10. Wallin L, et al. Safety and efficiency of influenza vaccination in systemic lupus erythematosus patients. Acta Reumatol Port. 2009;34(3):498-502.

11. Kuruma KA, et al. Safety and efficacy of hepatitis B vaccine in systemic lupus erythematosus. Lupus. 2007;16(5):350-4.

12. Elkayam O, et al. Immunogenicity and safety of pneumococcal vaccination in patients with rheumatoid arthritis or systemic lupus erythematosus. Clin Infect Dis. 2002;34(2):147-53.

13. Farez MF, Correale J. Yellow fever vaccination and increased relapse rate in travelers with multiple sclerosis. Arch Neurol. 2011;68(10):1267-71.

14. Perez Villar R. Radiotherapy and immunity - a mini review, immunosuppression - role in health and diseases 2012. http://www.intechopen.com/books/ immunosuppression-role-in-health-and-diseases.

15. Formenti SC, Demaria S. Combining radiotherapy and cancer immunotherapy: a paradigm shift. J Natl Cancer Inst. 2013;105(4):256-65.

16. Centers for Disease Control and Prevention (CDC). CDC Health information for international travel, Chapter 8: Advising travelers with specific needs, travelers with chronicillness.http://wwwnc.cdc.gov/travel/yellowbook/ 2016/advising-travelers- with-specific-needs/travelerswith-chronic-illnesses. Zugegriffen 09. Januar 2015.

17. Schweizer Bundesamt für Gesundheit (BAG). Impfempfehlungen für Risikopatienten. http://www.bag.admin. ch/themen/medizin/00682/00685/14669/index.html? lang=de. Zugegriffen 09. Januar 2015.

18. MalletV, etal. Management of viral hepatitis in patients with haematological malignancy and in patients undergoing haemopoietic stem cell transplantation:recommendations of the 5th European Conference on Infections in Leukaemia (ECIL-5).Lancet Infect Dis. 2016;16(5):606-17.

19. Lanaya $H$, et al. EGFR has a tumour-promoting role in liver macrophages during hepatocellular carcinoma formation. NatCell Biol. 2014;16(10):971-81.

20. Freissmuth M. et al. Pharmakologie \& Toxikologie: von den molekularen Grundlagen zur Pharmakotherapie, 1st ed. Springer-Lehrbuch. Heidelberg: Springer; 2012, 129 Tabellen.

21. Hilal-Dandan R. et al. Goodman and Gilman's manual of pharmacology and therapeutics, 2nd ed. New York: McGraw-Hill; 2014., p vii, 1206.

22. McLean LP, et al. Vedolizumab for the treatment of ulcerative colitis and Crohn's disease. Immunotherapy. 2012;4(9):883-98.

23. Yaldizli O, Putzki N. Natalizumab in the treatment of multiple sclerosis. Ther Adv NeurolDisord. 2009;2(2):115-28.
24. Fischer SK, et al. The assay design used for measurement of therapeutic antibody concentrations can affect pharmacokinetic parameters: case studies. MAbs. 2012;4(5):623-31.

25. Yarilina A, et al. Regulation of inflammatory responses in tumor necrosis factor-activated and rheumatoid arthritis synovial macrophages by JAK inhibitors. Arthritis Rheum. 2012;64(12):3856-66.

26. Heine A, et al. Ruxolitinib is a potent immunosuppressive compound: is it time for anti-infective prophylaxis? Blood. 2013;122(23):3843-4.

27. Keine Autoren angegeben: Belimumab. No tangible efficacy but a risk of immunosuppression. Prescrire Int 2013;22(139):149

28. Bundesamt für Gesundheit (BAG), Eidgenössische Kommission für Impffragen (EKIF). Impfprinzipien und Empfehlungen für Personen mit autoimmun-entzündlichen rheumatischen Erkrankungen. http://www.bag.admin. ch/ekif/04423/04429/index.html?lang=de.Zugegriffen 25 . Januar 2016.

29. Bühler S, et al. Vaccination recommendations for adult patients with autoimmune inflammatory rheumatic diseases. Swiss Med Wkly. 2015;145:w14159.

30. Go AS, et al. Chronic kidney disease and the risks of death, cardiovascular events, and hospitalization. N Engl J Med. 2004;351(13):1296-305.

31. Bond TC, et al. Mortality of dialysis patients according to influenza and pneumococcal vaccination status. Am J Kidney Dis. 2012;60(6):959-65.

32. Verkade MA, et al. Functional impairment of monocyte-derived dendritic cells in patients with severe chronic kidney disease. NephrolDial Transplant. 2007;22(1):128-38.

33. Mathew R, et al. Vaccination issues in patients with chronic kidney disease. Expert Rev Vaccines. 2014;13(2):285-98.

34. DaRoza G, et al. Stage of chronic kidney disease predicts seroconversion after hepatitis B immunization: earlier is better. Am J Kidney Dis. 2003;42(6):1184-92.

35. Litjens $\mathrm{NH}$, et al. Impaired immune responses and antigenspecific memory CD4+ T cells in hemodialysis patients. J AmSoc Nephrol.2008;19(8):1483-90.

36. WasleyA, et al. The prevalence of hepatitis B virus infection in the United States in the era of vaccination. J Infect Dis. 2010;202(2):192-201.

37. Schroth RJ, et al. Hepatitis B vaccination for patients with chronic renal failure. Cochrane Database Syst Rev. 2004;3:CD003775.

38. Ghadiani $\mathrm{MH}$, et al. Response rates to $\mathrm{HB}$ vaccine in CKD stages 3-4 and hemodialysis patients. J Res Med Sci. 2012;17(6):527-33.

39. Centers for Disease Control and Prevention (CDC). A comprehensive immunization strategy to eliminate transmission of hepatitis B virus infection in the united states recommendations of the Advisory Committee on Immunization Practices (ACIP); Part II: Immunization of adults. MMWR Morb MortalWkly Rep. 2006;55:RR-16.

40. Weinstein T, et al. Improved immunogenicity of a novel third-generation recombinant hepatitis $\mathrm{B}$ vaccine in patients with end-stage renal disease. Nephron Clin Pract. 2004;97(2):c67-c72.

41. Guo H, et al. Pneumonia in incident dialysis patients - the United States renal data system. Nephrol Dial Transplant. 2008;23(2):680-6.

42. Centers for Disease Control and Prevention (CDC). Use of 13 -valent pneumococcal conjugate vaccine and 23 -valent pneumococcal polysaccharide vaccine for adults with immunocompromising conditions: recommendations of theAdvisory Committee on Immunization Practices (ACIP). MMWR Morb Mortal Wkly Rep. 2012;61(40):816-9. 
43. Kruger S, et al. A 5-year follow-up on antibody response after diphtheria and tetanus vaccination in hemodialysis patients. Am J Kidney Dis. 2001;38(6):1264-70.

44. World Health Organization (WHO). Vaccines against tickborne encephalitis: WHO position paper. Wkly Epidemiol Rec. 2011;86(24):241-56.

45. Neu AM. Immunizations in children with chronic kidney disease. Pediatr Nephrol. 2012;27(8):1257-63.

46. Zykova SN, et al. Altered cytokine and nitric oxide secretion in vitro by macrophages from diabetic type II-like $\mathrm{db} / \mathrm{db}$ mice. Diabetes. 2000;49(9):1451-8.

47. Amano H, et al. Impairment of endotoxin-induced macrophage inflammatory protein 2 gene expression in alveolar macrophages in streptozotocin-induced diabetes in mice. Infect Immun. 2000;68(5):2925-9.

48. PriceCL, etal. Methylglyoxalmodulatesimmuneresponses: relevance to diabetes. JCell Mol Med. 2010;14(6B):1806-15.

49. Ilyas R, et al. High glucose disrupts oligosaccharide recognition function via competitive inhibition: a potential mechanism for immune dysregulation in diabetes mellitus. Immunobiology.2011;216(1-2):126-31.

50. Centers for Disease Control and Prevention (CDC). Use of hepatitis B vaccination for adults with diabetes mellitus: recommendations of the Advisory Committee on Immunization Practices (ACIP). MMWR Morb Mortal Wkly Rep. 2011;60(50):1709-11.

51. Lau D, et al. Effectiveness of influenza vaccination in working-age adults with diabetes: a population-based cohort study. Thorax. 2013;68(7):658-63.

52. Looijmans-Van den Akker I, et al. Clinical effectiveness of first and repeat influenza vaccination in adult and elderly diabetic patients. Diabetes Care. 2006;29(8):1771-6.

53. Coffelt SB, Visser KE de. Immune-mediated mechanisms influencing the efficacy of anticancer therapies. Trends Immunol.2015;36(4):198-216.

54. Meerveld-Eggink A, et al. Response to influenza virus vaccination during chemotherapy in patients with breast cancer.Ann Oncol.2011;22(9):2031-5.

55. Zengin E, Sarper N. Humoral immunity to diphtheria, tetanus, measles, and hemophilus influenzae type $\mathrm{b}$ in children with acute lymphoblastic leukemia and response to re-vaccination. Pediatr Blood Cancer. 2009;53(6):967-72.

56. Maloney DG. Anti-CD20 antibody therapy for B-cell lymphomas. NEngl J Med.2012;366(21):2008-16.

57. YriOE, etal. Rituximab blocks protective serologic response to influenza A (H1N1) 2009 vaccination in lymphoma patients during or within 6 months after treatment. Blood. 2011;118(26):6769-71.

58. Berglund $A$, et al. The response to vaccination against influenza $A(H 1 N 1)$ 2009, seasonal influenza and Streptococcus pneumoniae in adult outpatients with ongoing treatment for cancer with and without rituximab. Acta Oncol. 2014;53(9):1212-20.

59. Oh MJ, Lee HJ. A study of hepatitis B virus reactivation associated with rituximab therapy in real-world clinical practice: a single-center experience. Clin Mol Hepatol. 2013;19(1):51-9.

60. Tavazzi E, et al. Progressive multifocal leukoencephalopathy: an unexpected complication of modern therapeutic monoclonal antibody therapies. Clin Microbiol Infect. 2011;17(12):1776-80.

61. Yang Q, et al. Idelalisib: first-in-class PI3 K delta inhibitor for the treatment of chronic lymphocytic leukemia, small lymphocytic leukemia, and follicular lymphoma. Clin Cancer Res. 2015;21(7):1537-42.

62. Mattiuzzi GN, et al. Development of Varicella-Zoster virus infection in patients with chronic myelogenous leukemia treated with imatinib mesylate. Clin Cancer Res. 2003;9(3):976-80.

63. Seggewiss R, et al. Imatinib inhibits T-cell receptormediated T-cell proliferation and activation in a dosedependent manner. Blood.2005;105(6):2473-9.

64 . Mumprecht $S$, et al. Imatinib mesylate selectively impairs expansion of memory cytotoxic $\mathrm{T}$ cells without affecting the control of primary viral infections. Blood. 2006;108(10):3406-13.

65. Ikeda $\mathrm{K}$, et al. Fatal hepatitis $\mathrm{B}$ virus reactivation in a chronic myeloid leukemia patient during imatinib mesylate treatment. Leuk Lymphoma. 2006;47(1):155-7.

66. Lavallade $\mathrm{H}$ de, et al. Tyrosine kinase inhibitors impair B-cell immune responses in CML through off-target inhibition of kinases important for cell signaling. Blood. 2013;122(2):227-38.

67. Reeves PM, et al. Disabling poxvirus pathogenesis by inhibition of Abl-family tyrosine kinases. Nat Med. 2005;11(7):731-9.

68. Fraser CK, et al. Dasatinib inhibits recombinant viral antigen-specific murine CD4+ and CD8+ T-cell responses and NK-cell cytolytic activity in vitro and in vivo. Exp Hematol.2009;37(2):256-65.

69. Sillaber C, et al. Immunosuppression and atypical infections in CML patients treated with dasatinib at $140 \mathrm{mg}$ daily. Eur J Clin Invest. 2009;39(12):1098-109.

70. Wahren B, et al. Transfer and persistence of viral antibodyproducing cells in bone marrow transplantation. J Infect Dis. 1984;150(3):358-65.

71. Lum LG. The kinetics of immune reconstitution after human marrow transplantation. Blood. 1987;69(2):369-80.

72. Lum LG, et al. The detection of specific antibody formation to recall antigens after human bone marrow transplantation. Blood. 1986;67(3):582-7.

73. Ljungman P, etal. Response to tetanus toxoid immunization after allogeneic bone marrow transplantation. J Infect Dis. 1990;162(2):496-500.

74. Hilgendorf I, et al. Vaccination of allogeneic haematopoietic stem cell transplant recipients: report from the international consensus conference on clinical practice in chronic GVHD. Vaccine. 2011;29(16):2825-33.

75. Deutsche Gesellschaft für Hämatologie und Onkologie (DGHO). Onkopedia-Leitlinie „Antivirale Prophylaxe“. https://www.onkopedia.com/de/onkopedia/guidelines/ antivirale-prophylaxe.Zugegriffen 15. Mai 2016.

76. Leigh IM, et al. Role of human papillomaviruses in cutaneous and oral manifestations ofimmunosuppression. JAcquir Immune Defic Syndr. 1999;21 (Suppl 1):S49-S57.

77. Savani BN, et al. Increased risk of cervical dysplasia in longterm survivors of allogeneic stem cell transplantation implications for screening and HPV vaccination. Biol Blood MarrowTransplant. 2008;14(9):1072-5.

78. Dengler TJ, et al. Vaccination against tick-borne encephalitis under therapeutic immunosuppression. Reduced efficacy in heart transplant recipients. Vaccine. 1999;17(7-8):867-74.

79. Wiedermann $U$, et al. Vaccination recommendations for health care workers in Austria. Wien Klin Wochenschr. 2014;126(Suppl 1):S11-S22.

80. Danzinger-Isakov L, Kumar D. Guidelines for vaccination of solid organ transplant candidates and recipients. Am J Transplant. 2009;9(Suppl4):S258-S262.

81. Avery RK, Michaels M. Update on immunizations in solid organ transplant recipients: what clinicians need to know. AmJ Transplant. 2008;8(1):9-14.

82. Beckebaum S, et al. Hepatitis B and liver transplantation: 2008 update. Rev Med Virol. 2009;19(1):7-29. 
83. Posfay-Barbe KM, et al. Varicella-zoster immunization in pediatric liver transplant recipients: safe and immunogenic. Am J Transplant. 2012;12(11):2974-85.

84. Doran MF, et al. Frequency of infection in patients with rheumatoid arthritis compared with controls: apopulationbased study. Arthritis Rheum. 2002;46(9):2287-93.

85. Assen $S$ van, et al. Vaccination in adult patients with autoimmune inflammatory rheumatic diseases: a systematic literature review for the European League Against Rheumatism evidence-based recommendations for vaccination in adult patients with auto-immune inflammatory rheumatic diseases. Autoimmun Rev. 2011;10(6):341-52.

86. Assen $\mathrm{S}$ van, et al. EULAR recommendations for vaccination in adult patients with autoimmune inflammatory rheumatic diseases. Ann Rheum Dis. 2011;70(3):414-22.

87. Kapetanovic MC, et al. Influence of methotrexate, TNF blockers and prednisolone on antibody responses to pneumococcal polysaccharide vaccine in patients with rheumatoid arthritis. Rheumatology (Oxford).2006;45(1):106-11.

88. Gelinck LB, et al. Synergistic immunosuppressive effect of anti-TNF combined with methotrexate on antibody responses to the 23 valent pneumococcal polysaccharide vaccine. Vaccine. 2008;26(27-28):3528-33.

89. Franca IL, et al. TNF blockers show distinct patterns of immune response to the pandemic influenza A H1N1 vaccine in inflammatory arthritis patients. Rheumatology (Oxford). 2012;51(11):2091-8.

90. Mori S, et al. Pneumococcal polysaccharide vaccination in rheumatoid arthritis patients receiving tocilizumab therapy. Ann Rheum Dis. 2013;72(8):1362-6.

91. Mori S, et al. Impact of tocilizumab therapy on antibody response to influenza vaccine in patients with rheumatoid arthritis. Ann Rheum Dis. 2012;71(12):2006-10.

92. Ribeiro AC, et al. Abatacept and reduced immune response topandemic2009influenzaA/H1N1 vaccinationin patients with rheumatoid arthritis. Arthritis Care Res (Hoboken). 2013;65(3):476-80.

93. Kapetanovic MC, et al. Impact of anti-rheumatic treatment on immunogenicity of pandemic H1N1 influenza vaccine in patients with arthritis. Arthritis Res Ther. 2014;16(1):R2.

94. Hua C, et al. Effect of methotrexate, anti-tumor necrosis factor alpha, and rituximab on the immune response to influenza and pneumococcal vaccines in patients with rheumatoid arthritis: a systematic review and metaanalysis. Arthritis Care Res (Hoboken). 2014;66(7):1016-26.

95. Assen S van, et al. Humoral responses after influenza vaccination are severely reduced in patients with rheumatoid arthritis treated with rituximab. Arthritis Rheum. 2010;62(1):75-81.

96. Oren S, et al. Vaccination against influenza in patients with rheumatoid arthritis: the effect of rituximab on the humoral response. Ann Rheum Dis. 2008;67(7):937-41.

97. Bingham CO 3rd, et al. Immunization responses in rheumatoid arthritis patients treated with rituximab: results from a controlled clinical trial. Arthritis Rheum. 2010;62(1):64-74.

98. GelinckLB, et al. Poor serological responses upon influenza vaccination in patients with rheumatoid arthritis treated with rituximab. Ann Rheum Dis. 2007;66(10):1402-3.

99. Salinas GF, et al. Anti-TNF treatment blocks the induction of T cell-dependent humoral responses. Ann Rheum Dis. 2013;72(6):1037-43.

100. Heijstek MW, et al. Differences in persistence of measles, mumps, rubella, diphtheria and tetanus antibodies between children with rheumatic disease and healthy controls: a retrospective cross-sectional study. Ann Rheum Dis. 2012;71(6):948-54.
101. Dell' EL, et al. Vaccination of children and adolescents with rheumatic diseases. Rheumatology (Oxford). 2011;50(8):1358-65.

102. Smitten AL, et al. The risk of herpes zoster in patients with rheumatoid arthritis in the United States and the United Kingdom. Arthritis Rheum. 2007;57(8):1431-8.

103. Westra J, et al. Vaccination of patients with autoimmune inflammatory rheumatic diseases. Nat Rev Rheumatol. 2015;11(3):135-45.

104. Salliot C, Heijde D van der. Long-term safety of methotrexate monotherapy in patients with rheumatoid arthritis: a systematic literature research. Ann Rheum Dis. 2009;68(7):1100-4.

105. Zhang N, et al. Does methotrexate increase the risk of varicella or herpes zoster infection in patients with rheumatoid arthritis? A systematic literature review. Clin Exp Rheumatol.2012;30(6):962-71.

106. Strangfeld A, et al. Risk of herpes zoster in patients with rheumatoid arthritis treated with anti-TNF-alpha agents. JAMA. 2009;301(7):737-44.

107. Wolfe F, et al. Rates and predictors of herpes zoster in patients with rheumatoid arthritis and non-inflammatory musculoskeletal disorders. Rheumatology (Oxford). 2006;45(11):1370-5.

108. Winthrop KL, et al. Herpes zoster and tofacitinib therapy in patients with rheumatoid arthritis. Arthritis Rheum. 2014;66(10):2675-84.

109. Nath R, et al. High risk of human papillomavirus type 16 infections and of development of cervical squamous intraepithelial lesions in systemic lupus erythematosus patients. Arthritis Rheum. 2007;57(4):619-25.

110. Gatto M, et al. Human papillomavirus vaccine and systemic lupus erythematosus. Clin Rheumatol.2013;32(9):1301-7.

111. Mahadevan U, et al. The London Position Statement of the World Congress of Gastroenterology on Biological Therapy for IBD with the European Crohn's and Colitis Organisation: pregnancy and pediatrics. Am J Gastroenterol. 2011;106(2):214-23, quiz224.

112. Calligaro A, et al. Are biological drugs safe in pregnancy? Reumatismo. 2015;66(4):304-17.

113. Androulakis I, etal. Safety of anti-tumornecrosis factor therapy during pregnancy in patients with inflammatory bowel disease. World J Gastroenterol. 2015;21(47):13205-11.

114. Rahier JF, et al. Second European evidence-based consensus on the prevention, diagnosis and management of opportunistic infections in inflammatory bowel disease. J Crohns Colitis. 2014;8(6):443-68.

115. Toruner M, et al. Risk factors for opportunistic infections in patients with inflammatory bowel disease. Gastroenterology. 2008;134(4):929-36.

116. Chaudrey $\mathrm{K}$, et al. Updates in vaccination: recommendations for adult inflammatorybowel disease patients. World J Gastroenterol. 2015;21(11):3184-96.

117. Wilckens V, et al. The immunization status of patients with IBD is alarmingly poor before the introduction of specific guidelines. Scand J Gastroenterol.2011;46(7-8):855-61.

118. Austria Codex. Fachinformation Entyvio ${ }^{\circledR} 300 \mathrm{mg}$ Pulver zur Herstellung einer Infusionslösung. www.pharmazie. com. Zugegriffen 10. November 2015.

119. Ansari F, et al. Varicella immunity in inflammatory bowel disease. J Pediatr Gastroenterol Nutr. 2011;53(4):386-8.

120. Cullen G, et al. Varicella zoster virus infection in inflammatory bowel disease. Inflamm Bowel Dis. 2012;18(12):2392-403.

121. Gisbert JP, et al. Efficacy of hepatitis B vaccination and revaccinationandfactorsimpactingon responsein patients 
with inflammatory bowel disease. Am J Gastroenterol. 2012;107(10):1460-6.

122. AltunozME, etal. Patients with inflammatorybowel disease have a lower response rate to $\mathrm{HBV}$ vaccination compared to controls. Dig Dis Sci. 2012;57(4):1039-44.

123. Jacobson DL, et al. Immunogenicity and tolerability to human papillomavirus-like particle vaccine in girls and young women with inflammatory bowel disease. Inflamm BowelDis. 2013;19(7):1441-9.

124. Cullen G, et al. Serological response to the $2009 \mathrm{H} 1 \mathrm{~N} 1$ influenza vaccination in patients with inflammatory bowel disease. Gut. 2012;61(3):385-91.

125. Fiorino G, et al. Effects of immunosuppression on immune response to pneumococcal vaccine in inflammatory bowel disease: a prospective study. Inflamm Bowel Dis. 2012;18(6):1042-7.

126. Wyant $\mathrm{T}$, et al. Vedolizumab affects antibody responses to immunisation selectively in the gastrointestinal tract: randomised controlled trial results. Gut. 2015;64(1):77-83

127. Nieuwkamp DJ, et al. PML in a patient without severe lymphocytopenia receiving dimethyl fumarate. $\mathrm{N}$ Engl J Med.2015;372(15):1474-6.

128. European S3-Guidelines on the systemic treatment of psoriasis vulgaris. http:/ / www.euroderm.org/edf/index.php/ edf-guidelines/category/5-guidelines-miscellaneous? download=32:guideline-psoriasis. Zugegriffen 4. September 2015.

129. Wine-Lee L, et al. From the Medical Board of the National Psoriasis Foundation: Vaccination in adult patients on systemic therapy for psoriasis. J Am Acad Dermatol. 2013;69(6):1003-13.

130. Schett G, et al. Apremilast: a novel PDE4 inhibitor in the treatment of autoimmune and inflammatory diseases. Ther Adv MusculoskeletDis. 2010;2(5):271-8.

131. McCann FE, et al. Apremilast, a novel PDE4 inhibitor, inhibits spontaneous production of tumour necrosis factor-alpha from human rheumatoid synovial cells and ameliorates experimental arthritis. Arthritis Res Ther. 2010;12(3):R107.

132. Schafer PH, et al. Apremilast is a selective PDE4 inhibitor with regulatory effects on innate immunity. Cell Signal. 2014;26(9):2016-29.

133. Papp K, et al. Apremilast, an oral phosphodiesterase 4 (PDE4) inhibitor, in patients with moderate to severe plaque psoriasis: Results of a phase III, randomized, controlled trial (Efficacy and Safety Trial Evaluating the Effects of Apremilast in Psoriasis [ESTEEM] 1). J Am Acad Dermatol.2015;73(1):37-49.

134. Salemi S, et al. Influenza vaccine administration in rheumatoid arthritis patients under treatment with TNFalpha blockers: safety and immunogenicity. Clin Immunol. 2010;134(2):113-20.

135. Brodmerkel C, et al. Immune response to pneumococcus and tetanus toxoid in patients with moderate-to-severe psoriasis following long-term ustekinumab use. J Drugs Dermatol. 2013;12(10):1122-9.

136. Chioato A, et al. Treatment with the interleukin-17 Ablocking antibody secukinumab does not interfere with the efficacy of influenza and meningococcal vaccinations in healthy subjects: results of an open-label, parallel-group, randomized single-center study. Clin Vaccine Immunol. 2012;19(10):1597-602.

137. Titanji K, et al. Loss of memory B cells impairs maintenance of long-term serologic memory during HIV-1 infection. Blood.2006;108(5):1580-7.

138. Benson C. Oral Abstract\#96. CROI, Seattle. 2012.

139. BekkerV, etal.Varicella vaccination in HIV-1-infected childrenafterimmunereconstitution.AIDS.2006;20(18):2321-9

140. Levin MJ, et al. Administration of live varicella vaccine to HIV-infected children with current or past significant depression of CD4(+) T cells. J Infect Dis. 2006;194(2):247-55.

141. Compston A. McAlpine's multiple sclerosis, 4th ed. Philadelphia: Churchill LivingstoneElsevier;2005., px, 982.

142. Langer-Gould A, et al. Vaccines and the risk of multiple sclerosis and other central nervous system demyelinating diseases. JAMA Neurol.2014;71(12):1506-13.

143. Huynh W, et al. Post-vaccination encephalomyelitis: literature review and illustrative case. J Clin Neurosci. 2008;15(12):1315-22.

144. Heekin R, etal. Seronegative neuromyelitis optica spectrum disorderfollowing exposure to hepatitis B vaccination. Case Rep Neurol. 2015;7(1):78-83.

145. McCarthy CL, et al. Immune competence after alemtuzumab treatment of multiple sclerosis. Neurology. 2013;81(10):872-6.

146. Pellegrino P, et al. Efficacy of vaccination against influenza in patients with multiple sclerosis: the role of concomitant therapies. Vaccine. 2014;32(37):4730-5.

147. Kaufman M, et al. Natalizumab treatment shows no clinically meaningful effects on immunization responses in patients with relapsing-remitting multiple sclerosis. J Neurol Sci. 2014;341(1-2):22-7.

148. Nazi I, et al. The effect of rituximab on vaccine responses in patients with immune thrombocytopenia. Blood. 2013;122(11):1946-53.

149. Kim W, et al. Reduced antibody formation after influenza vaccination in patients with neuromyelitis optica spectrum disorder treated with rituximab. Eur J Neurol. 2013;20(6):975-80.

150. Keshtkar-Jahromi M, et al. Antibody response to influenza immunization in kidney transplant recipients receiving either azathioprine or mycophenolate: a controlled trial. Am J Nephrol. 2008;28(4):654-60.

151. Rentenaar RJ, et al. Immune responsiveness in renal transplant recipients: mycophenolic acid severely depresses humoral immunity in vivo. Kidney Int. 2002;62(1):319-28.

152. Goldacker S, et al. Vaccination in adult patients with chronic inflammatory rheumatic diseases. Z Rheumatol. 2013;72(7):690-4, 696-700, 702-694. 